\title{
الألوهية في فلسفة " جوناثان إدواردز"
}

د. علي محمد عليان عبد الرازق الخطيب (*)

مما لاشك فيه أن الحديث عن الألوهية ( The Divinity) لم يكن أمرًا

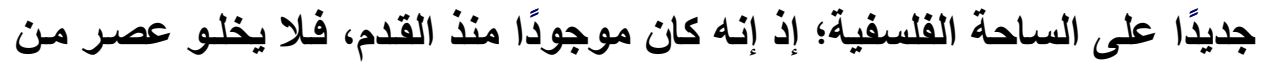

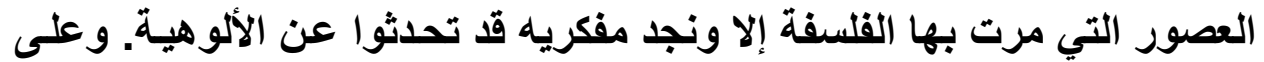

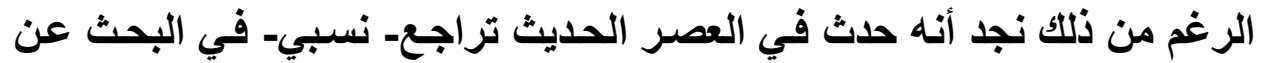
الإله، لارجة أنه تم وصف العصر الحديث بأنه عصر تراجع فيه البحث عن الإله.

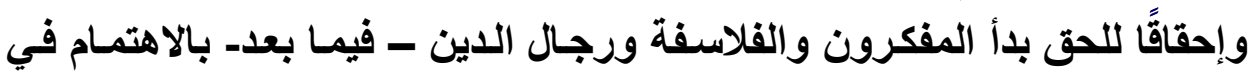

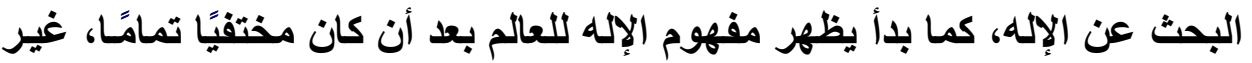

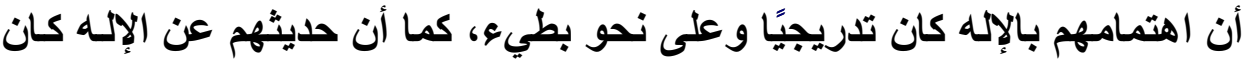

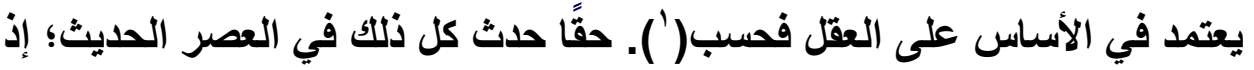

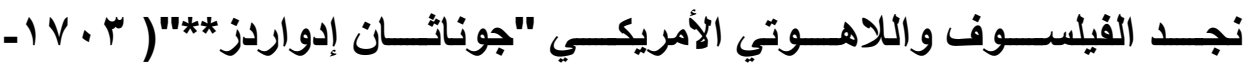

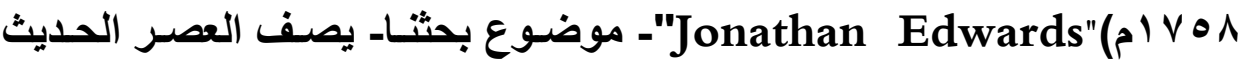

(*) مدرس الفلسفة الحديثة والمعاصرة - قسم الفلسفة ـ كلبة الآداب - جامعة المنيا.

1-McClymond, M .J. (1998) "Encounters With God :An Approach to the Theology of Jonathan Edwards,"New York, Oxford University Press.p. 81

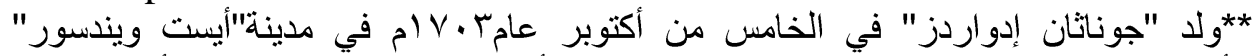

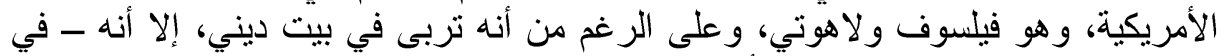

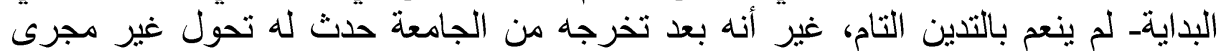

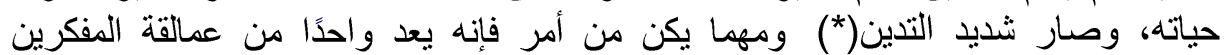

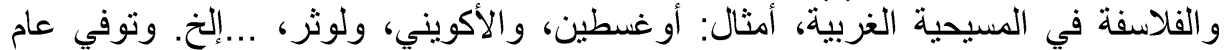

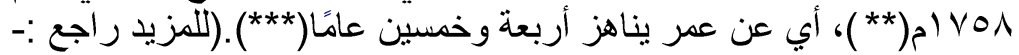

*Haykin, M. A. (1995) "Jonathan Edwards and His Legacy", Reformation \& Revival, A Quarterly Journal for Church Leadership, Vol.4, No.3.pp. 65-66.

**Lee, S. H. (2014) "Jonathan Edwards" in, "Early Modern Philosophy of Religion" (ed) Graham Oppy\& N. N .Trakakis, Vol. 3, The History Of Western Philosophy Of Religion, Rout ledge, London \&New York.p.223

***Fisher, G. P. (1879)"The Philosophy of Jonathan Edwards", the North American Review, Vol.128, No.268, University of Northern Iowa.p.303 
مجلة كلية الآداب، جامعة سوهاج، العدد التاسع والأربعون، الجزء الأول، أكتوبر 1 + بام

الأي كان يعيش فيه بأنه عصر ميث، ولا يطبق الدين الصحيح، ولا يستطيع أن يتعرف على روح الله(").

بالتالي حدثت أزمة عظيمة بشأن الألوهية ولاسيما في العصر الحديث،

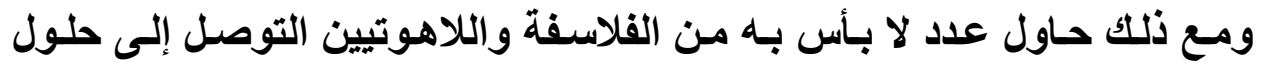

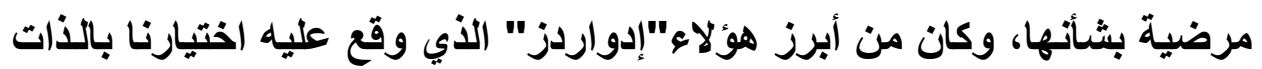

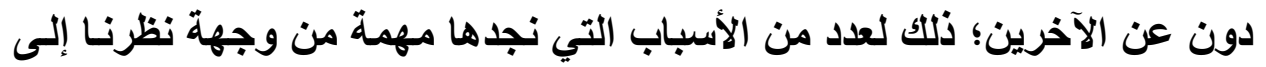
حد كبير، لعل من أبرزها:

يعد " إدواردز" من أكثر الفلاسفة واللاهوتيين الذين شعروا بـأن العالم

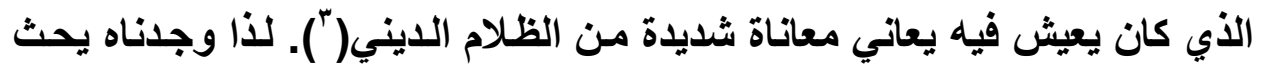

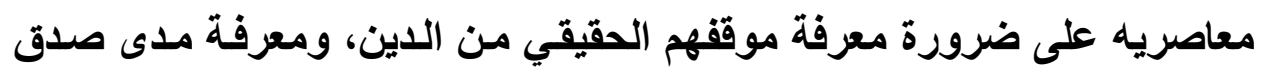

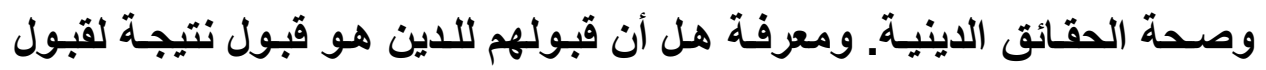

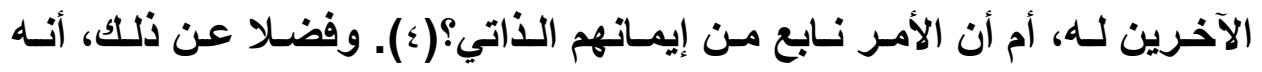

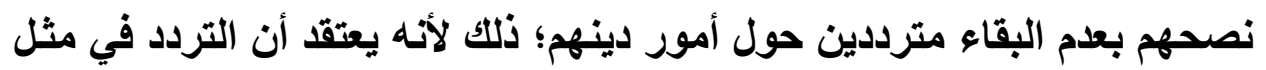

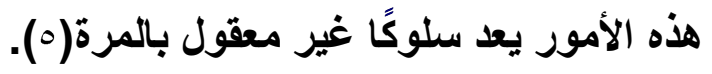

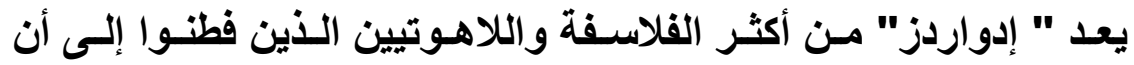

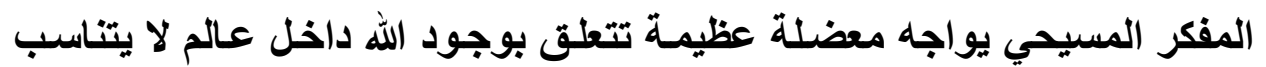

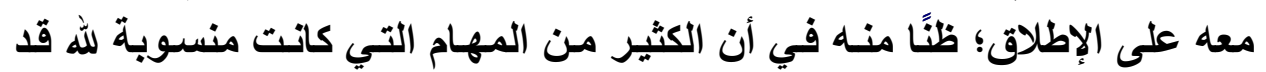

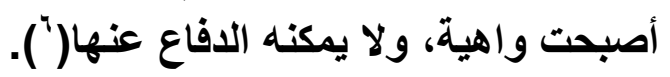

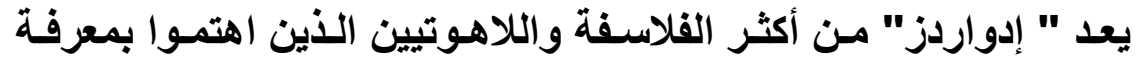
حقيقة إلوهية الله؛ ذلك لأنه كان يحث النـاس دومًا على ضرورة زيـادة معرفتهم

${ }^{2}$ McClymond, M .J. (1998) "Encounters With God :An Approach to the Theology of Jonathan Edwards ",p.94

${ }^{3}$ McDermott, G. R. (2000) " Jonathan Edwards Confronts the Gods : Christian Theology, Enlightenment Religion, and Non - Christian Faiths", Oxford University Press.p.64

${ }^{4}$ Edwards, J. "The Unreasonableness of Indetermination in Religion, (http://www.prayermeetings.org/files/The Unreasonableness of Indetermi nation In Religion.pdf) . P.8(Y. IV_V_r • تم الذخول على الموقع بتاريخ ()

${ }^{5}$ Ibid,p.5

${ }^{6}$ McClymond, M . J. (1998) "Encounters With God :An Approach to the Theology of Jonathan Edwards ",p.81 


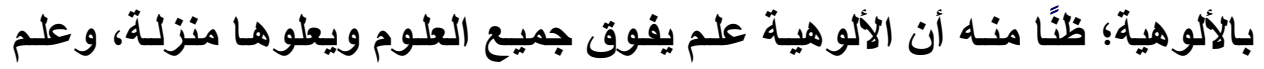

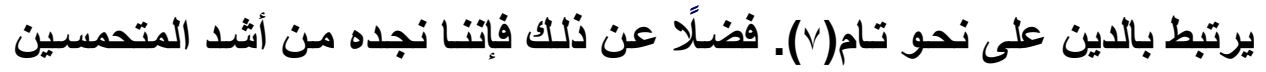

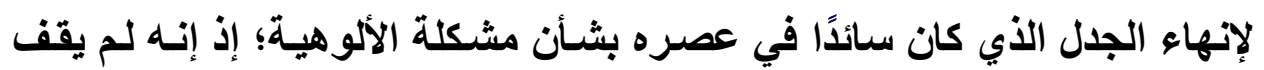
مكتوف اليدين تجاه هذه المشكلة كما سنرى، وإنما بحث عن الأن الأسباب الحقيقية

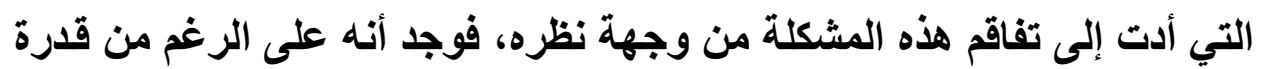

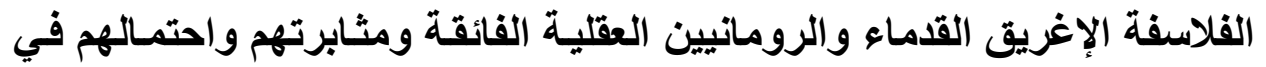

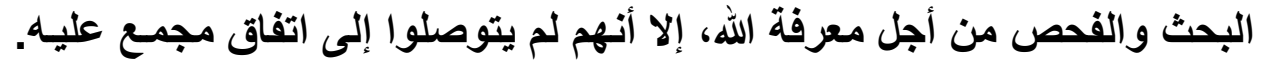

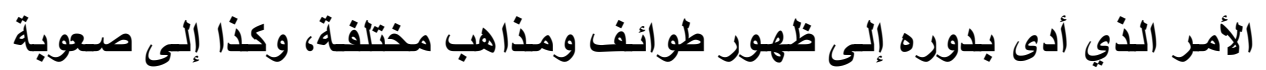
التوصل إلى معرفة يقينية عن الله. كما نجده يرى ألن الند الفلاسفة الصينيين الذين

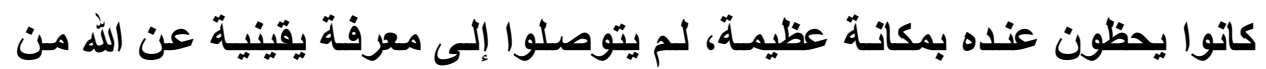

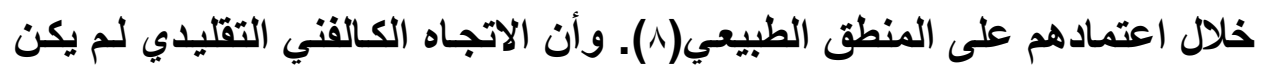

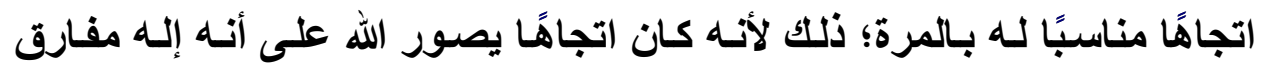

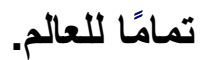

ترتب على ذلك إصراره على أن حديث مفكري وفلاسفة العصر الحديث

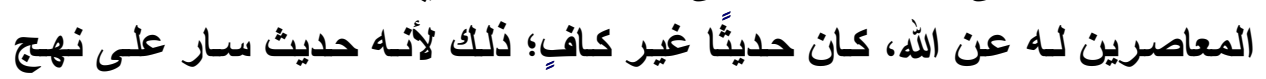

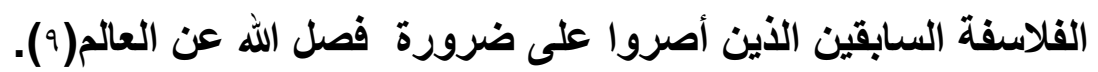

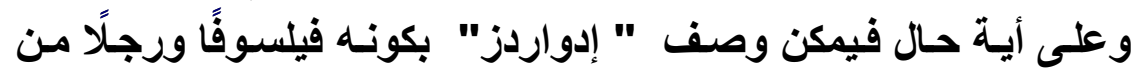

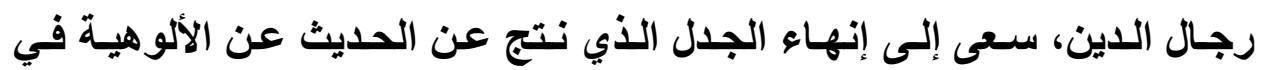
عصره، كما سعى إلى تقيم المعرفة اللازمـة للناس ليعشوا حياة في خدمة اللها،

${ }^{7}$ Edwards, J . "Christian Knowledge".

(https://biblesnet.com/Jonathan\%20Edwards\%20Christian\%20Knowled

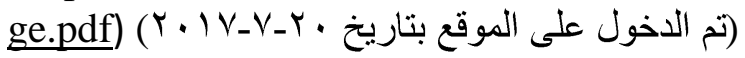

${ }^{8}$ McClymond, M..J. (1998) "Encounters With God :An Approach to the Theology of Jonathan Edwards",p.94

${ }^{9}$ Smith, J. E. (1976) "Jonathan Edwards as Philosophical Theologian", The Review of Metaphysics, Vol.30, No.2, Philosophical Education Society Inc.p.314 
معتمدًا في ذلك على الوحي- دون إغفاله لأهمية العقل-؛ ذلك لأنه يرى أن الوحي

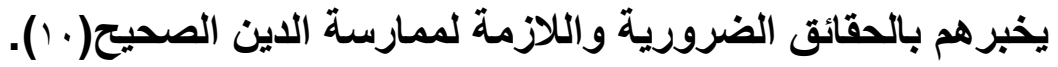
لذا جاءت هذه الاراسة من أجل الإجابة عن التساؤلات المهمة الآتية:

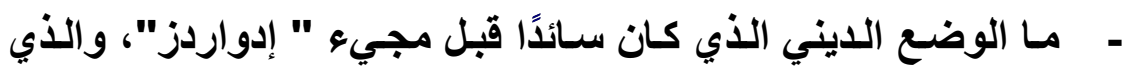

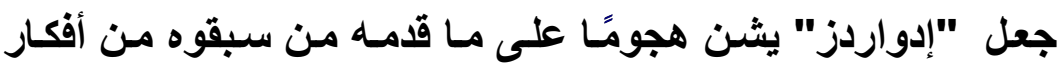

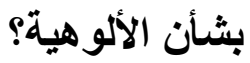

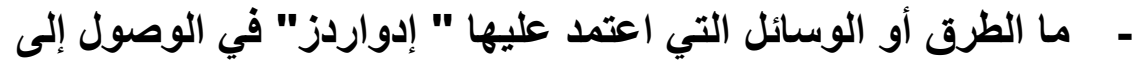

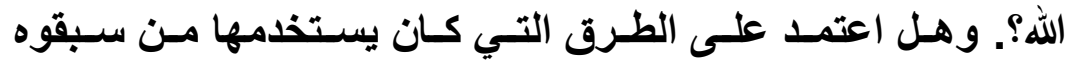

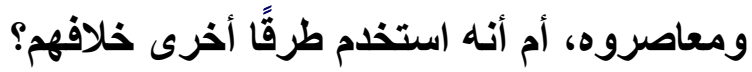

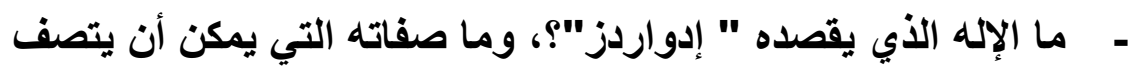

بها?

- هل توجد علاقة بين الله والكون ككل؟ وإذا كاتـت هنـآك علاقةة، فمـا طبيعة هذه العلاقة؟ وما طبيعة علاقة الله بالمخلوقات بوصفهم جزيًا

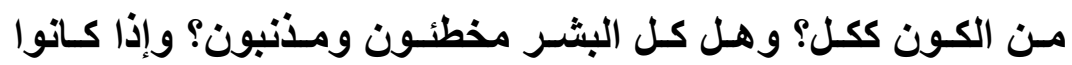
مخطئين، فهل هناك إمكاتية لتطهير هم من الخطيئةٌ وإذا كاتت هنـاك إمكانية لتطهير هم بالفعل من الخطيئة، فمن الأي يقدر على فئ فعل ذلتك

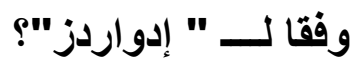

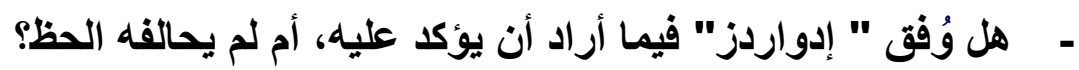

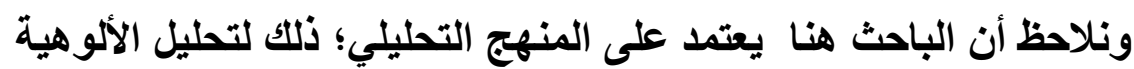

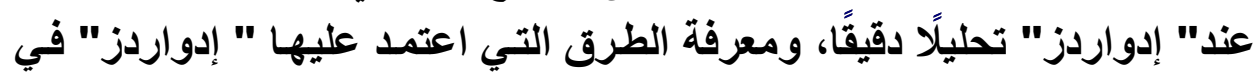

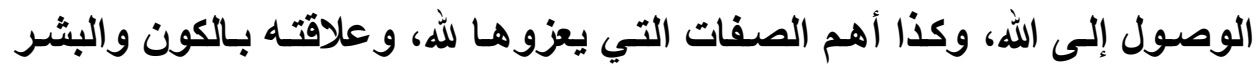

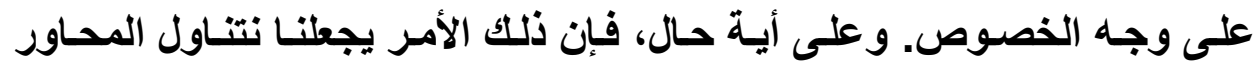
الآتية:

${ }^{10}$ McClymond, M .J. (1998) "Encounters With God :An Approach to the Theology of Jonathan Edwards ",p 94 
أولًا: الوضع الدينـي قبل " إدواردز ".

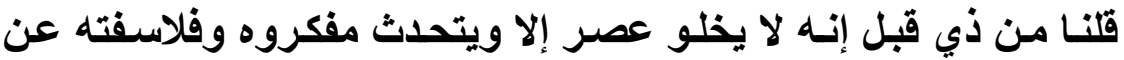

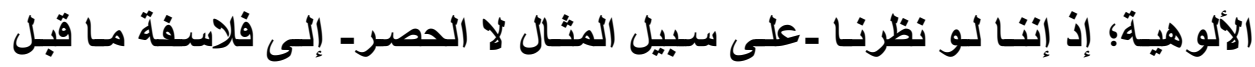

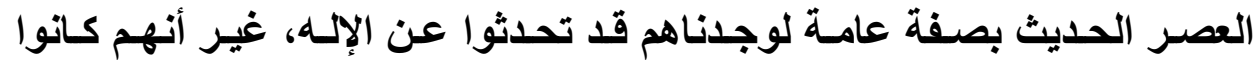

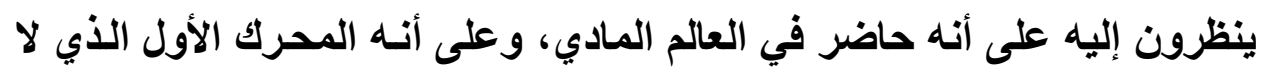

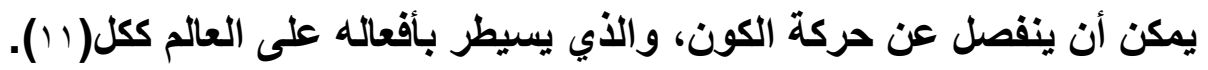

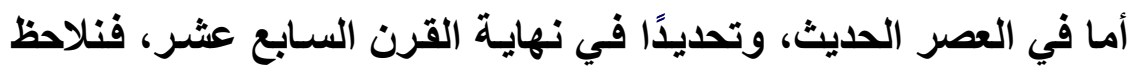

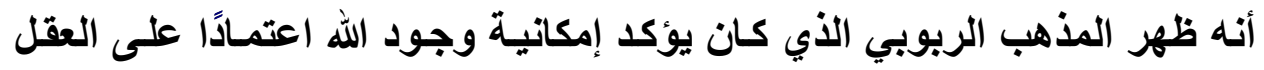

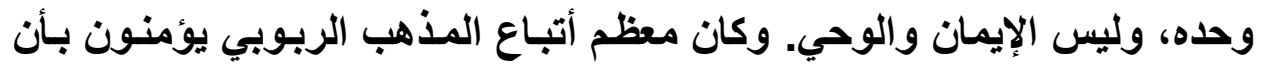

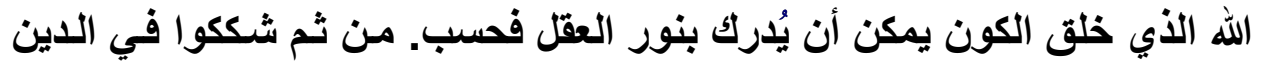

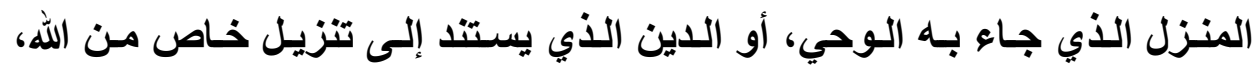

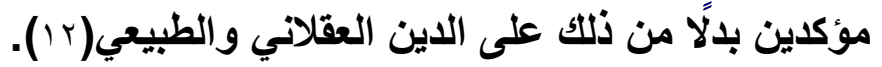

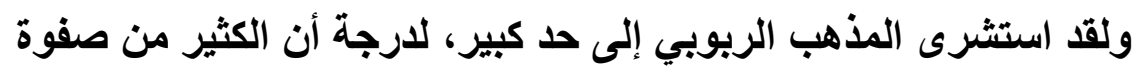

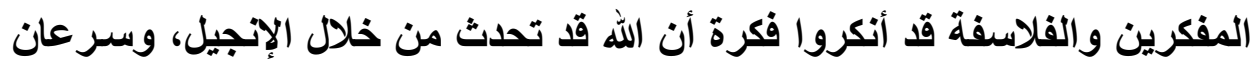

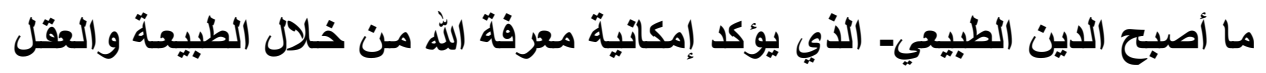

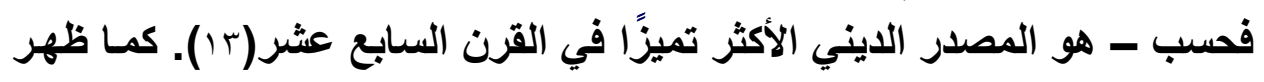

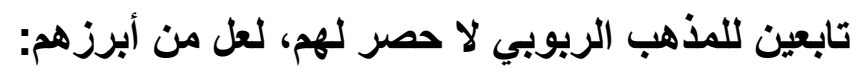

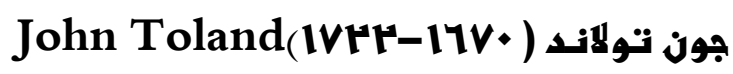

هو من أبرز التابعين للمذهب الربوبي؛ إذ إنه أكد مقدرتنا على معرفة الله

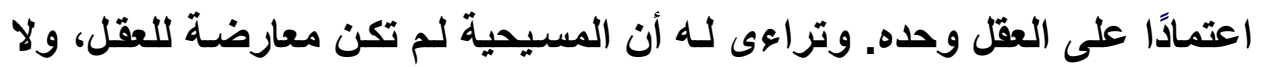

${ }^{11}$ McDermott, G. R. (2000) " Jonathan Edwards Confronts the Gods : Christian Theology, Enlightenment Religion, and Non - Christian Faiths",p.82

${ }^{12}$ Zakai, A. (2010) "Jonathan Edwards's Philosophy of Nature: the Reenchantment of the World in the Age of Scientific Reasoning" ,T\&T Clark International.pp.211-212

${ }^{13}$ McDermott, G. R. (2000) " Jonathan Edwards Confronts the Gods : Christian Theology, Enlightenment Religion, and Non - Christian Faiths",p.71 
مجلة كلية الآداب، جامعة سوهاج، العدد التاسع والأربعون، الجزء الأول، أكتوبر 1 ـ ب م

يمكن أن تفـوق العقل على الإطلاق(ء) (). وعلى هذا النحو صسار واحدًا مسن

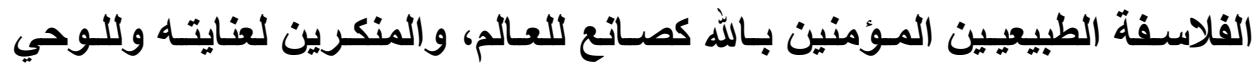
وللانفس وللآخر(10).

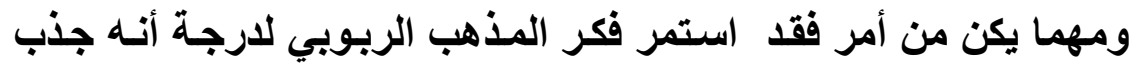

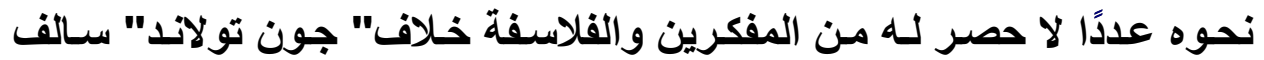
الأكر، ولارجة أن الله قد أصبح بعيدًا عن العالم بشكل تدريجي، وأصبح مجرد وداد

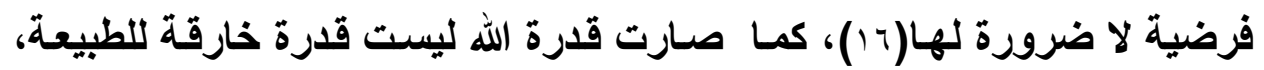

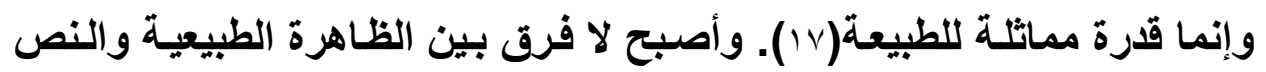

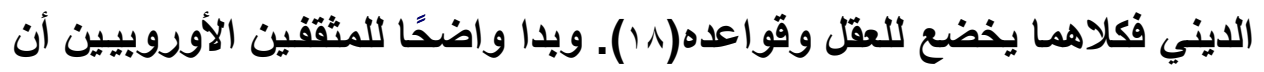
كل شيء يمكن تفسيره دون الرجوع إلى الله. وقد أدى ذلتك في النهاية إلى طرح

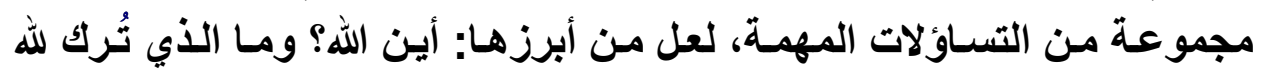

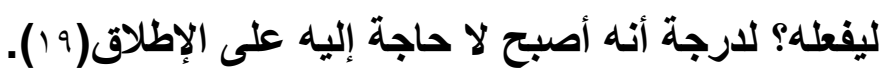

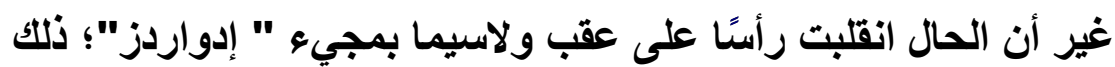

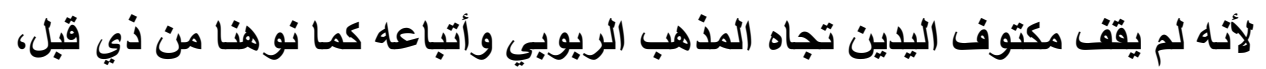

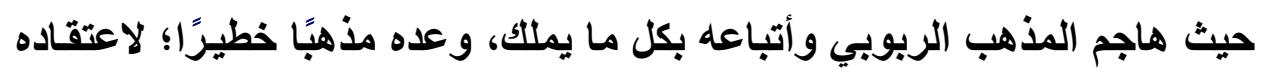

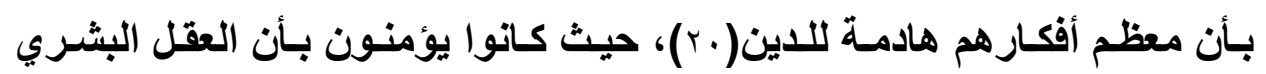

${ }^{14}$ Zakai, A. (2010) "Jonathan Edwards's Philosophy of Nature: the Reenchantment of the World in the Age of Scientific Reasoning" ,p.212

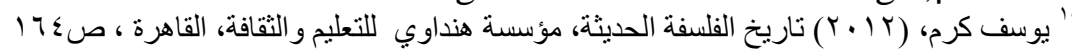

${ }^{16}$ McClymond, M. J. (1998) "Encounters With God :An Approach to the Theology of Jonathan Edwards ",p.81

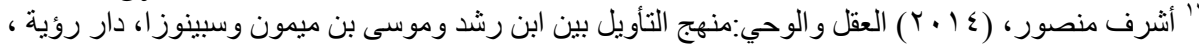

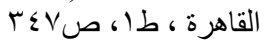

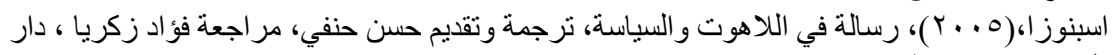

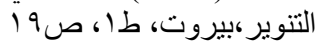

${ }^{19}$ McClymond, M. J. (1998) "Encounters With God :An Approach to the Theology of Jonathan Edwards ",p.81

${ }^{20}$ Zakai, A. (2010) "Jonathan Edwards's Philosophy of Nature: the Reenchantment of the World in the Age of Scientific Reasoning" ,p.211 


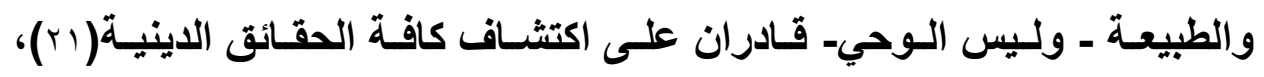

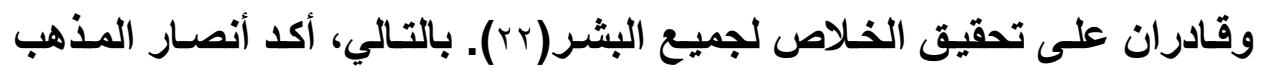

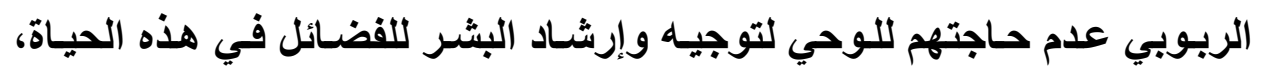
وللسعادة في الحياة الأخروية(rr).

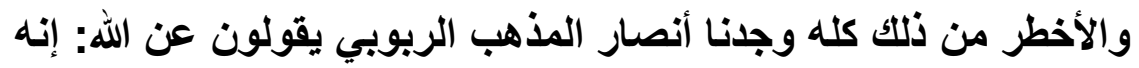

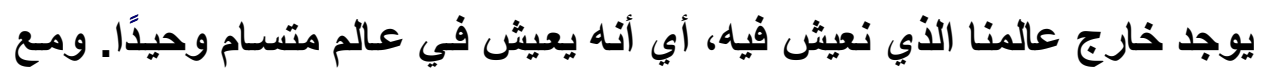

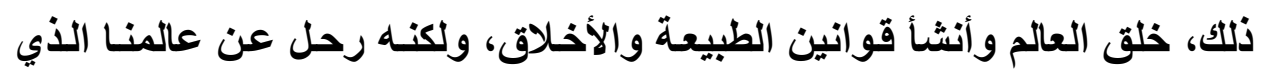

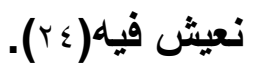

وعلى الرغم من تصدي " إدواردز" للمذهب الربوبي كما ذكرنـا آنفًا، إلا إلا

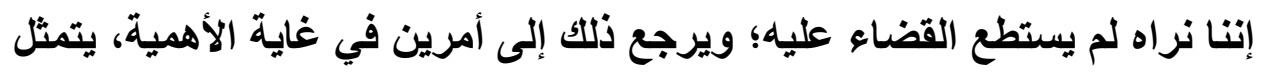

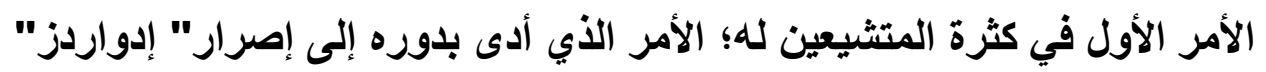

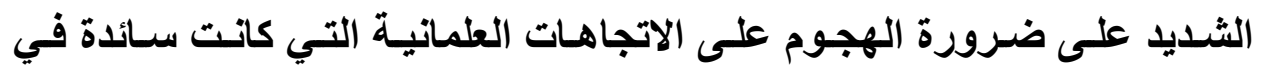

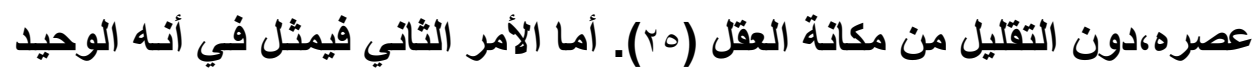

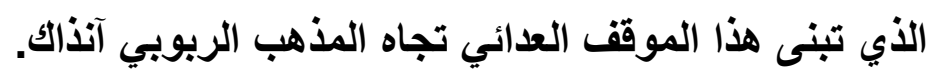

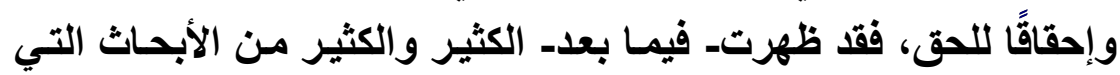

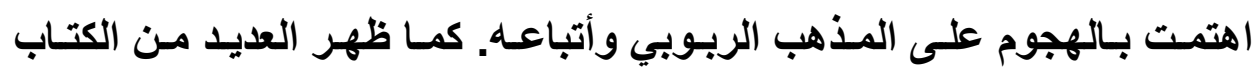

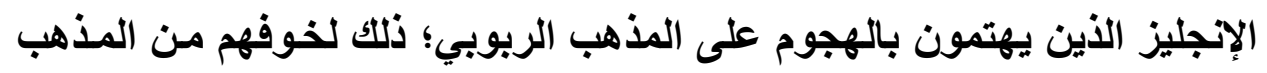

${ }^{21}$ McDermott, G .R. (2000) " Jonathan Edwards Confronts the Gods : Christian Theology, Enlightenment Religion, and Non - Christian", p.173

${ }^{22}$ McDermott .G. R. (1996) "The Deist Connection Jonathan Edwards and Islam" Part .3, In :" Jonathan Edwards's Writings: Text, Context, Interpretation", (ed)Stein. Stephen J, Indiana University Press.p.44

${ }^{23}$ McDermott,G. R. (2000) " Jonathan Edwards Confronts the Gods : Christian Theology, Enlightenment Religion, and Non - Christian Faiths", p.173 \&see also: McDermott .G. R. (1996) "The Deist Connection Jonathan Edwards and Islam" Part .3,p.44

${ }^{24}$ McClymond, M .J. (1998) "Encounters With God :An Approach to the Theology of Jonathan Edwards ", p.83

${ }^{25}$ Anderson, O. (2010) "A Short Life of Jonathan Edwards" ,Journal of History and Sociology of Religion, Blackwell Publishing Ltd.p.317 
مجلة كلية الآداب، جامعة سوهاج، العدد التاسع والأربعون، الجزء الأول، أكتوبر 1 + بام

الربوبي الأي اجتاح إنجلترا في أواخر القرن السـابع عثر، واعتقادهم أن من أن

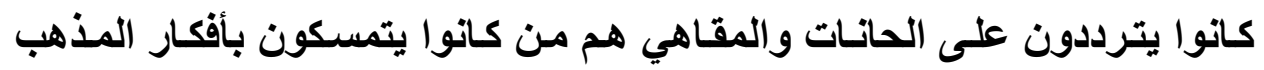

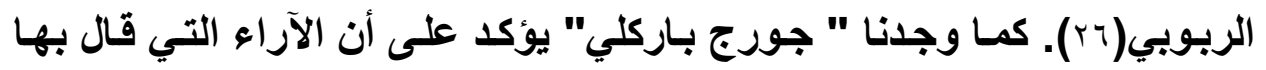

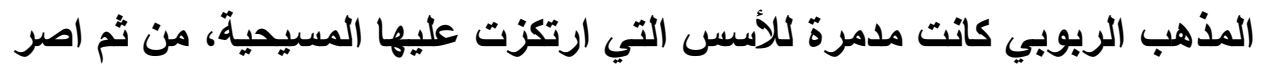

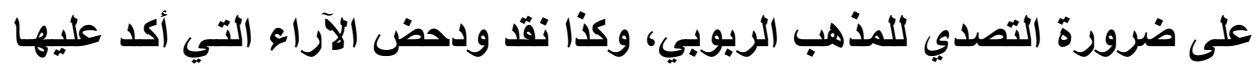

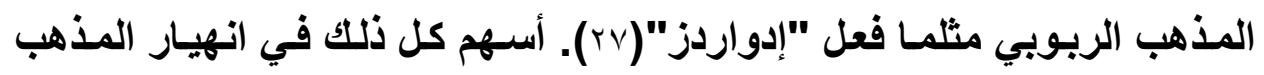

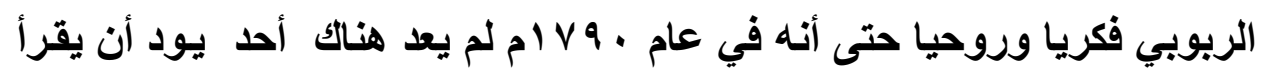

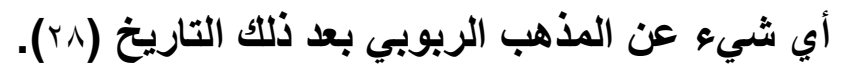

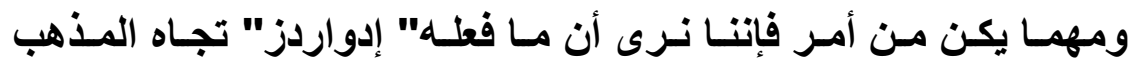

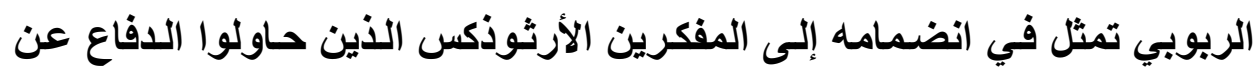

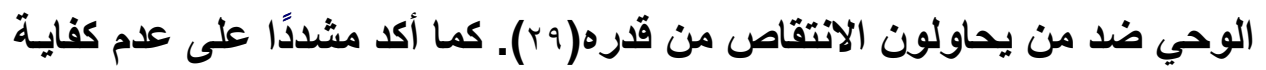

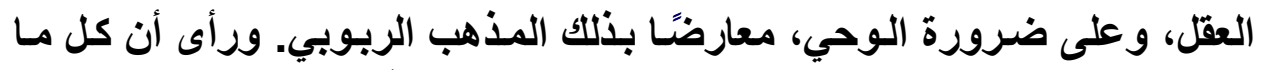

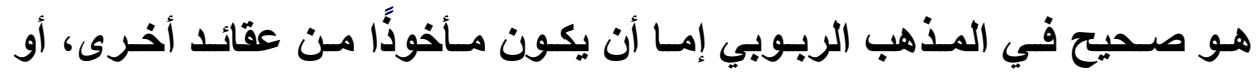

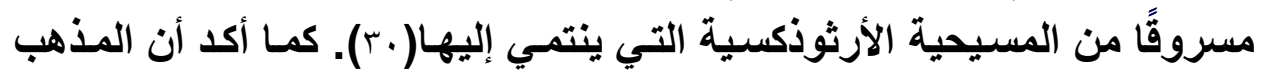

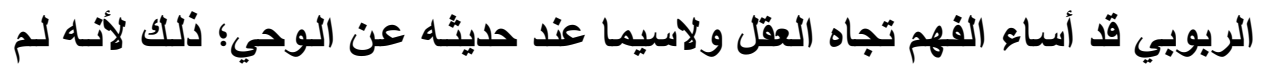

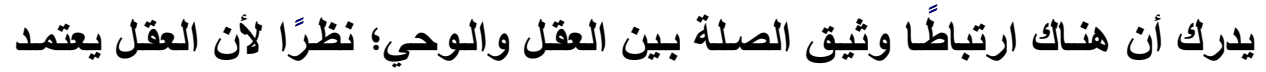

${ }^{26}$ McDermott, G .R. (2000) " Jonathan Edwards Confronts the Gods : Christian Theology, Enlightenment Religion, and Non Christian,pp.37-38

${ }^{27}$ Zakai, A. (2010) "Jonathan Edwards's Philosophy of Nature: the Reenchantment of the World in the Age of Scientific Reasoning" ,p.213

${ }^{28}$ McDermott, G. R. (2000) " Jonathan Edwards Confronts the Gods : Christian Theology, Enlightenment Religion, and Non - Christian Faiths",pp.37-38

${ }^{29}$ Ibid, p.71

${ }^{30}$ McClymond, M..J. (1998) "Encounters With God :An Approach to the Theology of Jonathan Edwards ",pp.94-95 
على الوحي، كما أن العقل يتثكل ويحظى بالدعم من خلال الوحي بطرق لا يمكن

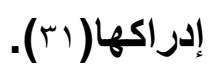

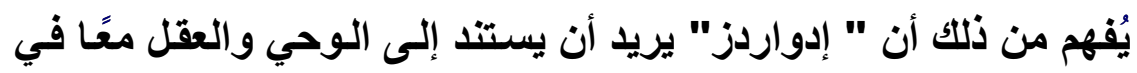

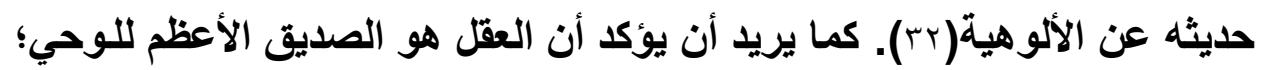

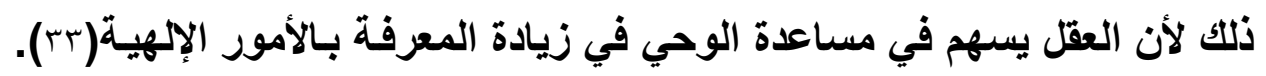

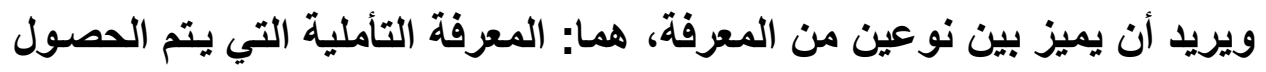

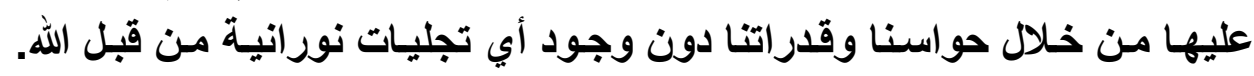

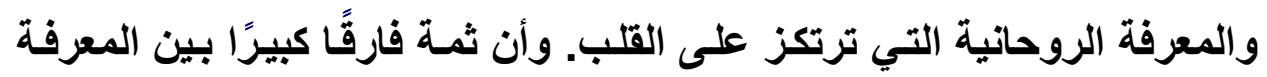

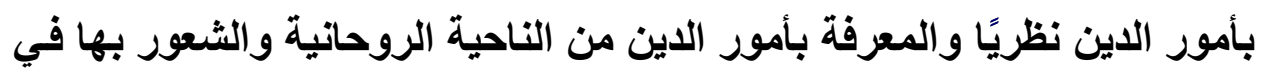

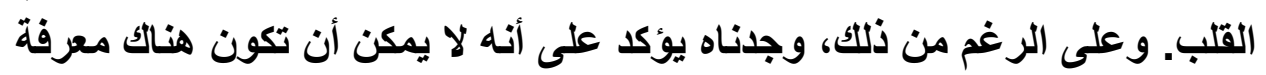
روحانية لثيء ما في غياب المعرفة العقلية (عب).

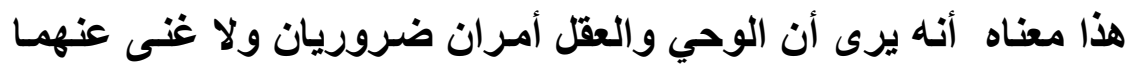

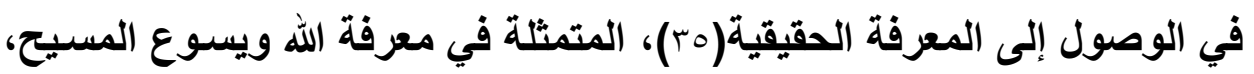

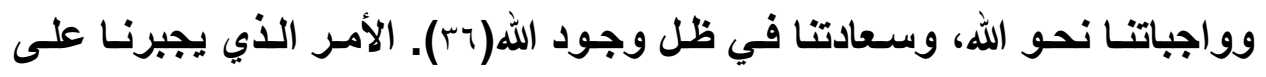

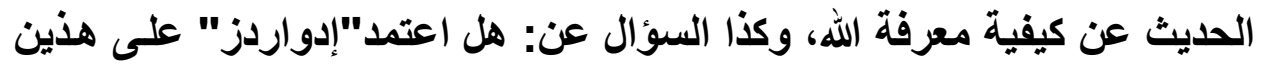

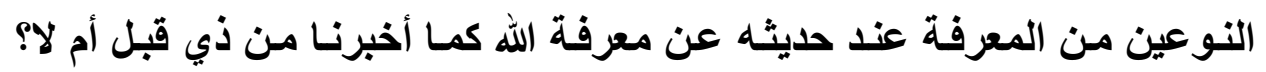

${ }^{31}$ McDermott, G. R. (2000) " Jonathan Edwards Confronts the Gods : Christian Theology, Enlightenment Religion, and Non - Christian Faiths", pp.71-72

${ }^{32}$ Smith, J.E. (1976) "Jonathan Edwards as Philosophical Theologian",p.307

${ }^{33}$ McDermott, G. R. (2000) " Jonathan Edwards Confronts the Gods : Christian Theology, Enlightenment Religion, and Non - Christian Faiths",p.62

${ }^{34}$ Edwards, J . "Christian Knowledge"

${ }^{35}$ Sevcikova. M. (2009)" Alternative Viewpoint: Edwards and Philosophy"," in " Understandings Jonathan Edwards: An Introduction to America's Theologian, (ed) McDermott, G..R.. Oxford University Press.p. 174

${ }^{36}$ Edwards, J. "Christian Knowledge" 
مجلة كلية الآداب، جامعة سوهاج، العدد التاسع والأربعون، الجزء الأول، أكتوبر 1 ـ ب م

وهذا يقود حتمًا إلى الحديث عن طرق معرفـة الله عند " إدواردز"، وهذا هو نقوم به الآن عبر السطور الآتية.

\section{ثانيًا: طروق معرفة الله عند "إدواردز".}

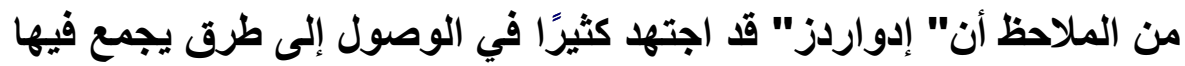
بين الوحي والعقل(rv)؛ بهرف الوصول إلى الله، لعل من أبرزها ما يلي:

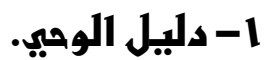

قبل الحديث عن الوحي بوصفه طريقًا من الطرق الرئيسـة لمعرفة الله عند" إدواردز"، نراه يعظم من مكانة العقل ودوره في الوصول إلى معرفة الله؛

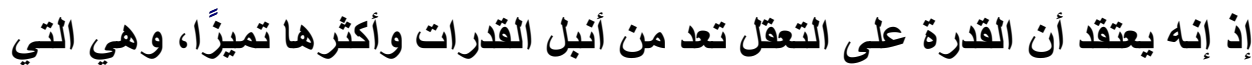

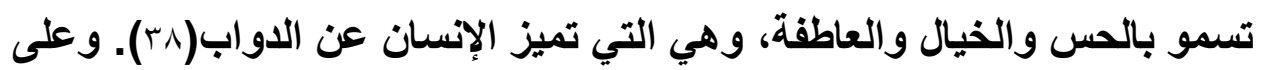

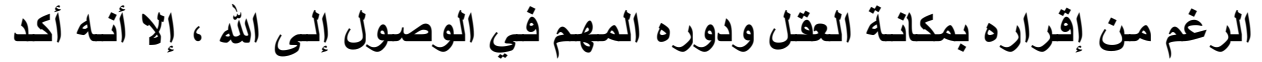

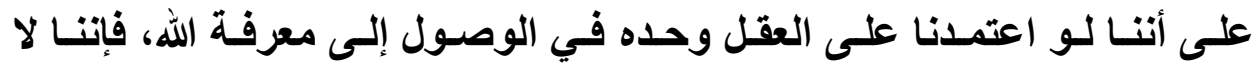

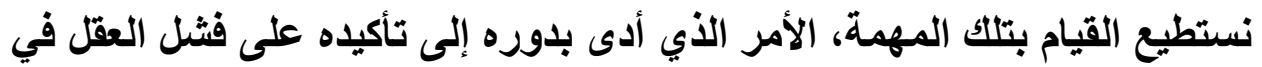

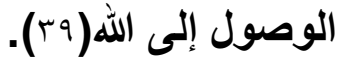

ترتب على ذلك تأكيده الجازم على أهمية الوحي، وإصراره على أنسه في

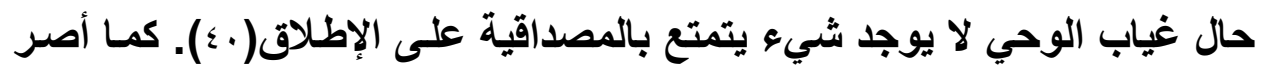

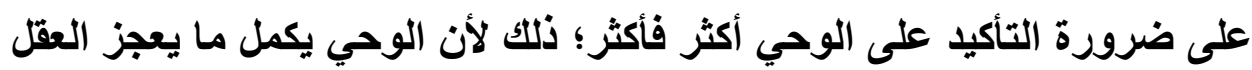

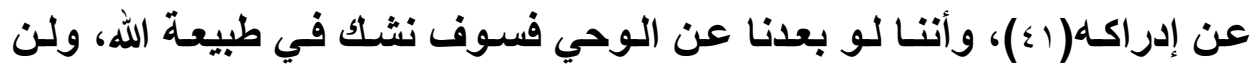

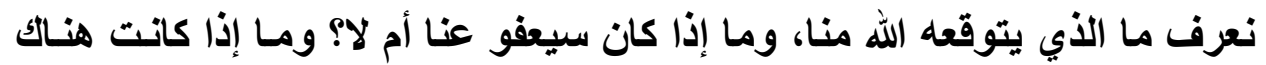

${ }^{37}$ Smith, J. E. (1976) "Jonathan Edwards as Philosophical Theologian",p.313

${ }^{38}$ McDermott, G.R. (2000) " Jonathan Edwards Confronts the Gods : Christian Theology, Enlightenment Religion, and Non - Christian Faiths",pp.56-57

${ }^{39}$ Ibid, pp 63-64

${ }^{40}$ Ibid,p39

${ }^{41}$ Zakai, A. (2010) "Jonathan Edwards's Philosophy of Nature: the Reenchantment of the World in the Age of Scientific Reasoning",p.214 


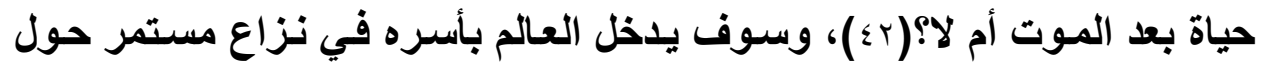

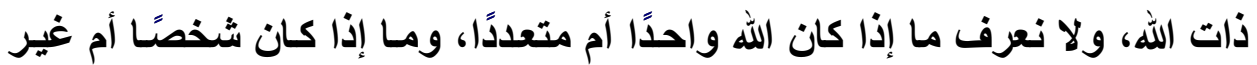

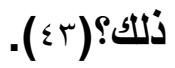

وعلى الرغم من إصراره على أهمية الوحي كما أسلفنا، إلا أنتا وجدناه

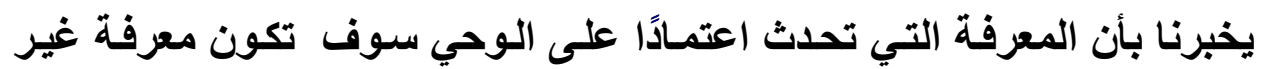

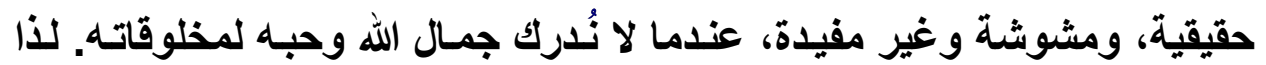

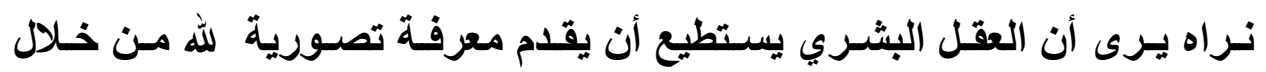

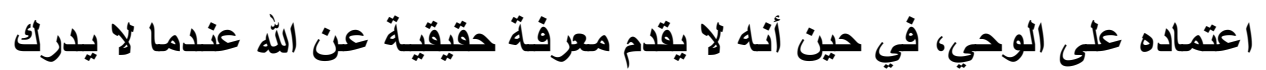

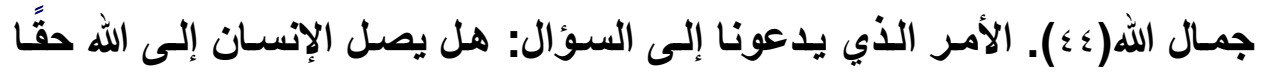

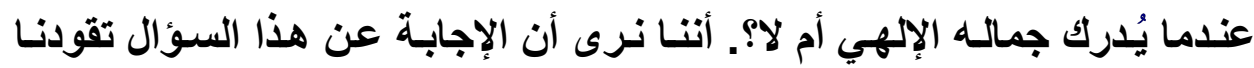

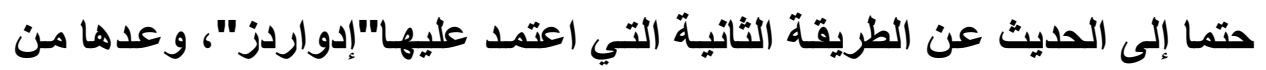
الطرق الرئيسة في الوصول إلى الله، ألا وهي: إدرالك الإنسان للجمال الإلهي.

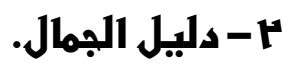

بداية نلاحظ أن الجمـال عند" إدواردز" يمثل الأسـاس الذي تستتـ إليه

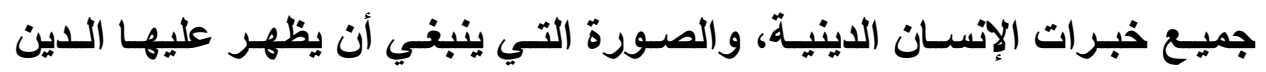

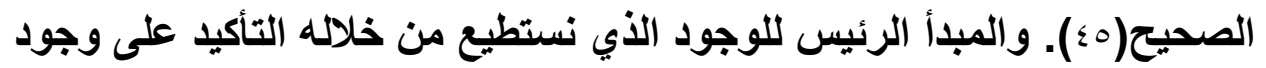

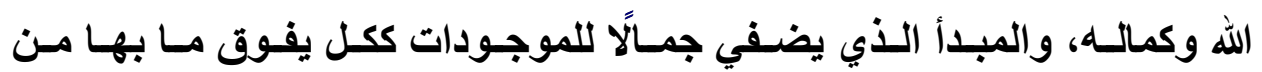

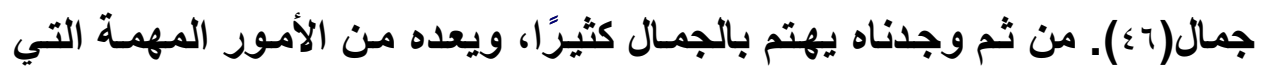

${ }^{42}$ McClymond, M .J. (1998) "Encounters With God :An Approach to the Theology of Jonathan Edwards ",p.94

${ }^{43}$ McDermott, G. R. (2000) " Jonathan Edwards Confronts the Gods :

Christian Theology, Enlightenment Religion, and Non - Christian

Faiths",p.94

${ }^{44}$ Ibid,p.66

${ }^{45}$ Mitchell, L.J. (2007) "The Theological Aesthetics of Jonathan

Edwards", Theology Today, Vol.64. p.42

${ }^{46}$ Delattre, R. A. (2003) "Aesthetics and Ethics: Jonathan Edwards and the Recovery of Aesthetics for Religious Ethics", Journal of Religious Ethics, Inc.p.277 
مجلة كلية الآداب، جامعة سوهاج، العدد التاسع والأربعون، الجزء الأول، أكتوبر 1 + بام

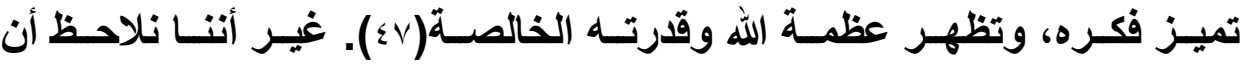

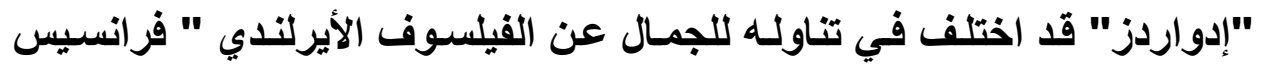

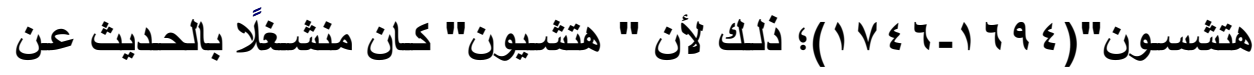

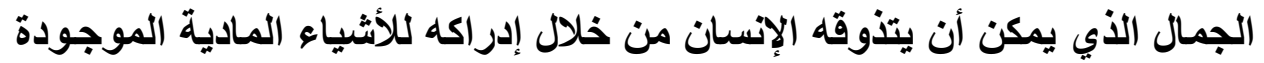

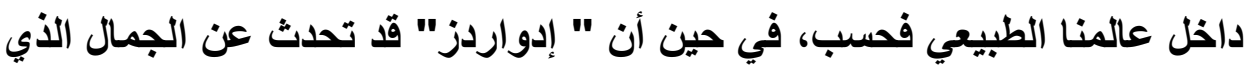
يمكن أن يتذوقه الإنسان من خلال إدراكه للأشياء المادية. كما تحدث عن عن الجمال الدال

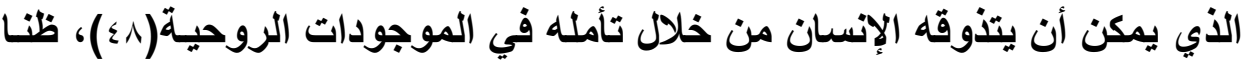

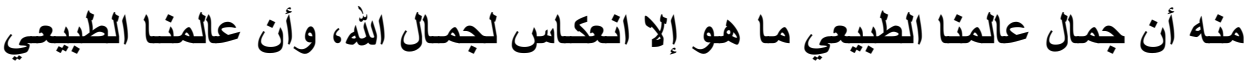

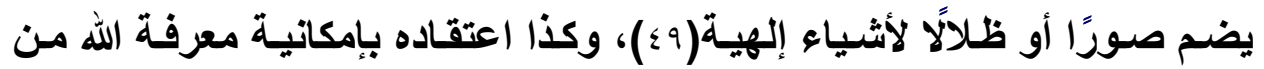

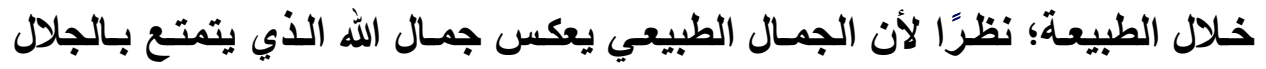
والهيبة(0.0).

ترتب على ذلك إصرار" إدواردز" على تقسيم الجمـال إلى نـوعين همـا:

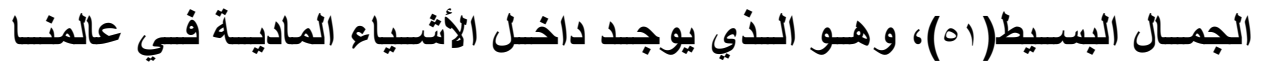

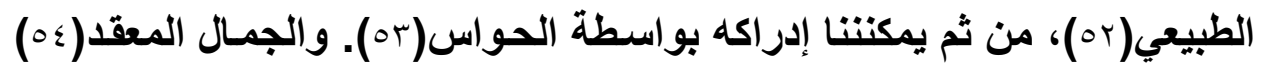
وهو الذي يوجد داخل الموجودات الروحيـة(00). وعلى أيسة حسال يمثل الجمـال

${ }^{47}$ Smith, J. E. (1976) "Jonathan Edwards as Philosophical Theologian",p.316

${ }^{48}$ Louie, K, Y. (2007), "The Theological Aesthetics of Jonathan Edwards", University Of Edinburgh,p56

${ }^{49}$ Wainwright, W. J. (1980) "Jonathan Edwards and the Language of God" Journal of the American Academy of Religion, Vol.48, No.4, Oxford University press.p.519

${ }^{50}$ Ibid,p.523

${ }^{51}$ Lee ,S. H. (2014) "Jonathan Edwards" in, "Early Modern Philosophy of Religion",p.226

${ }^{52}$ Louie, K. Y. (2007), "The Theological Aesthetics of Jonathan Edwards",p.57

${ }^{53}$ Ibid,p.55

${ }^{54}$ Lee ,S. H. (2014) "Jonathan Edwards" in, "Early Modern Philosophy of Religion",p.226

${ }^{55}$ Louie, K. Y. (2007), "The Theological Aesthetics of Jonathan Edwards",p.57 


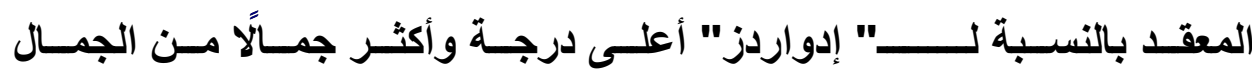

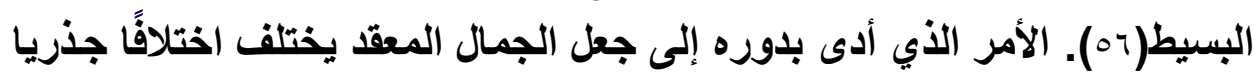

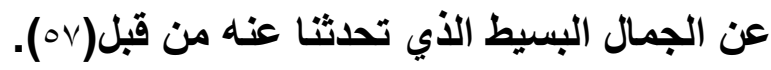

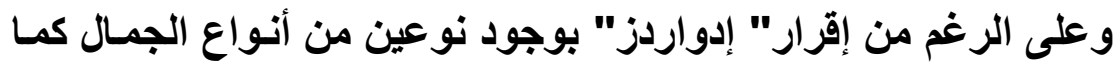

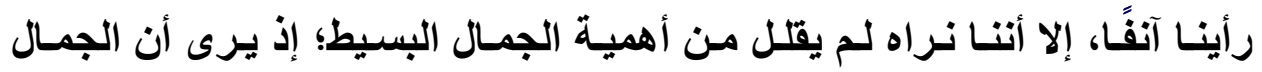

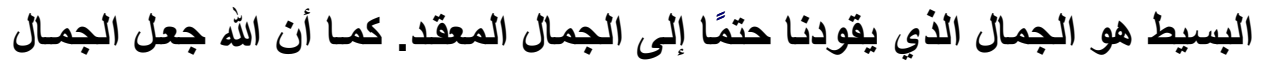

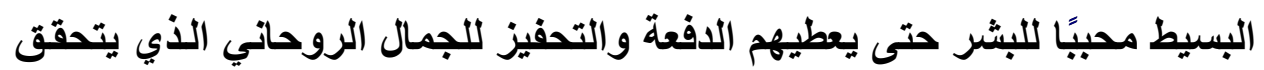

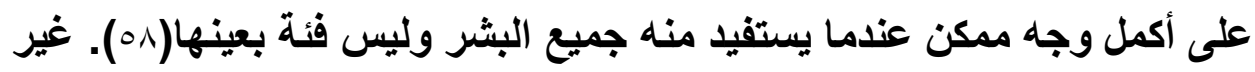

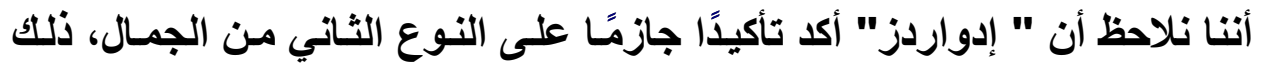

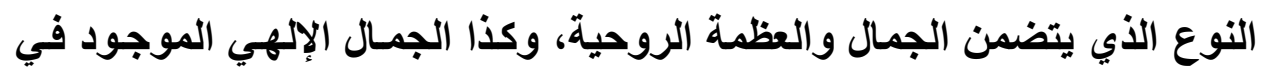

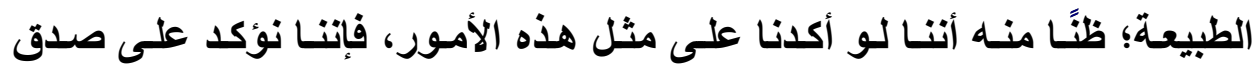

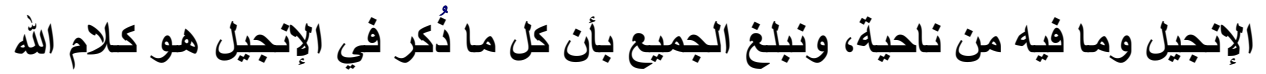

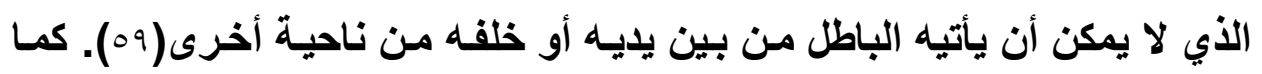

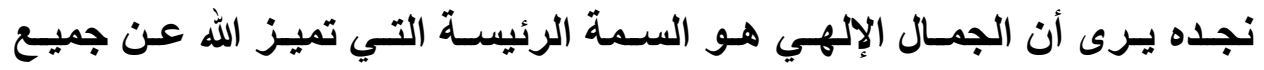

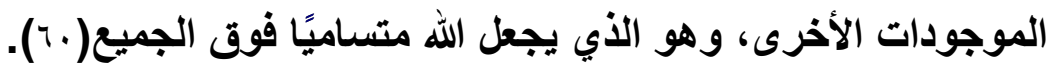

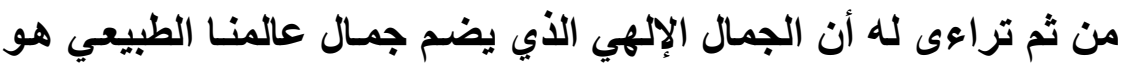
الجمال الحقيقي، وأن الأثياء الجميلة في حـ ذاتها، والتي لا لتعتمـ على الجمـال

${ }^{56}$ Lee ,S. H. (2014) "Jonathan Edwards" in, "Early Modern Philosophy of Religion",p.226

${ }^{57}$ Louie, K. Y. (2007), "The Theological Aesthetics of Jonathan Edwards",p.55

${ }^{58}$ Ibid,pp.57-58

${ }^{59}$ Edwards, J. "Evidence of the Truth of the Gospel", New hope, Presbyterian church.

(http://www.newhopefairfax.org/files/Edwards Evidence Truth Gospel.pdf)

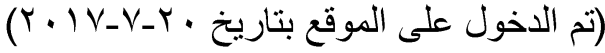

${ }^{60}$ Delattre, R. A. (2003) "Aesthetics and Ethics: Jonathan Edwards and the Recovery of Aesthetics for Religious Ethics",p.281 
مجلة كلية الآداب، جامعة سوهاج، العدد التاسع والأربعون، الجزء الأول، أكتوبر 1 + بام

الإلهي، تتصف بصفة الجمال الزائف والمحدود( (7)؛ ويرجع ذلك إلى اعتقاده أن

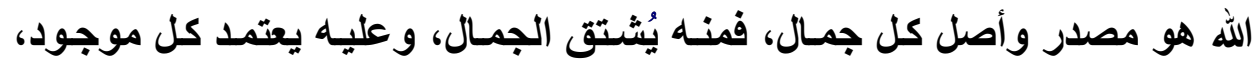
وجماله يسع كل جمال، ووجوده يسع كل موجود بشكل يفوق الثـمس التي هي هي

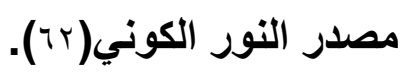

ولقد علل لنا " إدواردز" سبب كون الله جميلًا؛ مؤكدًا على أنسه جميل؛

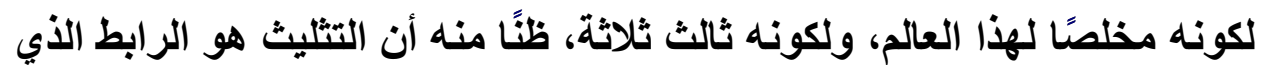

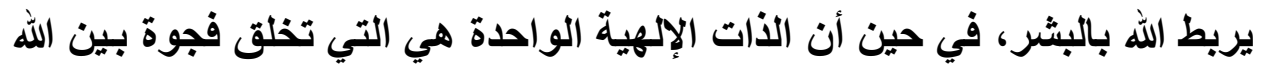

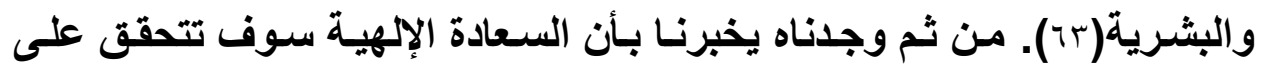

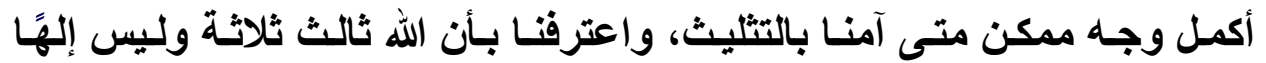

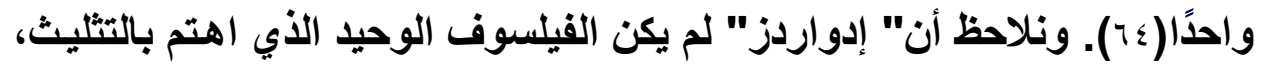

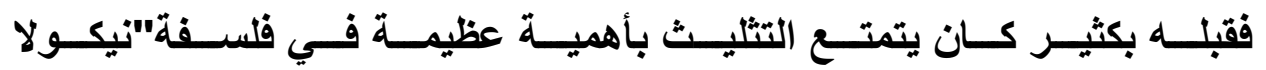

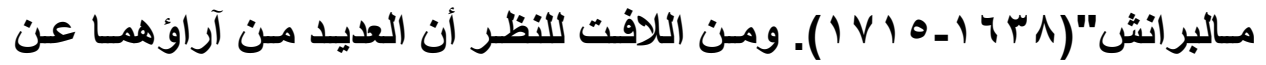

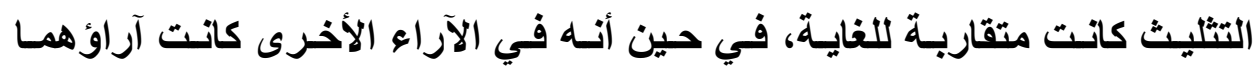
مختلفة كثيرًا (ro).

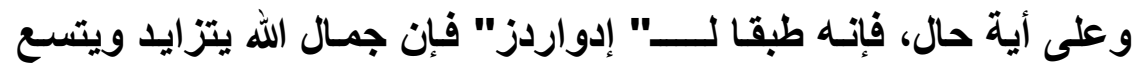
مجاله حالما يشرع القديسون في معرفة وحب جمال الله، وكذا جمـال الموجودات

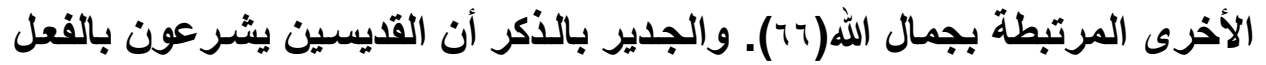

${ }^{61}$ Lee, S. H. (2009) "Edwards and Beauty" in," Understandings Jonathan Edwards: An Introduction to America's Theologian, (ed) McDermott, G. R.. Oxford University Press. P.115

${ }^{62}$ Mitchell, L .J. (2007) "The Theological Aesthetics of Jonathan Edwards",p.38

${ }^{63}$ Louie, K. Y. (2007), "The Theological Aesthetics of Jonathan Edwards",p.91

${ }^{64}$ Ibid,p.96

${ }^{65}$ Reid, J. (2002) "The Trinitarian Metaphysics of Jonathan Edwards and Nicolas Malebranche" Hey j Xliii, Ltd, Oxford, UK \&Boston, USA,pp.152-153

${ }^{66}$ Lee, S. H. (2009) "Edwards and Beauty" in, " Understandings Jonathan Edwards: An Introduction to America's Theologian,p.113 
في التأمل في الأمور الإلهية، ومـا تحويسه من أسرار إلهيـة. لذا فهم يشعرون

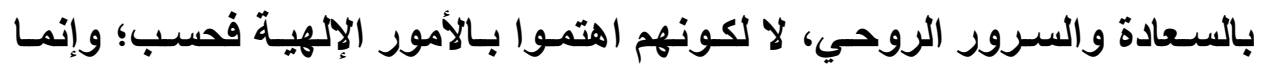

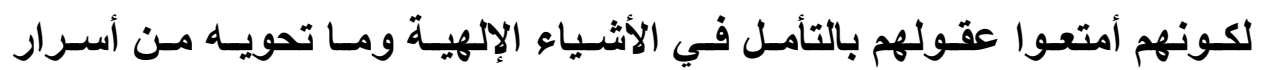

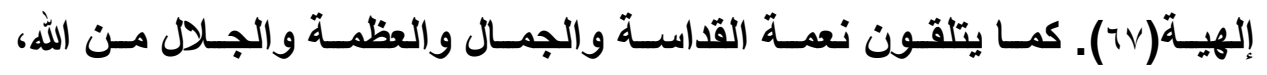
ويشاركون في الحياة الأتية لله(1)). وهذا هو ما يميزهم عن المنافقين؛ ذلك لأن

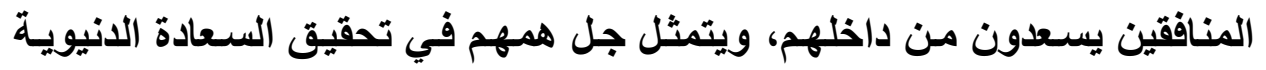

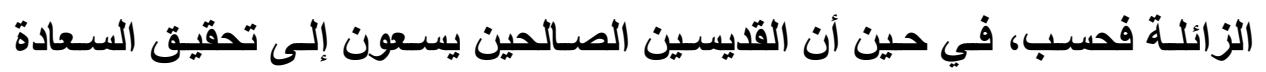

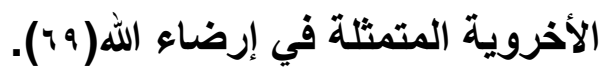

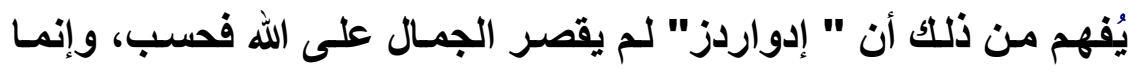

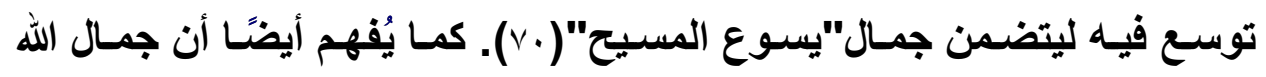

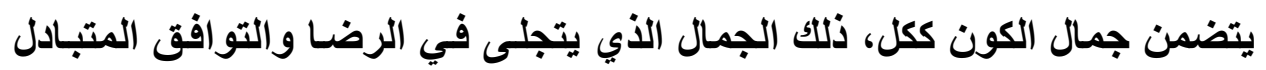

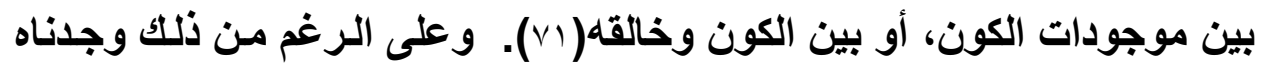

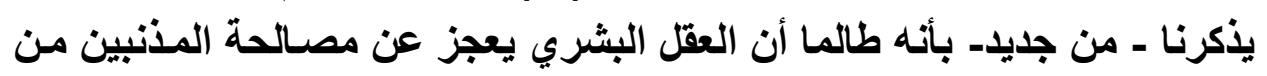

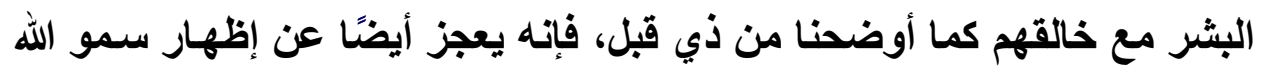
وجماله اللأين يؤكدان على وجود الله وكماله. من ثم وجدناه يؤكد على فئ إمكانيـة

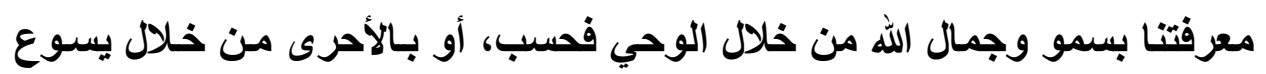

${ }^{67}$ Edwards, J. "The Believers Delight in the Beauty of Divine Things", Form Religious Affection. (ed), by John E. Smith, Vol, 2 Works, Yale 1959.

(http://www.newhopefairfax.org/files/edwardsbelieversdelight.pdf ) تم

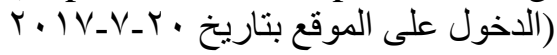

${ }^{68}$ Strobel , K. (2016) "Jonathan Edwards's Reformed Doctrine of Theosis", Harvard Theological Review.p.378

${ }^{69}$ Edwards, J. "The Believers Delight in the Beauty of Divine Things", Form Religious Affection

${ }^{70}$ Mitchell, L .J. (2007) "The Theological Aesthetics of Jonathan Edwards",p.41

${ }^{71}$ Jenson, R. W. (1988)" Americas Theologian: A Recommendation of Jonathan Edwards", New York, Oxford University Press.p.16 
مجلة كلية الآداب، جامعة سوهاج، العدد التاسع والأربعون، الجزء الأول، أكتوبر 1 ـ ب م

المسـيح؛ ظنَّا منـهـه أن إدراك جمـال الله يُرى ويُدرك في المقـام الأول مـن خـلال يسوع المسيح (الوحي)(r)م).

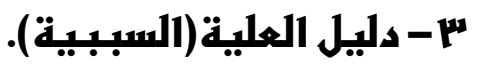

نلاحظ أن " إدواردز" قد اهتم بدليل العليـة اهتمامًا عظيمًا؛ إذ يعتقد أنـه

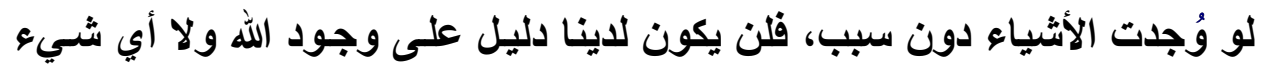

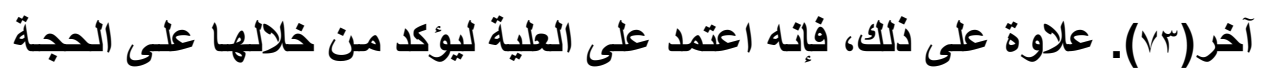

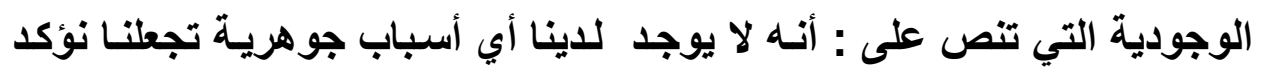

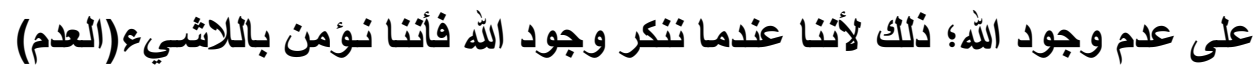
الأي يكون شيئًا غير حقيقي ولا وجود له، في حين أنتا لو اعتقدنا في وجود الله،

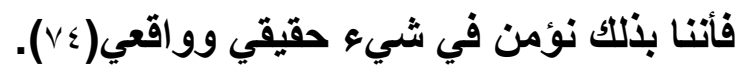

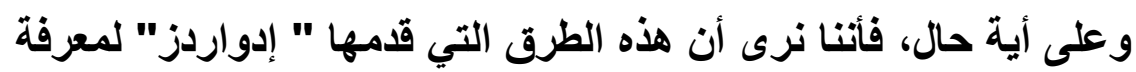

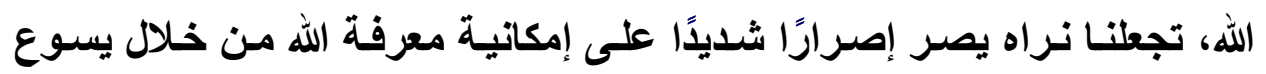

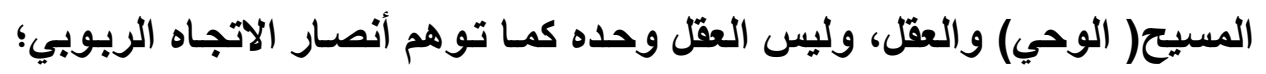
ذلك لأنه يرى أن الله كيان روحي محض، ويمكنتا التوصل إليهه وإدراكه اعتمـادًا

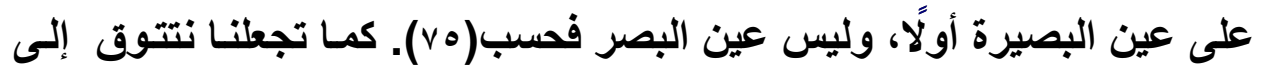
معرفة ذات الله وصفاته حسبما تصور ها"إدواردز"، وهذا هو مـا يجعلنا نتحدث ولهين عن: " ذات الله وصفاته".

${ }^{72}$ McDermott, G. R. (2000) " Jonathan Edwards Confronts the Gods : Christian Theology, Enlightenment Religion, and Non - Christian Faiths",pp.65-66

${ }^{73}$ Smith, J. E. (1976) "Jonathan Edwards as Philosophical Theologian",p.321

${ }^{74}$ McDermott, G. R. (2000) " Jonathan Edwards Confronts the Gods : Christian Theology, Enlightenment Religion, and Non - Christian Faiths",p.57

${ }^{75}$ Edwards, J. "The Pure in Heart blessed", (http://www.prayermeetings.org/files/The_Pure_in_Heart_Blessed.pdf)

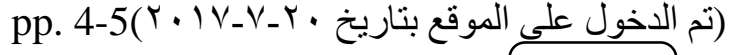




\section{ثنالثًا: ذات الله وصفاته.}

إن الأتات الإلهية عند " إدواردز" هي أشبه بالإلـه الذي يكون جل همـه

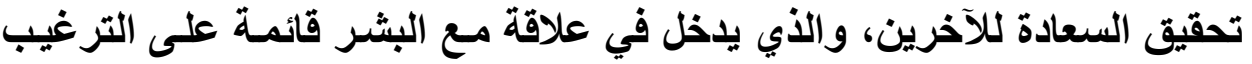

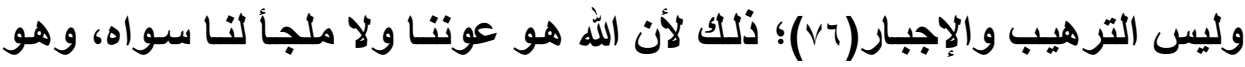

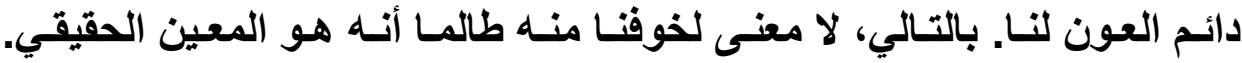

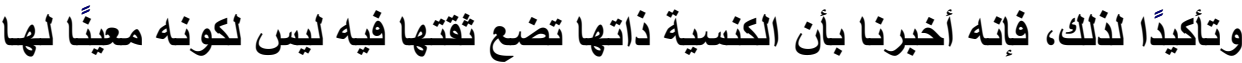
فحسب؛ وإنما لكونه هو الأي يجلب السعادة والراحة لنا في أوقات الثدة (vv).

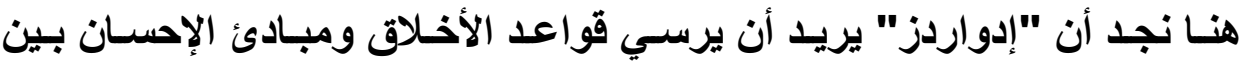

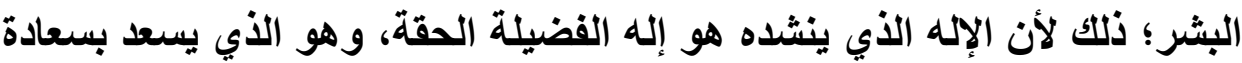

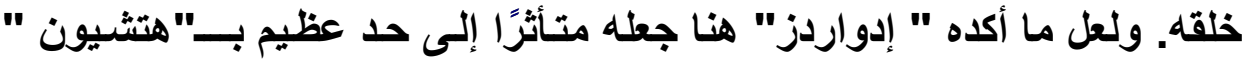

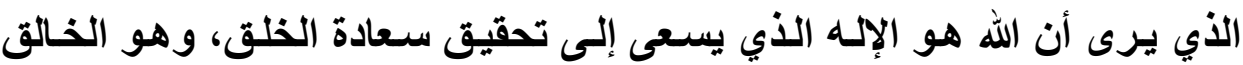

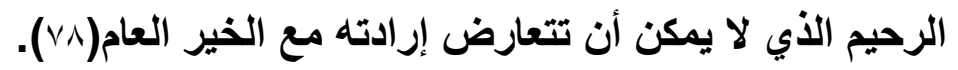

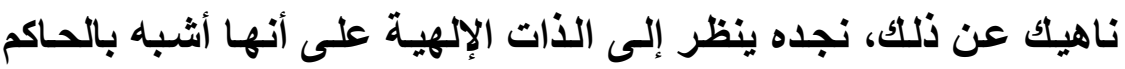

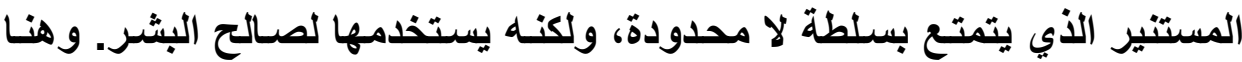

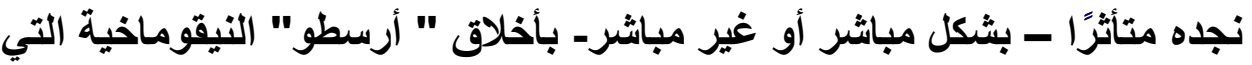

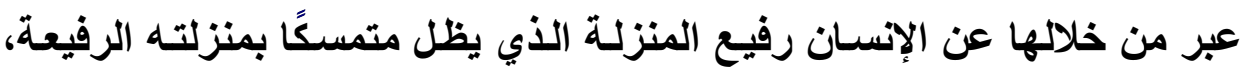

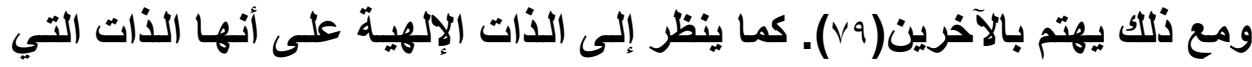

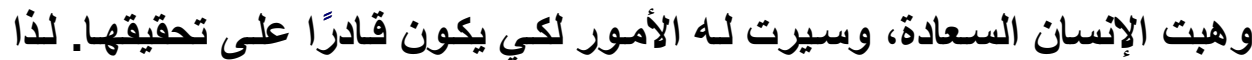
يسعى الإنسان بحكم طبيعته إلى تحقيق تلك السـعادة، فيجدها متمثلـة في روئية الإنة

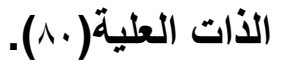

${ }^{76}$ McDermott, G. R. (2009) "Conclusion: Edwards's Relevance Today", in" Understandings Jonathan Edwards: An Introduction to America's Theologian, (Ed) McDermott, G. R. Oxford University Press. P.202

${ }^{77}$ Edwards, J. (1735) "The Sole Consideration, that God is God Sufficient to Still All Objections to his Sovereignty", Sermon II.

(https://www.monergism.com/thethreshold/sdg/pdf/edwards_divinesove

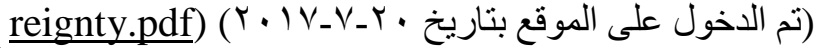

${ }^{78}$ McClymond, M .J. (1998) "Encounters With God :An Approach to the Theology of Jonathan Edwards ",p.59

${ }^{79}$ Ibid,p.61

${ }^{80}$ Edwards, J. "The Pure in Heart blessed", p.11 
مجلة كلية الآداب، جامعة سوهاج، العدد التاسع والأربعون، الجزء الأول، أكتوبر 1 ـ ب م

وروئة الذات العلية التي يقصدها هنا لا تعدث بعين الجسد، وإنما تحدث

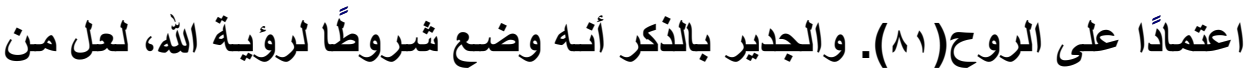

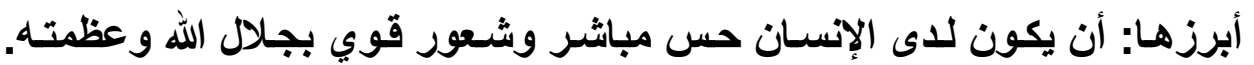

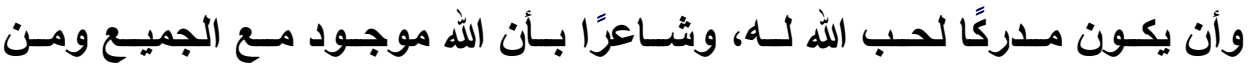

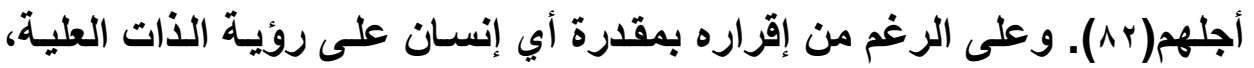

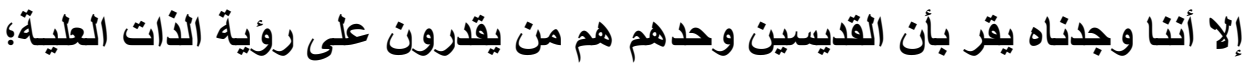

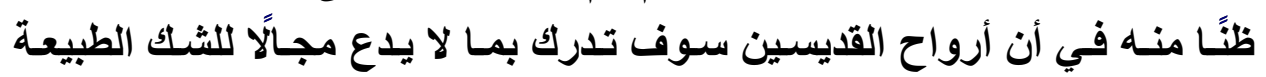

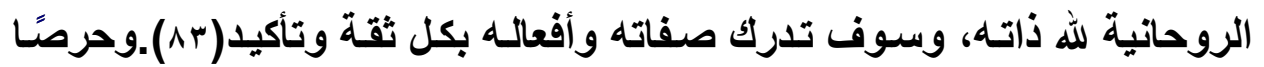

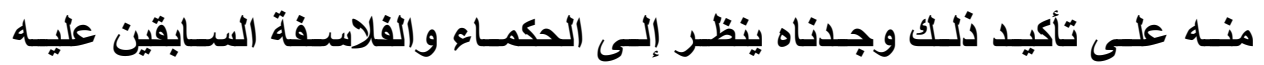

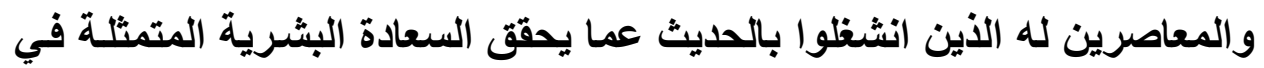

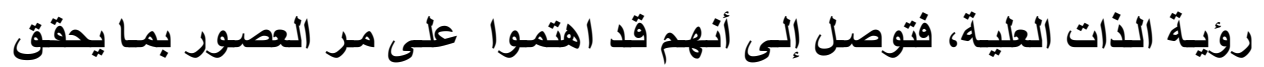

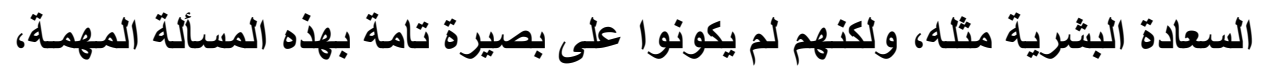

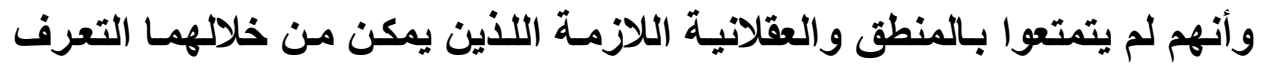

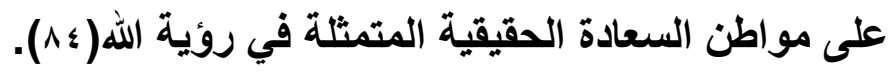

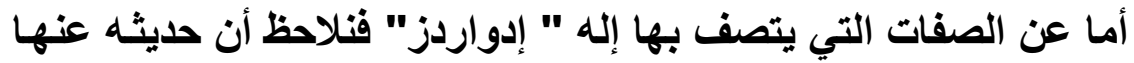

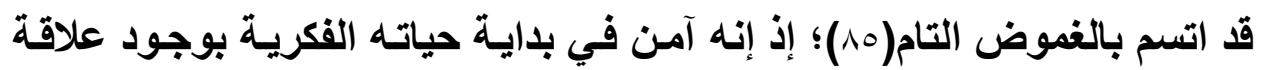

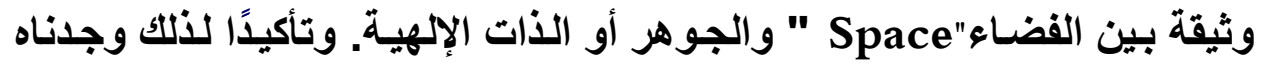

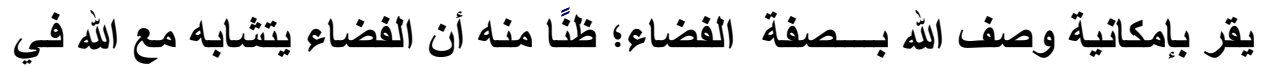

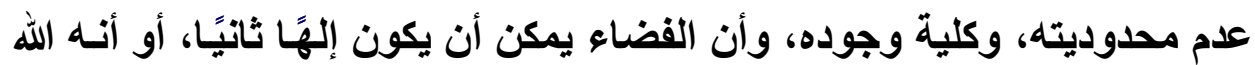

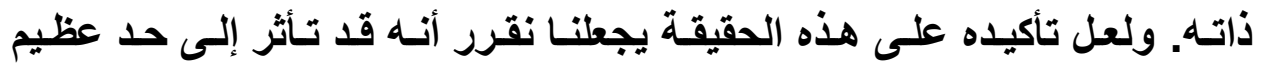

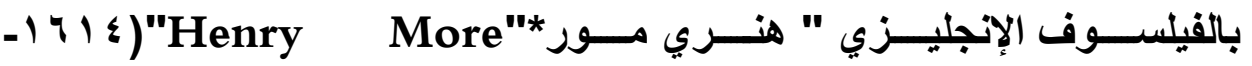

${ }^{81}$ Edwards, J. "The Pure in Heart blessed", p.3

${ }^{82}$ Ibid,p.5

${ }^{83}$ Ibid,p.7

${ }^{84}$ Ibid,pp.11-12

${ }^{85}$ Crisp, O. D. (2003)"Jonathan Edwards on Divine Simplicity", Religious Studies, Vol.39, No.1, Cambridge University Press.p.28

*هنري مور: لاهوتي وفيلسوف انجليزي. تأثر إلى حد كيبر بالمذهب الأفلاطوني للمزيد

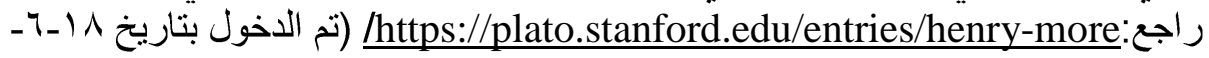




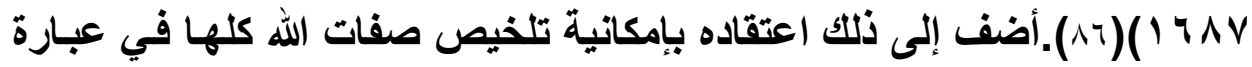

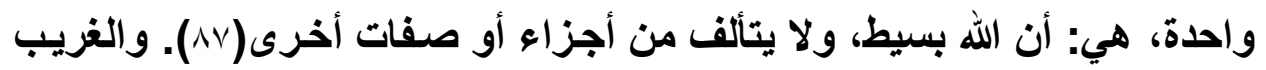

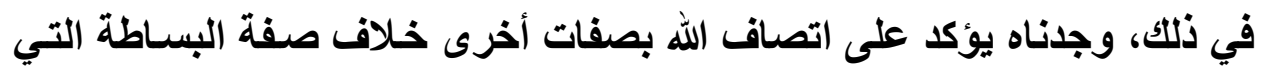

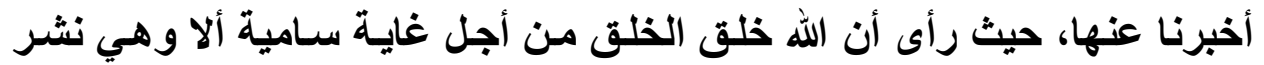

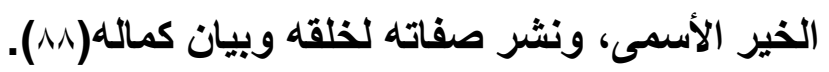

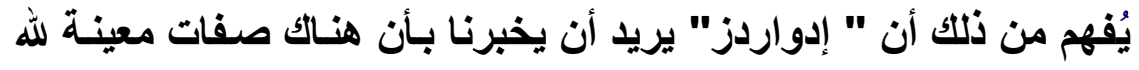

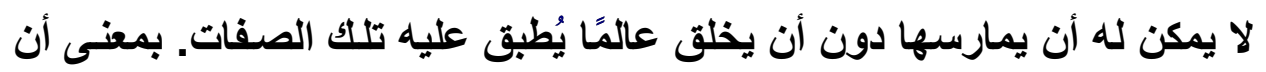

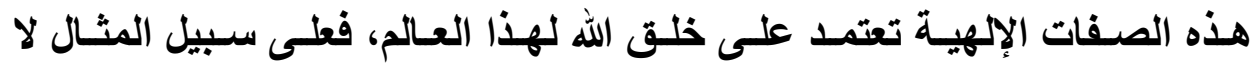

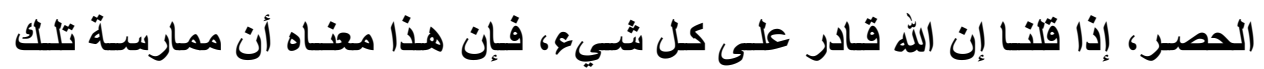

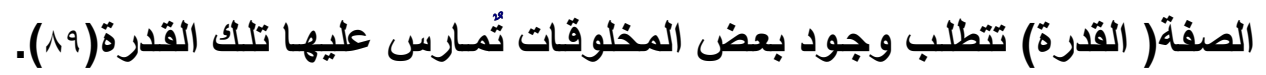

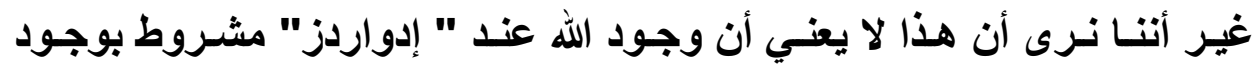

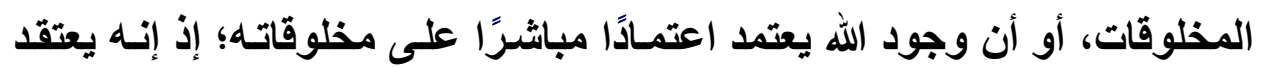

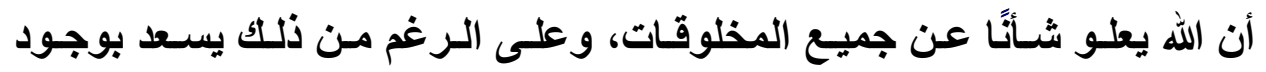

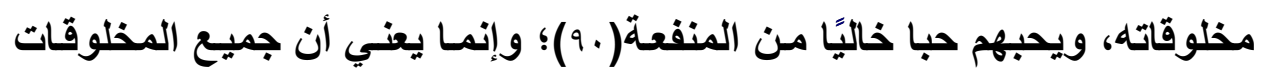
ت تعتمد في وجودها عليه( (9).

${ }^{86}$ Reid, J. (2003) "Jonathan Edwards on Space and God", Journal of The History of Philosophy, Vol.41, No.3, Johns Hopkins University Press.pp.385-386

${ }^{87}$ Crisp, O. D. (2003)"Jonathan Edwards on Divine Simplicity",p.32

${ }^{88}$ Woodbridge, F. J . (1904) "Jonathan Edwards", the philosophical Review, Vol.13, No.4, Duke University Press on behalf of philosophical Review,p.401

${ }^{89}$ Crisp, O. D. (2009) "Jonathan Edwards on the Divine Nature", Journal Reformed Theology .p.189

${ }^{90}$ Fisher, G. P. (1879)"The Philosophy of Jonathan Edwards",pp.297-298

${ }^{91}$ Louie, K ,Y. (2007), "The Theological Aesthetics of Jonathan Edwards",p.94 
مجلة كلية الآداب، جامعة سوهاج، العدد التاسع والأربعون، الجزء الأول، أكتوبر 1 ـ ب م

كما وصف الله بالكمال الإلهي المطلق، والرضـا والسعادة الذاتيـة الناتجـة

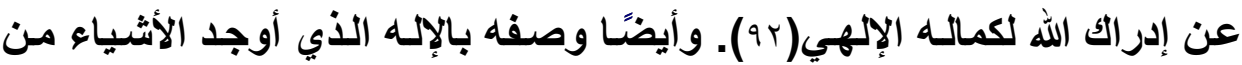
عدم. والقادر على التحكم في جميع مخلوقاته بشكل مستمر دون نهاية(به). وأنه وأن والنه قدرته علينا لا تعلوها قدرة، وهي قدرة لا محدودة. وهو القادر على أن ينزل بنـا

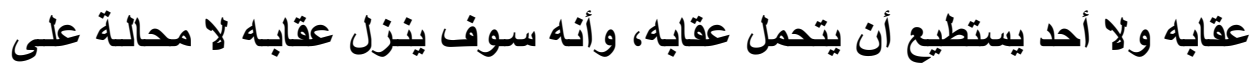

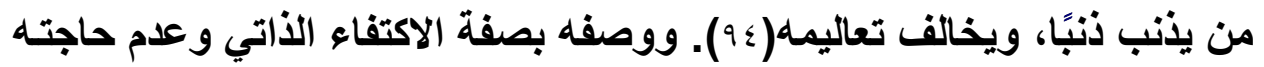

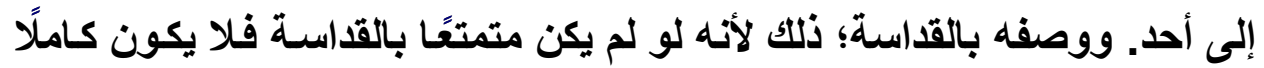

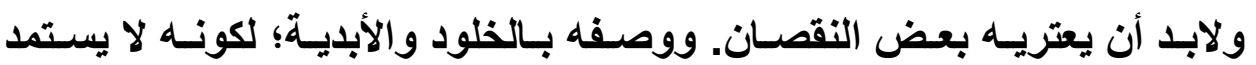
وجوده من أحد، ولا يوجد شيء يحده يدة زمانًا كان أو مكانًا (90).

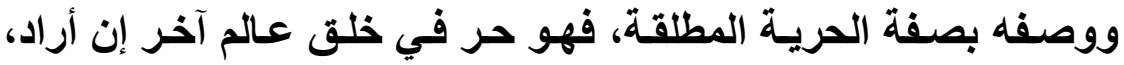

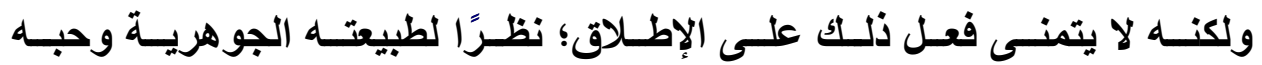

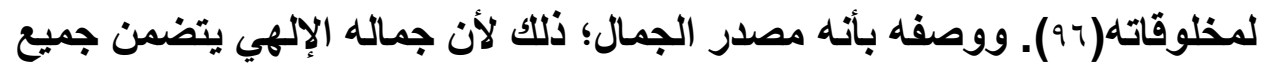

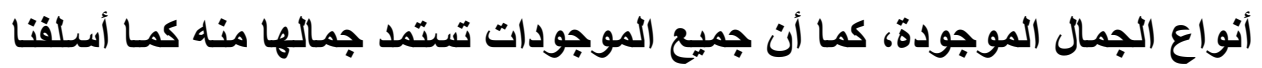

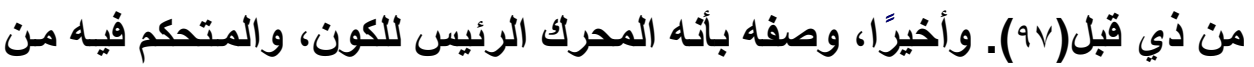

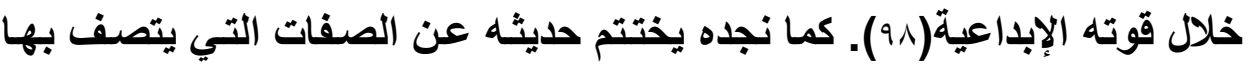

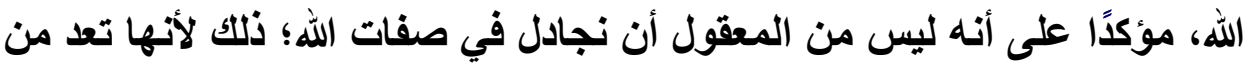

${ }^{92}$ Edwards, J." An Unpublished Essay on the Trinity" (http://www.monergism.com/thethreshold/sdg/Edwards, \%20Jonathan\%20\%20An\%20Unpublished\%20Essay\%20on\%20the\%20Tr.pdf)p.1) تم الدخول

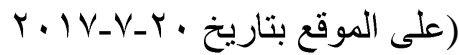

${ }^{93}$ Edwards, J. (1735) "The Sole Consideration, that God is God Sufficient to Still All Objections to his Sovereignty", Sermon II.

${ }^{94}$ Edwards, J. "The Justice of God in The Damnation of Sinners" (www.jonathan-edwards.org/Justice.pdf ) (-V_r • تم الدخول على الموقع بتاريخ r.IV)

${ }^{95}$ Edwards, J. (1735) "The Sole Consideration, that God is God Sufficient to Still All Objections to his Sovereignty", Sermon II.

${ }^{96}$ Crisp, O. D. (2009) "Jonathan Edwards on the Divine Nature",p.191

${ }^{97}$ Louie, K, Y. (2007), "The Theological Aesthetics of Jonathan Edwards", pp.92-93

${ }^{98}$ Delattre, R .A. (2003) "Aesthetics and Ethics: Jonathan Edwards and the Recovery of Aesthetics for Religious Ethics",p.277 
الغيبيات التي من المفترض ألا نجادل فيها. من ثم يتحتم عليــا أن نؤمن ونعتقد

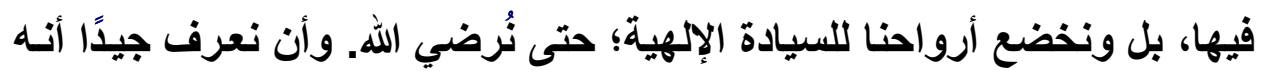

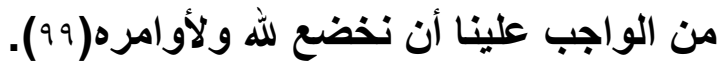

\section{رابـعًا: علاقة الله بـالكوز.}

من خلال عرضنا لذات الله وصفاته تبين لنا أن " إدواردز" يثير إثـارة صريحة إلى وجود ارتباط وثيق الصلة بين الله والكون؛ إذ إن الله هو المحرك

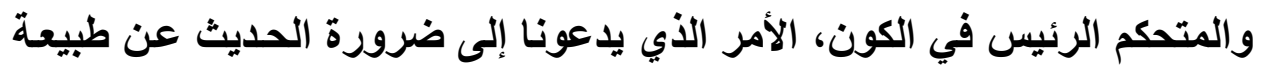

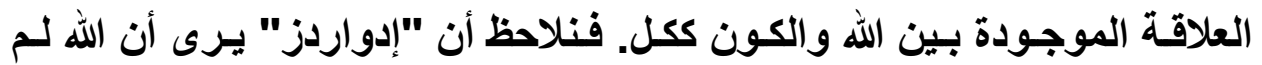

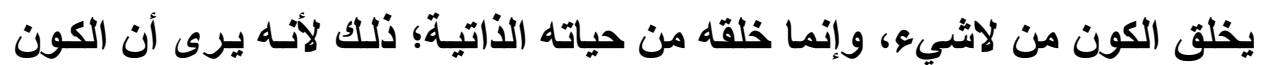

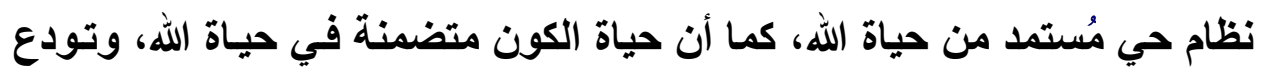

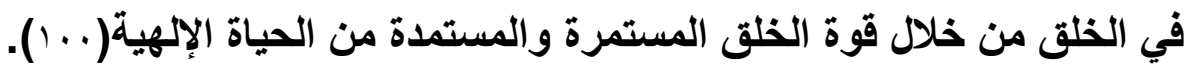

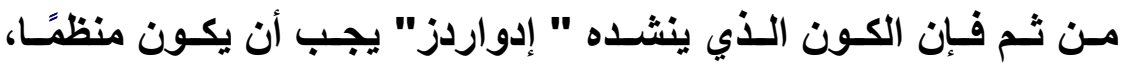
ومحكومًا من قبل الله من خلال نظام إبداعي وجمالي (1 ـ1). ويجب أن يكون الله

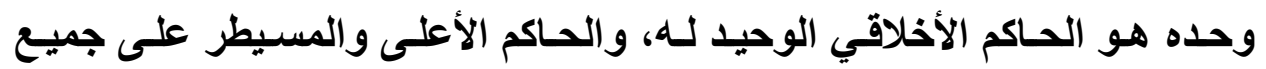
المخلوقات. وينبفي على الله أن يحكم الكون ويمسارس سلطته الهـ على مخلوقاتهـ

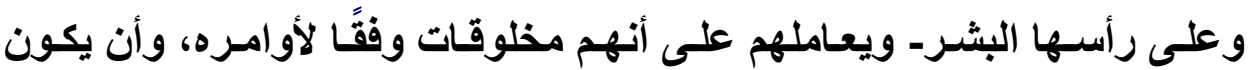

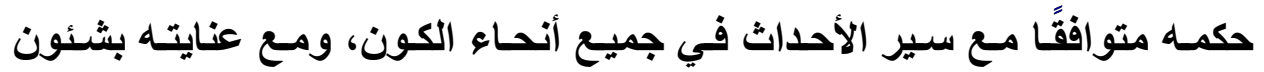
خلقه. وينبغي أن يحكم البشر من خلال تثريع قانون الخلاقي ليبين من خلافله

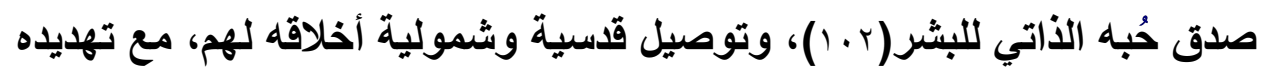

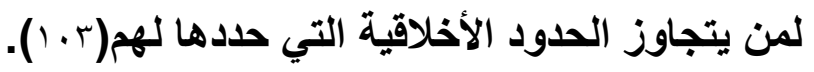

${ }^{99}$ Edwards, J. (1735) "The Sole Consideration, that God is God Sufficient to Still All Objections to his Sovereignty", Sermon II.

${ }^{100}$ Delattre, R , A. (2003) "Aesthetics and Ethics: Jonathan Edwards and the Recovery of Aesthetics for Religious Ethics",pp.278-279

${ }^{101}$ Ibid, p 281

${ }^{102}$ Hamilton, S. M. (2014)"Jonathan Edwards, Anselmic Satisfaction and God's Moral Government", International Journal of Systematic Theology, Vol.17, No.1, John Wiley \&Sons Ltd.pp.58-59 ${ }^{103}$ Ibid, p.60 
مجلة كلية الآداب، جامعة سوهاج، العدد التاسع والأربعون، الجزء الأول، أكتوبر 1 ـ ب م

كمـــا نلاحـظ أن" إدواردز" قــــ انتقــل إلــى الحـــيث عـن علاقــة الله بالمخلوقات، فرأى أن جميع المخلوقات الموجودة داخل الكون- وعلى رأسـها

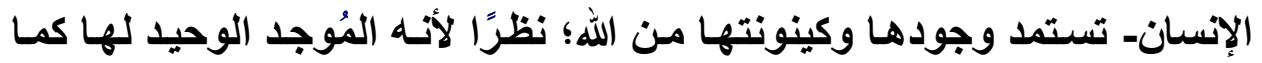

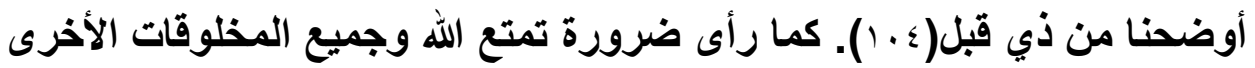

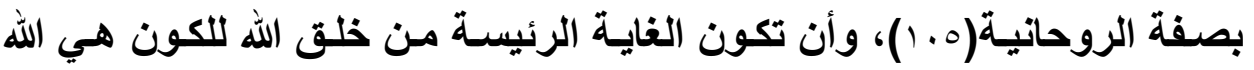

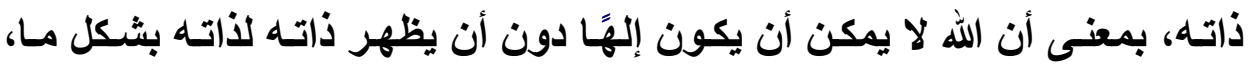

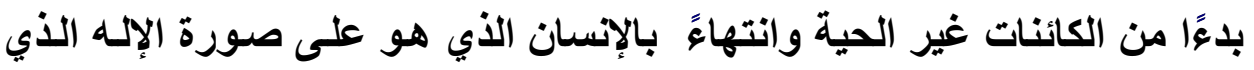

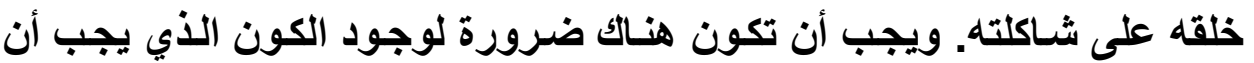
يكون متصلًا بالله لا محالة (7 1).

يُفهم من ذلك أن" إدواردز" يرى أنه من المستحيل النظر إلى العالم الأي يحيا فيه الإنسان بنظرة مادية محضة؛ ظنا منه أن هذه النظرة تعمل على التقليل

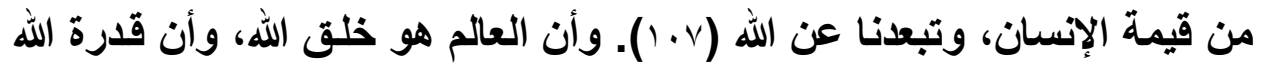

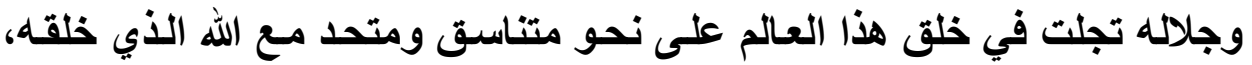
بوصفه سيدًا للكون. و وأن رضا الله يتحقى عندما يرى الله التناست والاتحـاد بينه وبين الموجودات الأخرى (1 (1).

والجدير بالأكر إنتا نرى " إدواردز" لم يهدف من تأكيده على التناست النق

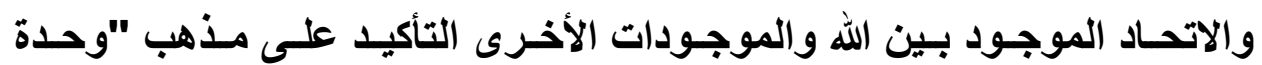

${ }^{104}$ Salladin, J. (2016) "Nature and Grace: Two Participations in the Thought of Jonathan Edwards", International Journal of Systematic Theology, Vol.18, No.3,p298

${ }^{105}$ Veto. M. (2009) "Edwards and Philosophy", in " Understandings Jonathan Edwards: An Introduction to America's Theologian", (ed) McDermott, G. R.. Oxford University Press. P.155

${ }^{106}$ Smith, J. E. (1976) "Jonathan Edwards as Philosophical Theologian", p.317

${ }^{107}$ Zakai, A. (2010) "Jonathan Edwards's Philosophy of Nature: the Reenchantment of the World in the Age of Scientific Reasoning" ,p.263 ${ }^{108}$ Creegan, N. H. (2007) "Jonathan Edward's Ecological and Ethical Vision of Nature", Stimulus, Vol.15, No.4.p.49 
الوجود" الأي قال به "سبينوزا"؛ إذ يرى أن الله يخلق كائنات ومخلوقات مميزة

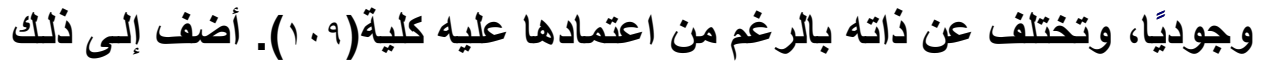

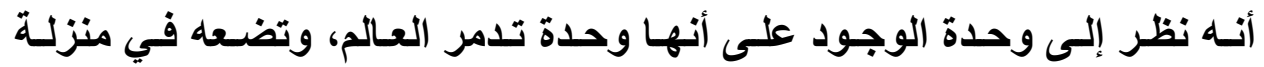

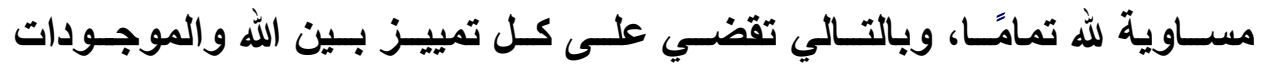
الأخرى(·) (1). ولكنه كان يهدف إلى التأكيد على وحدة الوجود من نوع خـاص

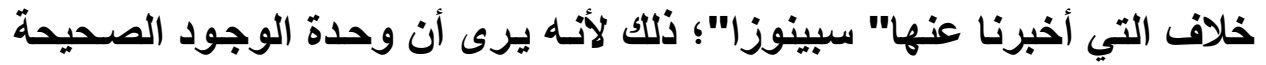

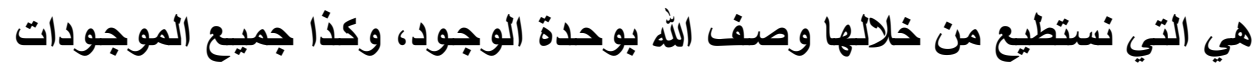

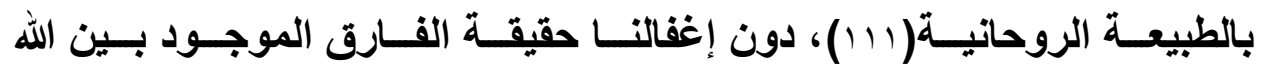

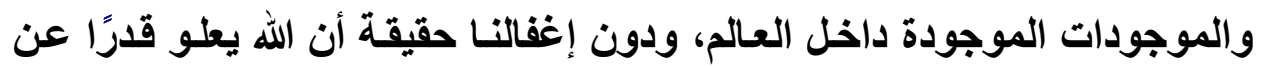

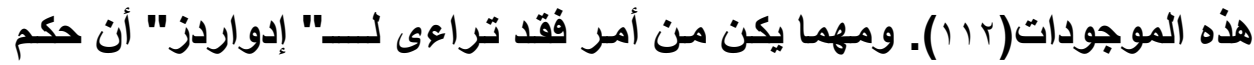
الله الأخلاقي للبشر قد أبطلته خطيئة آدم التي تعد تعديا على التى قانون الله الأخلاقي

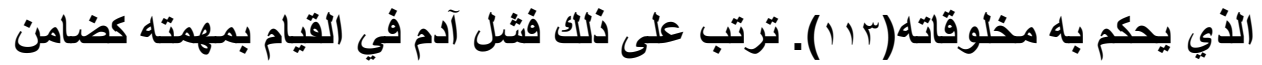

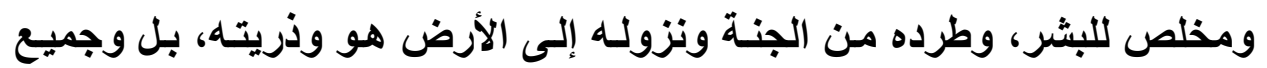

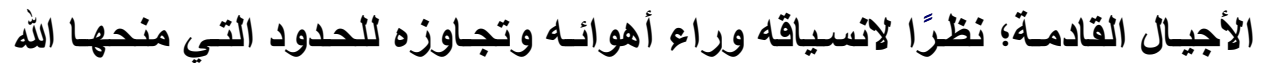

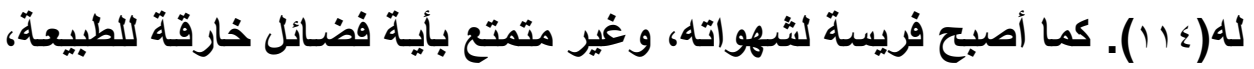

${ }^{109}$ Reid, J. (2006) "The Metaphysics of Jonathan Edwards and David Hume", Hume Studies, Vol.32, No.1.p.61

${ }^{110}$ Smith, J. E. (1976) "Jonathan Edwards as Philosophical Theologian",p.314

${ }^{111}$ Veto. M. (2009) )"Edwards and Philosophy", in " Understandings Jonathan Edwards: An Introduction to America's Theologian",p.155

${ }^{112}$ McClymond, M .J. (1998) "Encounters With God :An Approach to the Theology of Jonathan Edwards "p.31

${ }^{113}$ Hamilton, S. M. (2014)"Jonathan Edwards, Anselmic Satisfaction and God's Moral Government", p.60

${ }^{114}$ Edwards, J. "Jesus Christ the Same Yesterday, Today, and Forever",(http://www.prayermeetings.org/files/Jesus Christ The Same Ye sterday Today And Forever.pdf ).p.6 (-V-Y.r تم الاخول على الموقع بتاريخ $r \cdot$ IV) 
مجلة كلية الآداب، جامعة سوهاج، العدد التاسع والأربعون، الجزء الأول، أكتوبر 1 ـ ب م

وعـاد إلى طبيعته البشـرية المحضـة(10)). الأمسر الذي أدى بـدوره إلى فسـاد الطبيعة البشرية (1) - (1)).

وتمثل فساد الطبيعة البشرية في غرق معظم البشر في الأنوب، لارجة

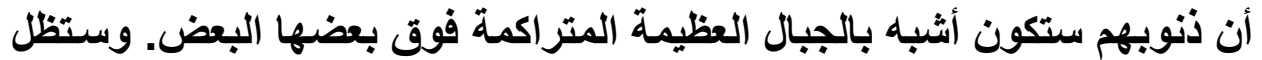

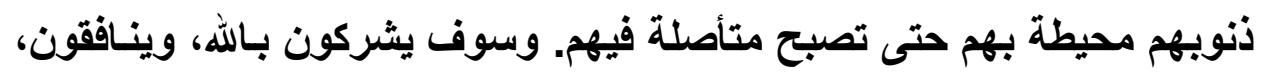

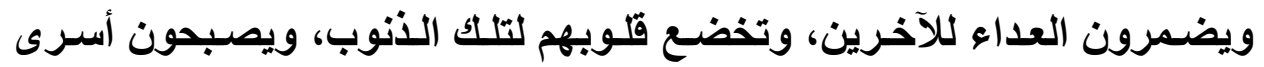

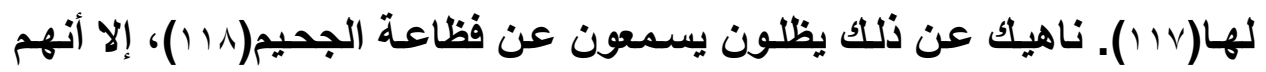

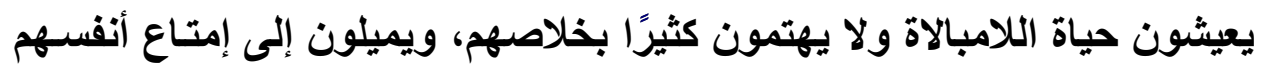
متعة زائلة ومؤقتة. ويغامرون بأنفسهم ويفضلون السعادة التي يحصلون ونئ عليها

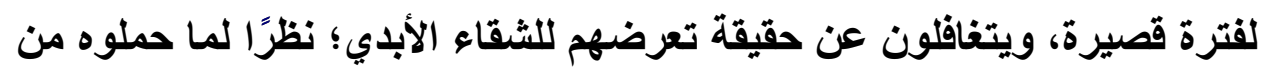

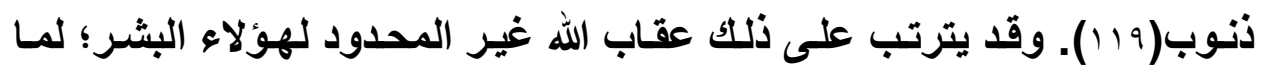

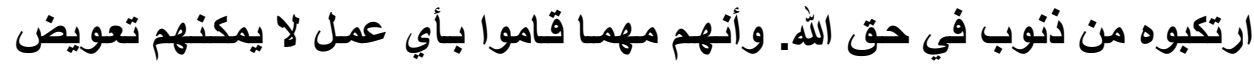

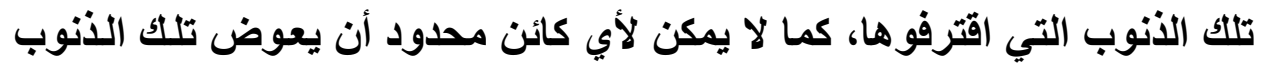

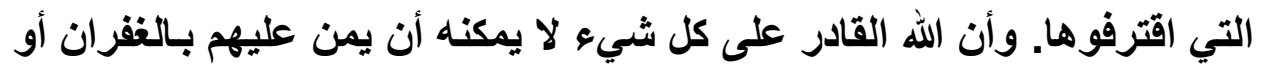

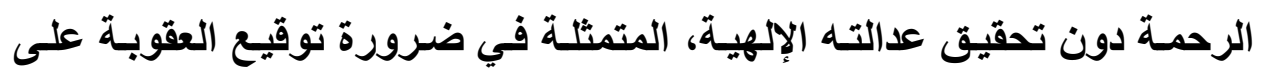

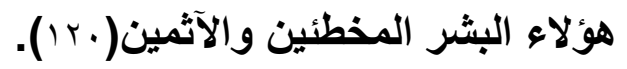

${ }^{115}$ Helm, P. (2004) "The Great Christian Doctrine (Original Sin)", in A God Entranced Vision of All Things: The Legacy of Jonathan Edwards, (Ed), John P. and Justin T, Crossway Books. P.189

${ }^{116}$ Edwards, R , B.( 1998) Edwards, Jonathan. The Works of Jonathan Edwards: Sermons and Discourses, 1723-1729, The Review of metaphysics, vol.52, no. 1, philosophy Education society inc,p141

${ }^{117}$ Edwards, J. "The Justice of God in The Damnation of Sinners"

${ }^{118}$ Edwards, J. "Eternal Torment for the Wicked: Unavoidable and Intolerable", Chapel Library, (http://www.chapellibrary.org/files/2713/7643/3243/hellfg.pdf ).p.9 (تم

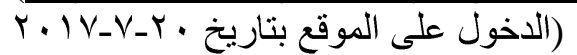

${ }^{119}$ Edwards, J. "Exhortation to Escape Hell", Chapel Library, (http://www.chapellibrary.org/files/2713/7643/3243/hellfg.pdf ).p.22( تم

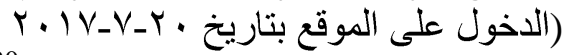

${ }^{120}$ Edwards, R .B.( 1998) Edwards, Jonathan. The Works of Jonathan Edwards: Sermons and Discourses,p.141 


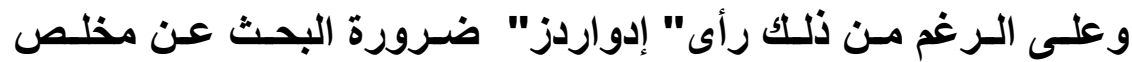

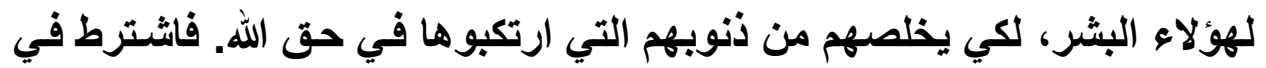

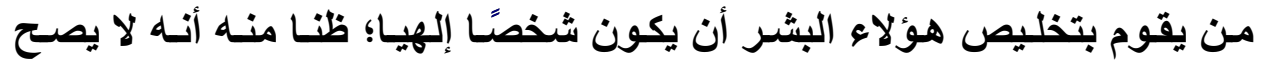

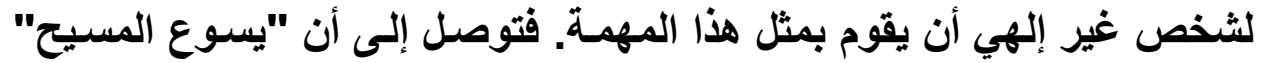

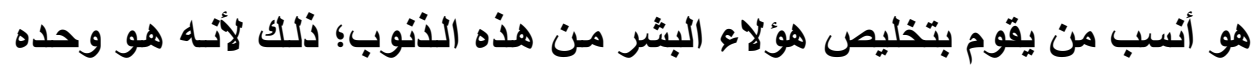

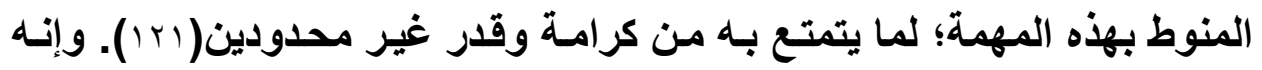
جاء ليخلص المذنبين من العقاب الأي قد يحل بهم جزاء أعمالهم التي اقترفوها،

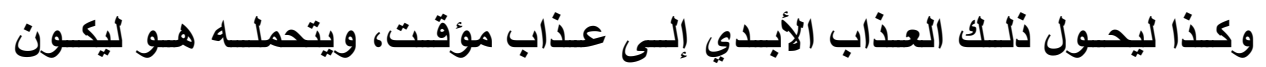

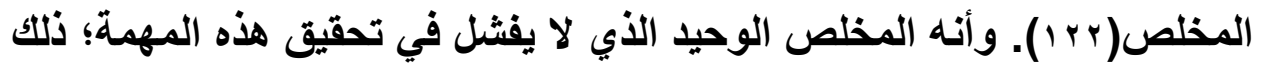

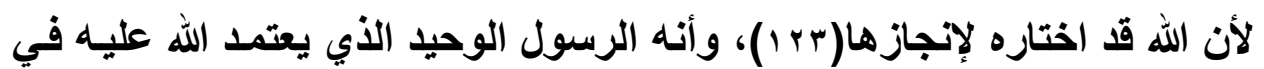

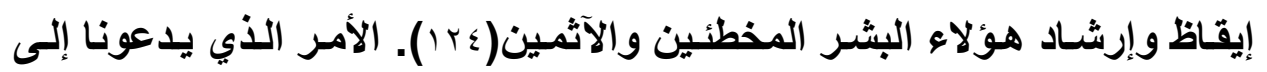

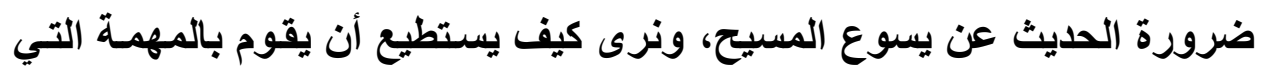
أسندت إليه من قبل الله.

${ }^{121}$ Edwards, J. "Gods Wisdom in Christ's Substitution", From " The Wisdom Of God Displayed in The Way Of Salvation", in "The Works Of Jonathan Edwards", Vol.2, (www.chapellibrary.org/files/7513/7643/3386/subsfg.pdf ). P.23 (تم الدخول r. IV_V_Y. • على الموقع بتاريخ)

${ }^{122}$ Edwards, J. "Exhortation to Escape Hell",p.23

${ }^{123}$ Edwards J. "Jesus Christ the Same Yesterday, Today, and Forever",p6 ${ }^{124}$ Edwards, J. "The Warning of Scripture are in the Best Manner Adapted to the Awakening and Conversion of

Sinners"(http://www.prayermeetings.org/files/The Warnings of Scripture.

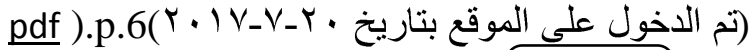




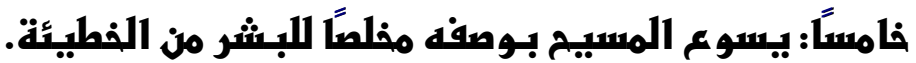

يرى " إدواردز" أن يسوع المسيح يقدر على تحقيق الخـلاص؛ نظرًا

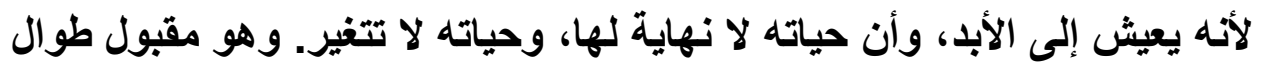

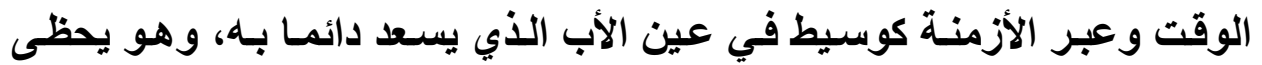

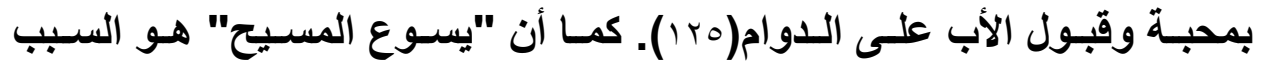

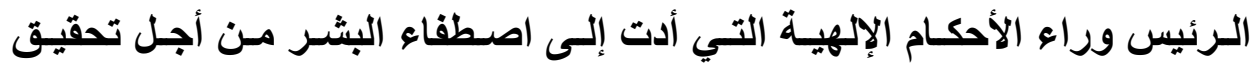

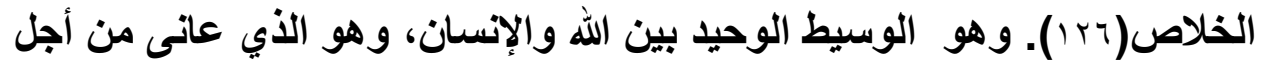

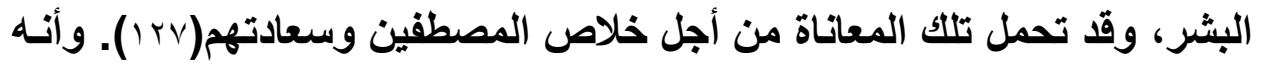

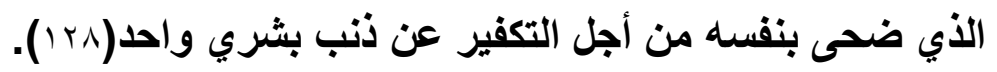

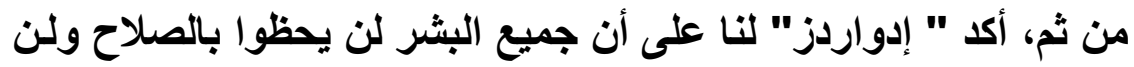

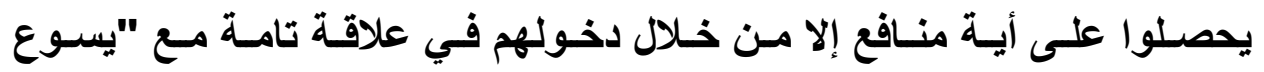

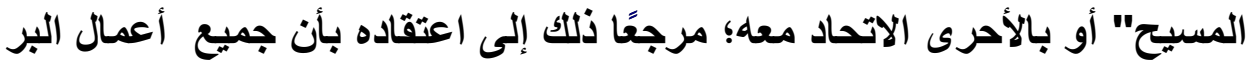

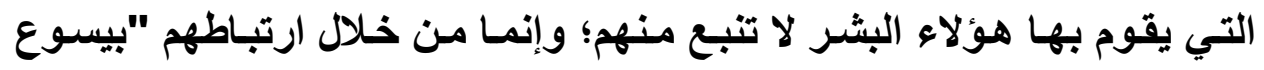

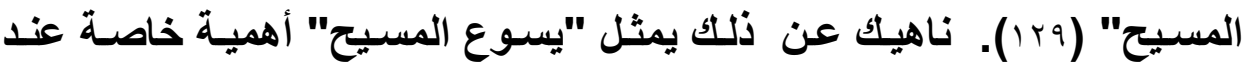

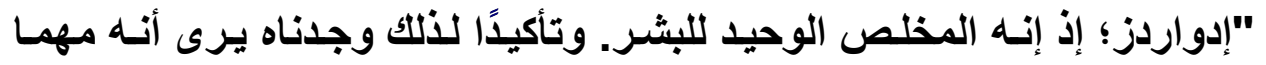

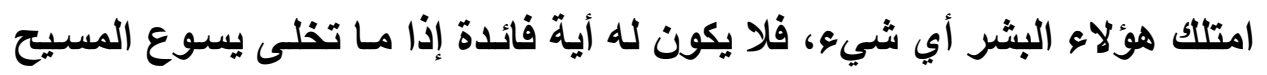

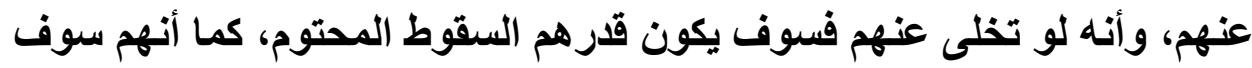

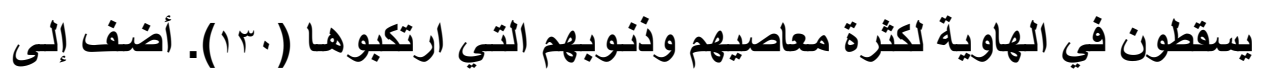

${ }^{125}$ Edwards. J. "Jesus Christ the Same Yesterday, Today, and Forever",p.4 ${ }^{126}$ Hamilton, S, M. (2016) "Jonathan Edwards on the Election of Christ", DE GRUYTER. P.526

${ }^{127}$ Edwards J. "Jesus Christ the Same Yesterday, Today, and Forever",p.5

${ }^{128}$ Cooley, D. W. (2014)" The New England Theology and The Atonement: Jonathan Edwards to Edwards Amasa park", Deerfield Illinois.pp.70-71

${ }^{129}$ Edwards, J. "Justified In Christ", Chapel Library, (http://www.chapellibrary.org/files/7313/7643/3397/uwchfg.pdf )pp.15-16(تم

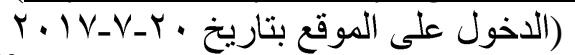

${ }^{130}$ Edwards, J. (1741) "Sinners in the Hands of an Angry God", Enfield Connecticut (https://www.blueletterbible.org/comm/edwards_jonathan/sermons/sinners.cf

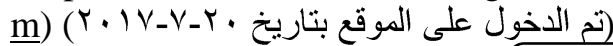


ذللك، فإن" يسوع المسيح يقوم بـالتكفير عن خطايـا البشر؛ لكونـه ممثثلا عنهم.

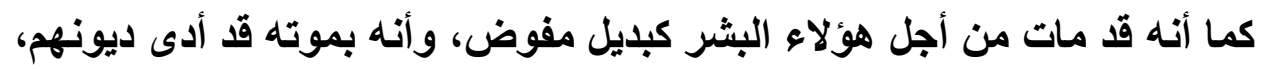

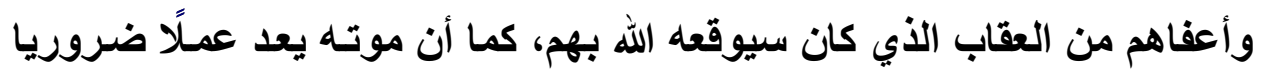

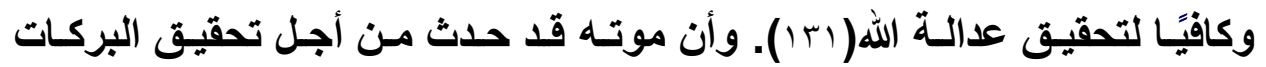
الإكهية. وكان برضا الله، وتخفيفًا لغضب الله من البشر (r آ ).

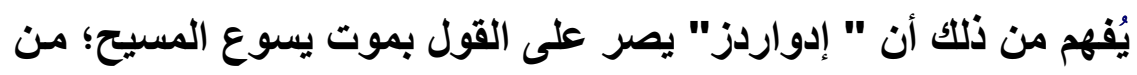

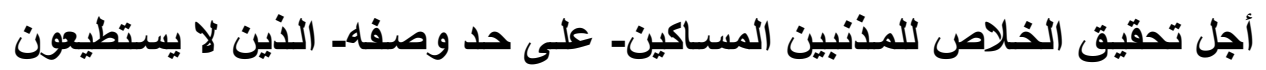

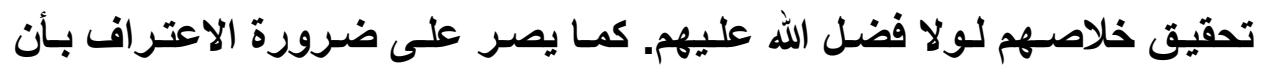

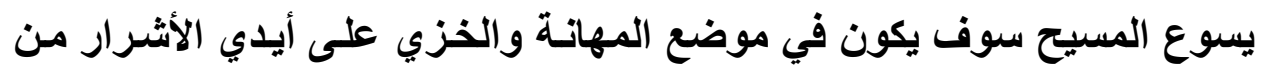

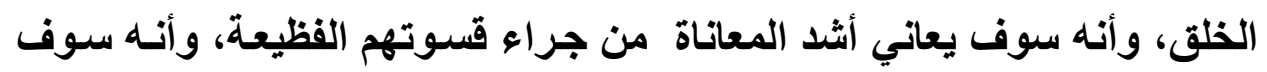
يخضع للمعاناة في ظل غضب الله، وأنه سـوف يكون حبيسًا في القبر من أجل أله تحقيق الخلاص للمذنبين من البشر.

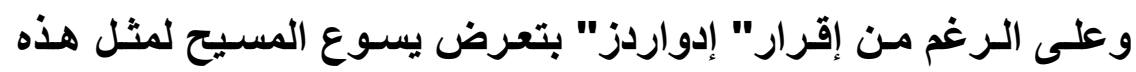

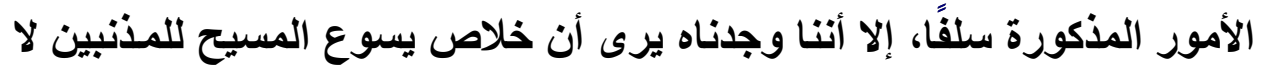

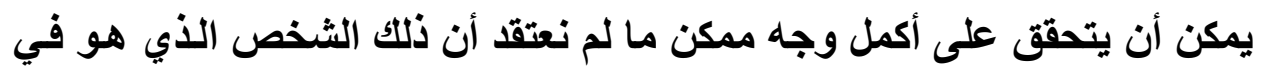

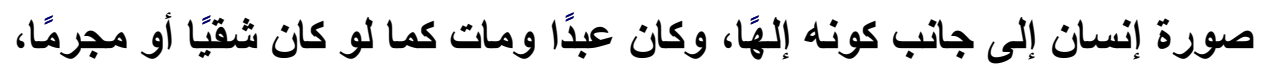

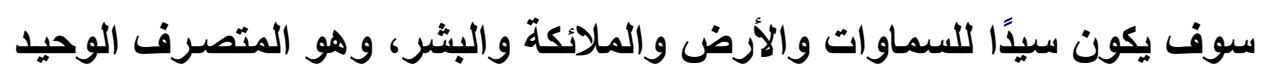
في الحياة الأبدية والموت،وهو الحيداكم المطلق لجميع الموجودات.

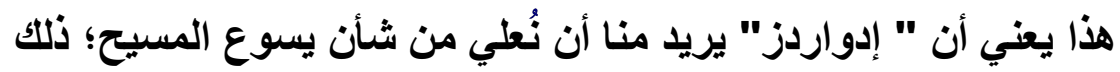

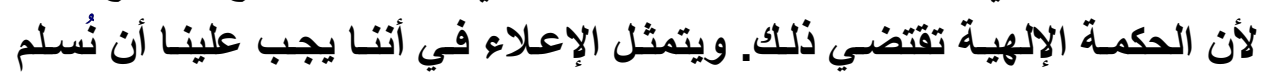

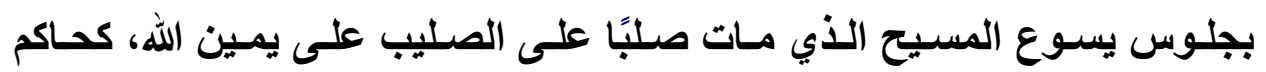
للعالم، ويكون له حق التصرف في جميع الأمور المرتبطة بخلاص البشر (Trاب).

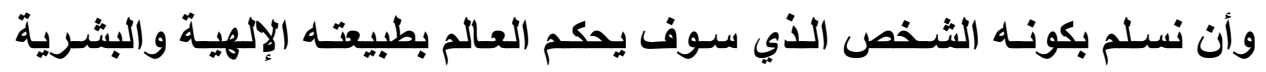

${ }^{131}$ Hamilton, S, M. (2016) "Jonathan Edwards on the Election of Christ",p.538

${ }^{132}$ Cooley, D. W. (2014)" The New England Theology and The Atonement: Jonathan Edwards to Edwards Amasa park",pp.73-74

${ }^{133}$ Edwards, J. "Gods Wisdom in Christ's Substitution", pp.25-26 
مجلة كلية الآداب، جامعة سوهاج، العدد التاسع والأربعون، الجزء الأول، أكتوبر 1 ـ ب م

بنفس الجسد البشري الذي صُلب، ونهض مرة أخرى، وصسد إلى السـماوات

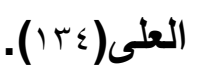

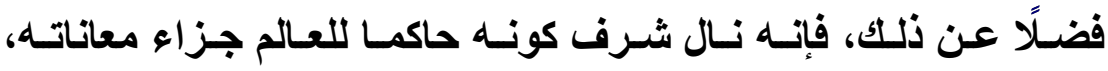

والمهانة التي تعرض لها. والجدير بالذكر أن" إدواردز" قد أصر على فئس ضرورة

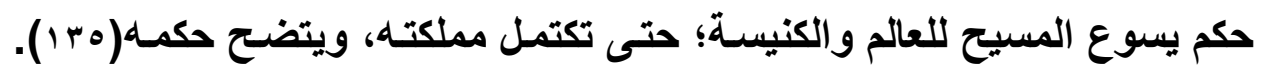

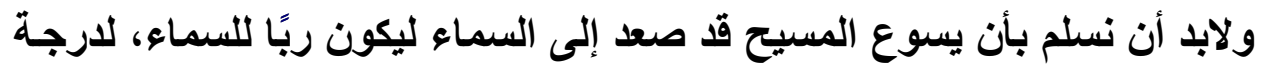

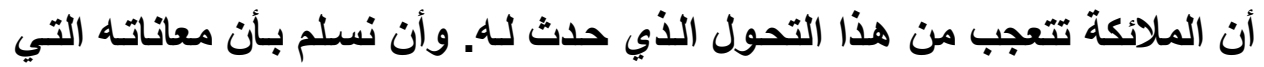

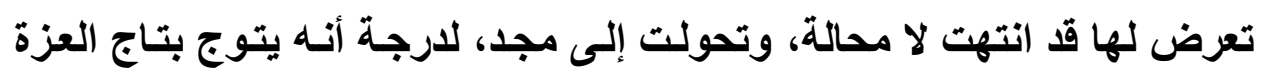
والمجد، ولهذا السبب وصف " إدواردز" يسوع المسيح بوصف" الرائع" The

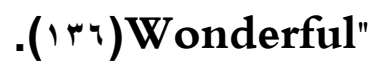

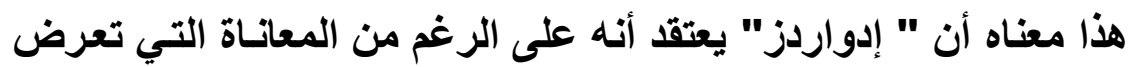

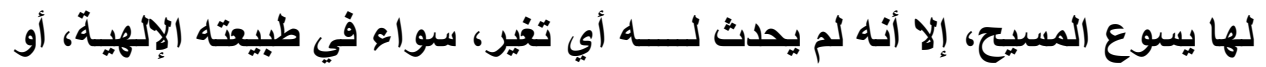

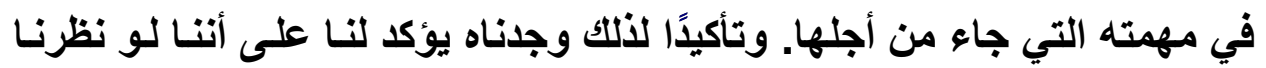

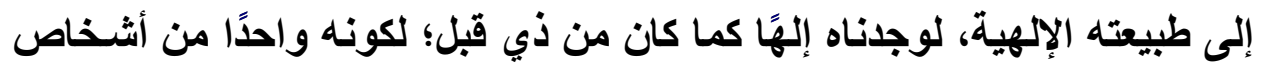

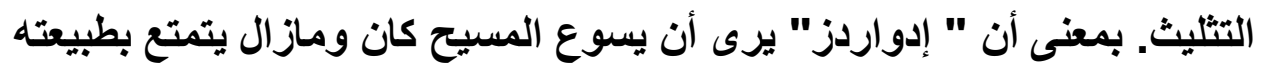

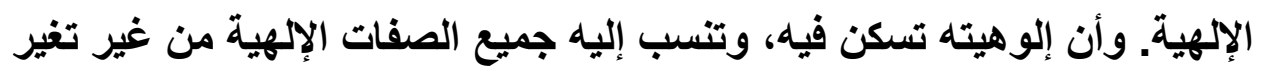

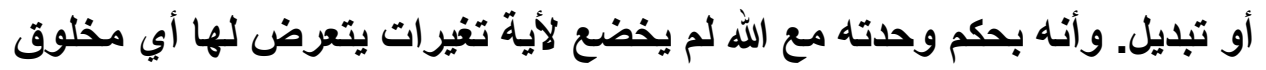
آخر، وأنه لكونه ذا طبيعة إلهية لم يرتكب الذنب والته والذل قط مثلما فعل " آدم". كما

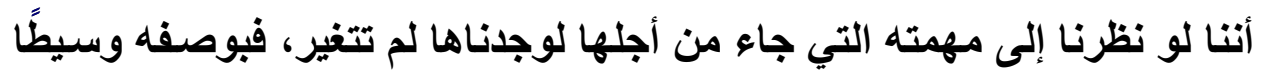

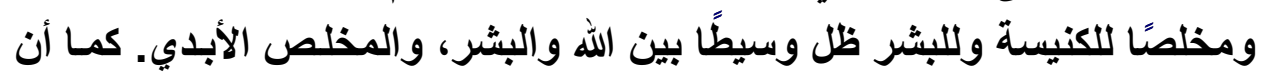

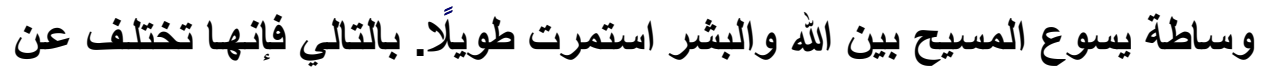

${ }^{134}$ Edwards, J. "Jesus Christ the Judge", From" The Final Judgment" , in "The Works Of Jonathan Edwards", Vol.2

(https://www.chapellibrary.org/files/7613/7643/3187/dojufg.pdf).pp7-8

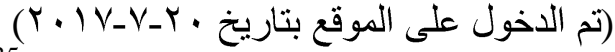

${ }^{135}$ Ibid, loc, cit

${ }^{136}$ Edwards, J. (1738) "Who is this King of Glory?"

(https://www.scribd.com/document/56163459/Who-is-This-King-of-

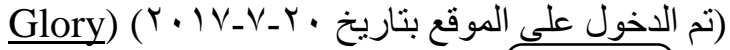


وسـاطة الأنبيـاء؛ إذ إنهـا اسـتمرت طويلا، في حين أن وسـاطة الأنبيـاء كانـت قصيرة؛ ذللك لأن الأنبياء ما لبثوا أن رحلوا، وجاء غير هم ليحل محلهم( (r I ).

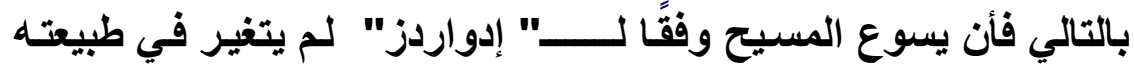
الإلهية أو في قيامسه بواجباته نحو البشر مثل غيره من البشر الآخرين الذين

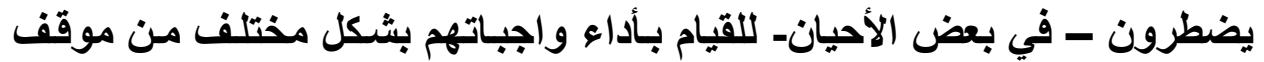
لآخر. ولكنه كان هو وسيظل دومًا هكذا. وهو مفوض من قبل الله ليقوم بواجبه هونه

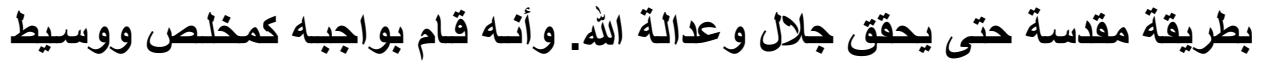

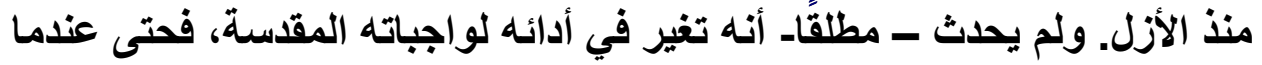

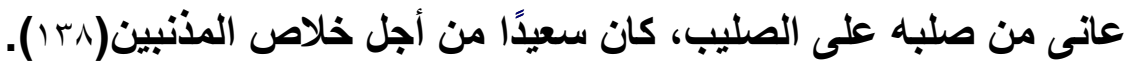

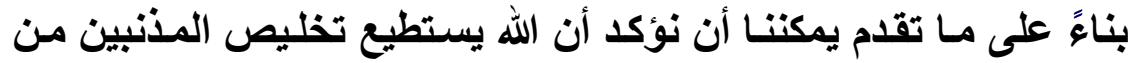

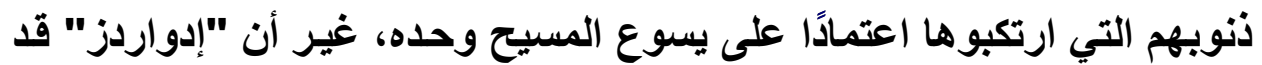

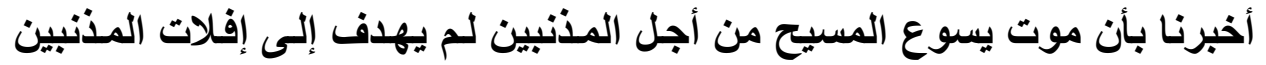
مسن عقـاب الله؛ وإنمـا يهـدف إلسى تخفيف التجـاوزات والمخالفـات التـي تنتهـك

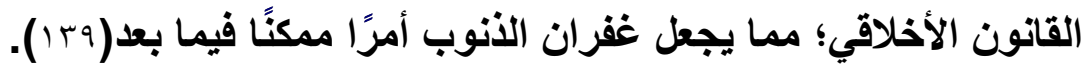

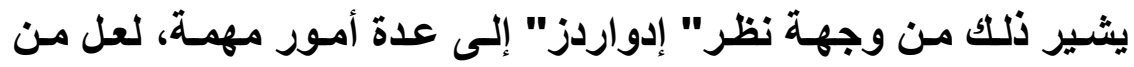

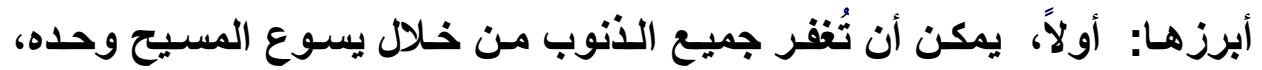

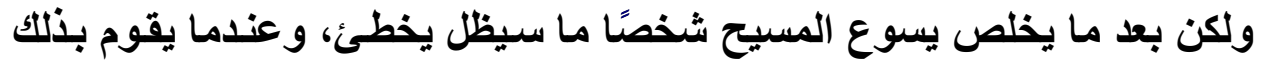

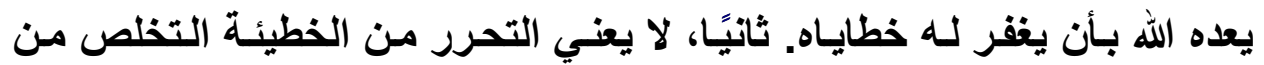

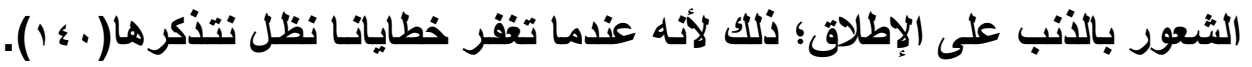

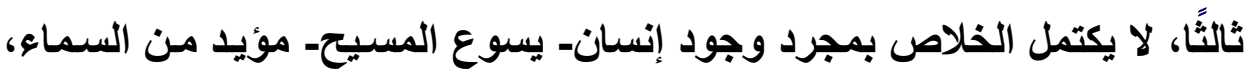

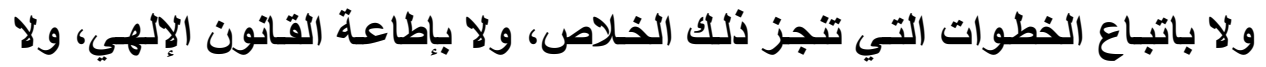

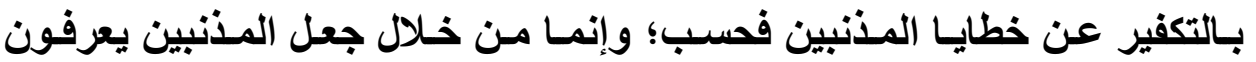

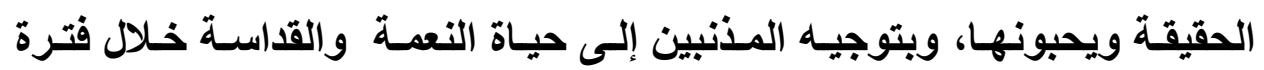

${ }^{137}$ Edwards J. "Jesus Christ the Same Yesterday, Today, and Forever",pp.2-3

${ }^{138}$ Ibid.p5

${ }^{139}$ Hamilton, S. M, (2014)"Jonathan Edwards, Anselmic Satisfaction and God's Moral Government",p.61

${ }^{140}$ Edwards, J, "The Justice of God in The Damnation of Sinners" 
حياتهم(1؛1). رابعًا وأخيرًا، لا يتضمن الخلاص عند " إدواردز" جميع البشر؛

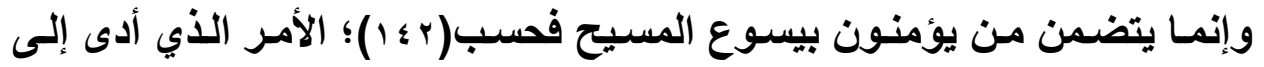

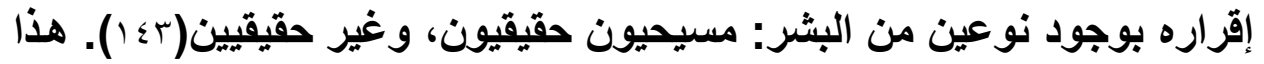
يعني أن " إدواردز" يرى أن البشر ينقسمون إلى نوعين: الصـالحون، والعصدية

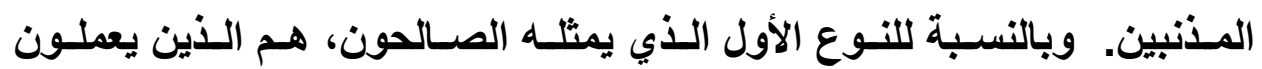

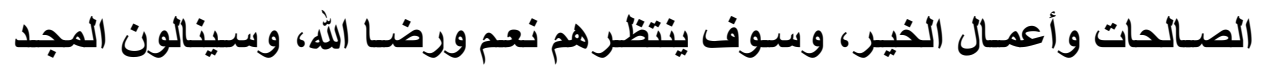

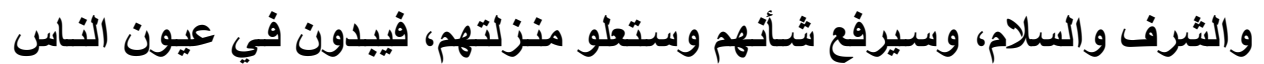

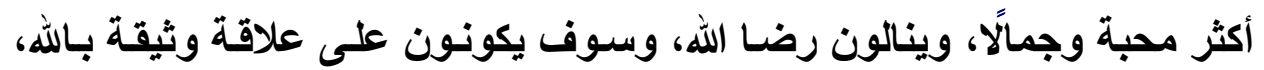

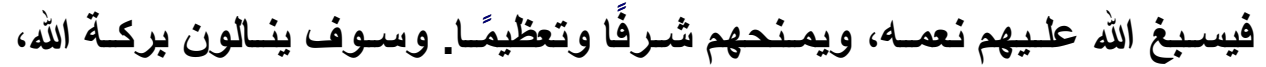

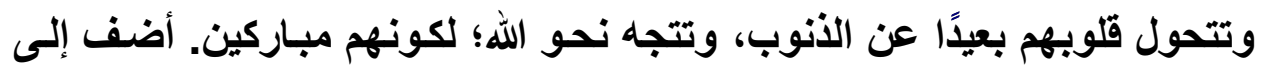

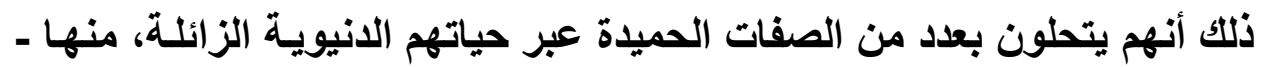

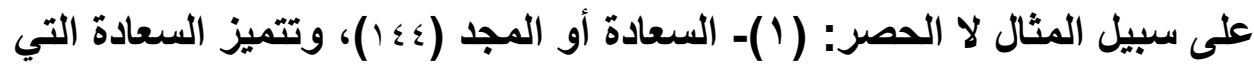

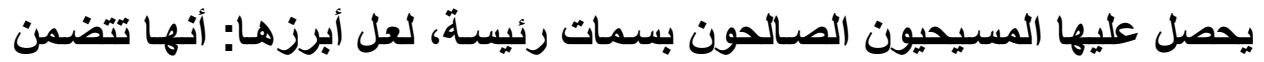

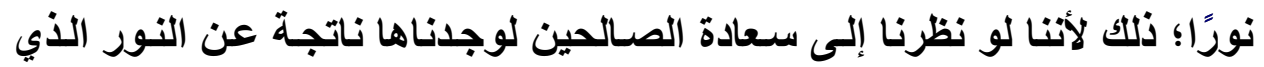

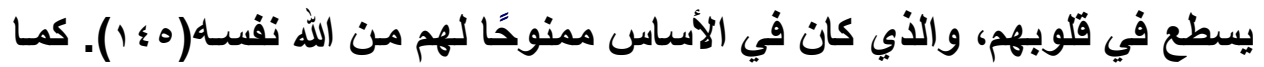
تتضمن الشعور بالراحة التامة. وتتضمن الشعور بالحياة على أكمل وجه ممكن.

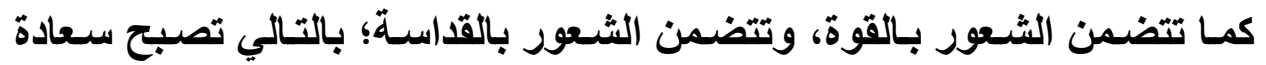

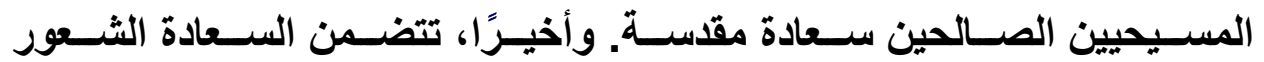

${ }^{141}$ Edwards, J, "Jesus Christ the Judge", From" The Final Judgment",pp.7-8

${ }^{142}$ McDermott, Gerald R. (2000) " Jonathan Edwards Confronts the Gods

: Christian Theology, Enlightenment Religion, and Non - Christian Faiths", p. 172

${ }^{143}$ Chamberlain, A. (1996)"Brides of Christ and Signs of Grace:

Edwards's Sermon Series on the Parable of the Wise and Foolish

Virgins" Part .1, In :" Jonathan Edwards's Writings: Text , Context, Interpretation", (ed)Stein. S. J, Indiana University Press. p. 8

${ }^{144}$ Edwards, J. (1740) "The Portion of the Righteous",

(http://www.pravermeetings.org/files/The Portion of the Righteous.pdf ). Pp.3-4(Y + IV_V_Y. • تم الدخول على الموقع بتاريخ

${ }^{145}$ Ibid,p.7 


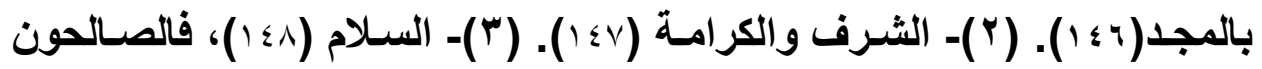

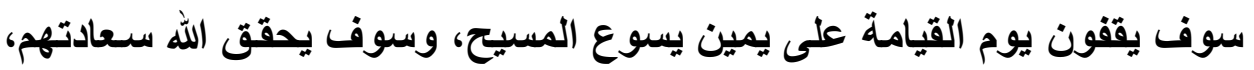

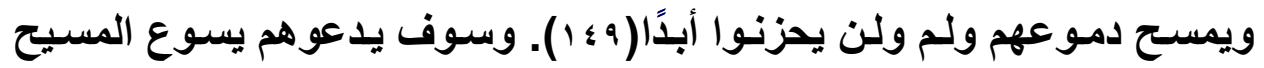

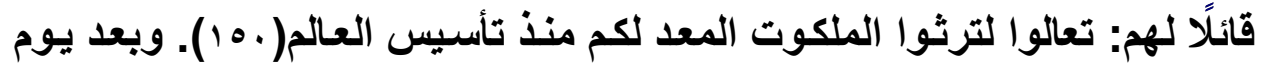

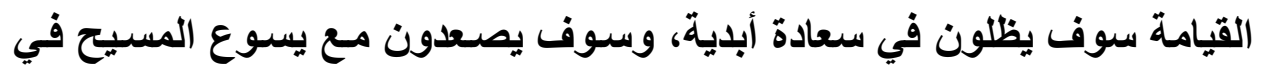

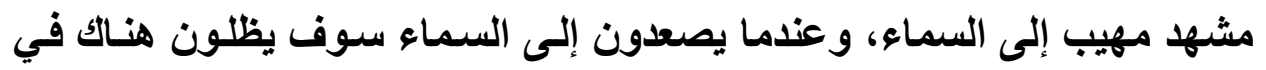

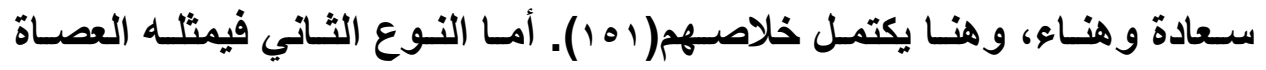

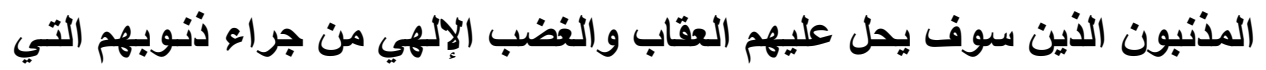

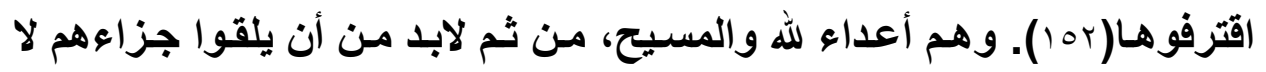

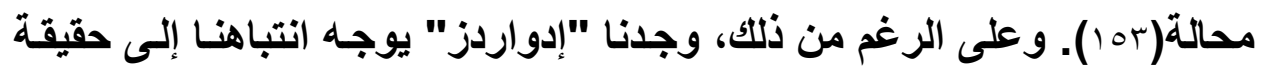

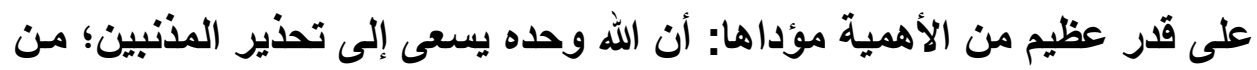

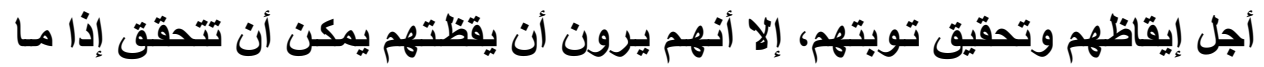
قام أحد من الأموات وجاء ليحذرهم، لارجة أنهم يقولون لأنفسـهر: لو أنتا رأينا

${ }^{146}$ Edwards, J. (1740) "The Portion of the Righteous", pp. 8-9

${ }^{147}$ Ibid, pp. $4-5$

${ }^{148}$ Ibid, pp. 5-6

${ }^{149}$ Edwards, J. (1773) "The End of the Wicked Contemplated by the Righteous, or the Torments of the Wicked in Hell, No Occasion of Grief to the Saints in Heaven",

(http://www.pravermeetings.org/files/The End of the Wicked Contemplat

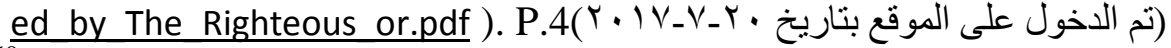

${ }^{150}$ Edwards, J. "The books Opened, the Sentence Pronounced and Executed", From" The Final Judgment", in "The Works of Jonathan Edwards", Vol.2

(https://www.chapellibrary.org/files/7613/7643/3187/dojufg.pdf). Pp. 16-17 (Y • IV_V_Y. • تم الدخول على الموقع بتاريخ (1740)

${ }^{151}$ Edwards, J. (1740) "The Portion of the Righteous", pp. 17-19

${ }^{152}$ Ibid, p.3

${ }^{153}$ Edwards, J. (1773) "The End of the Wicked Contemplated by the Righteous, or the Torments of the Wicked in Hell, No Occasion of Grief to the Saints in Heaven",p.3 
مجلة كلية الآداب، جامعة سوهاج، العدد التاسع والأربعون، الجزء الأول، أكتوبر 1 ـ ب م

الجحيم، أو سمعنا صراخ العصاة، أو رأينا شخصنًا ذاق ويـلات الجحيم، فِإن هذا

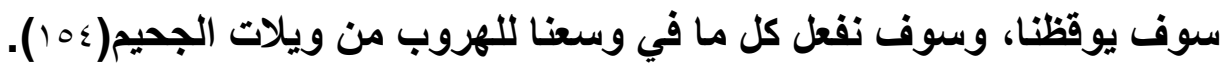
غير أنتانجد أن " إدواردز" يصر على على أن الله وحدهـ وليس الأمـواتـ

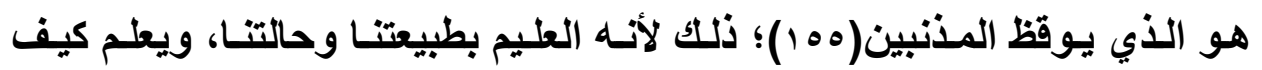

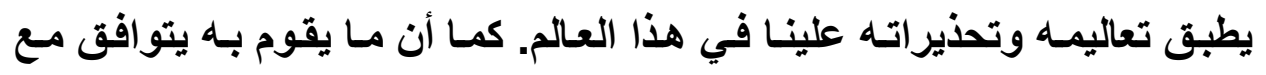

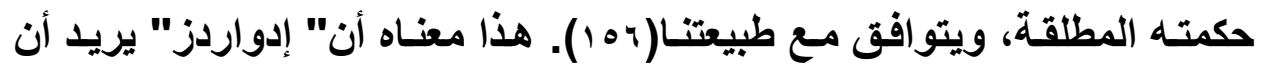

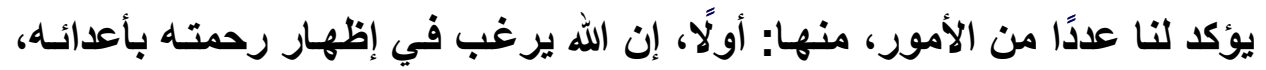

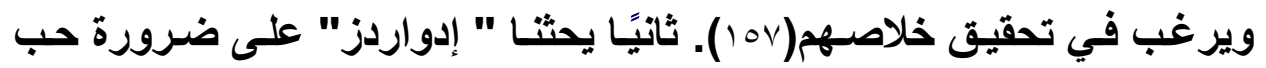

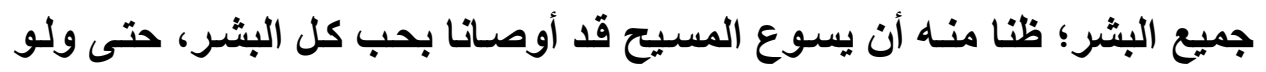

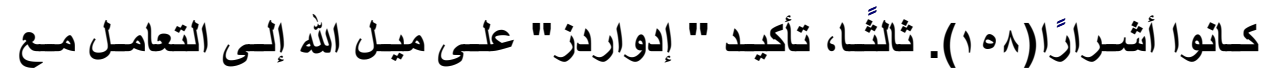

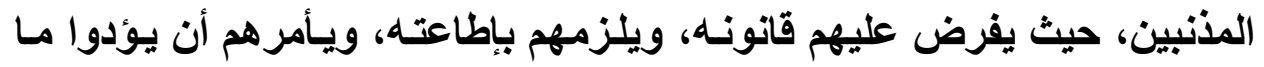

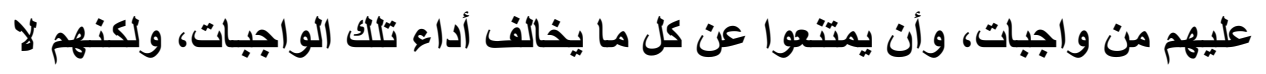

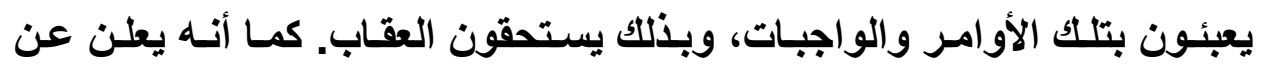

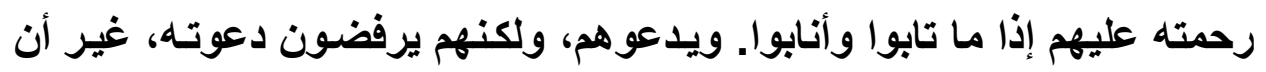

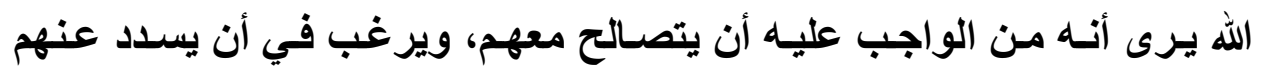

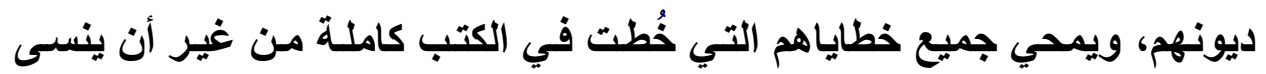

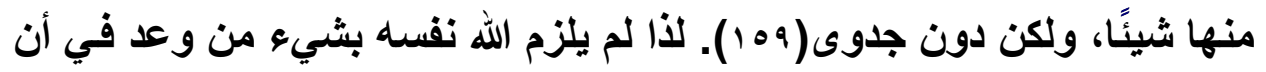

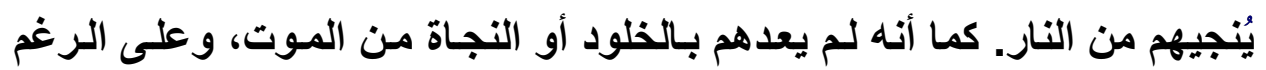

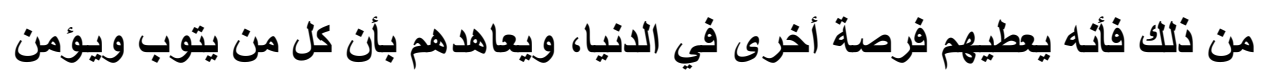

${ }^{154}$ Edwards, J. "The Warning of Scripture are in the Best Manner Adapted to the Awakening and Conversion of Sinners" pp. 2-3

${ }^{155}$ Ibid, p p . 3-4

${ }^{156}$ Ibid,p.5

${ }^{157}$ Edwards, J. (1735) "The Sole Consideration, that God is God Sufficient to Still All Objections to his Sovereignty", Sermon II.

${ }^{158}$ Edwards, J. (1773) "The End of the Wicked Contemplated by the Righteous, or the Torments of the Wicked in Hell, No Occasion of Grief to the Saints in Heaven ",pp. 8-9

${ }^{159}$ Edwards, J. "Eternal Torment for the Wicked: Unavoidable and Intolerable", p. 8 


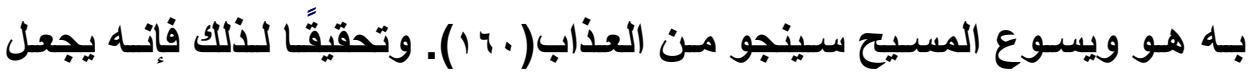
القديسين يتولون مهمة خلاصهم، ويطالبهم بأن يبذلوا كل ما في وسعهم لتحقيق

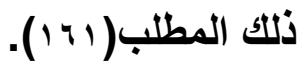

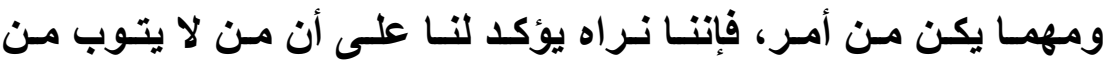

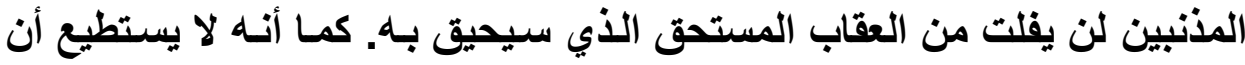

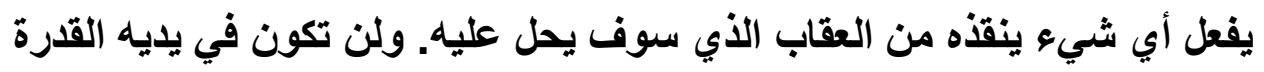

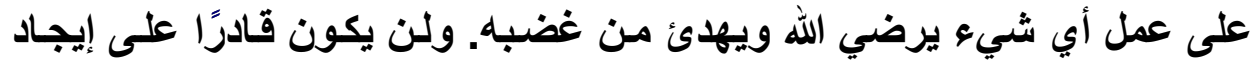

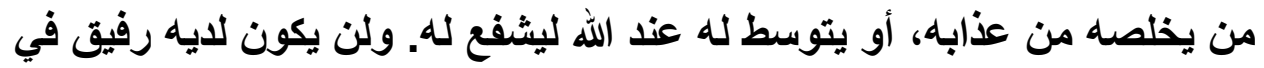

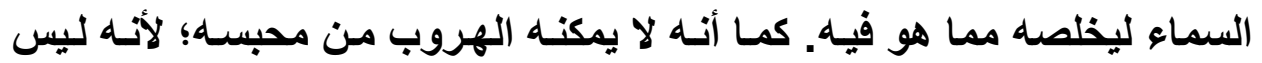

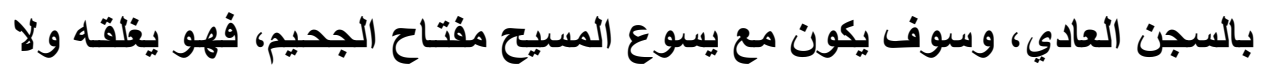

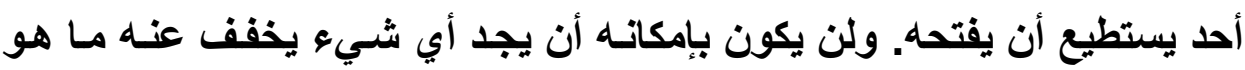

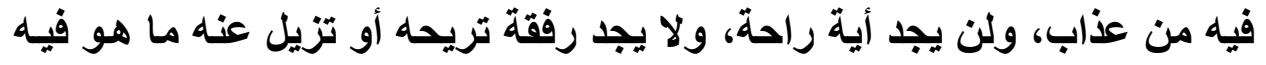

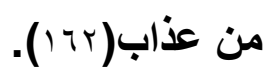

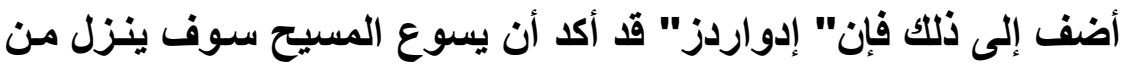

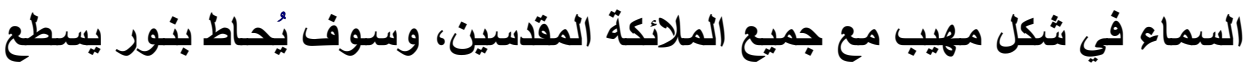

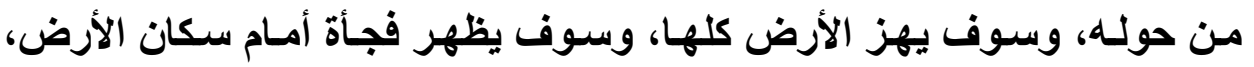

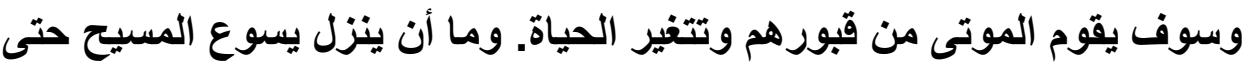

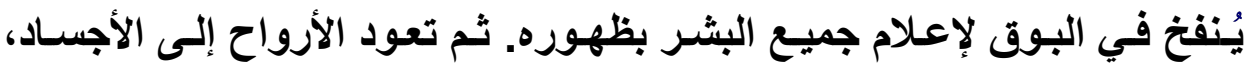

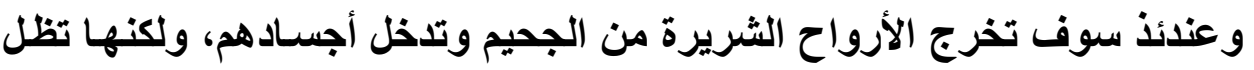

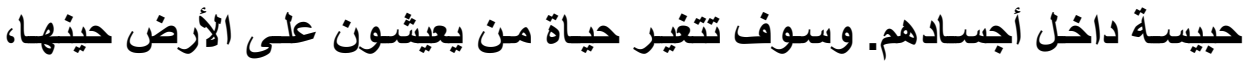

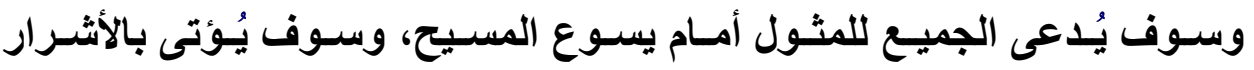

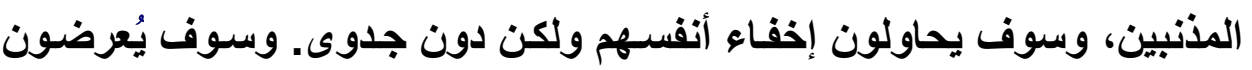

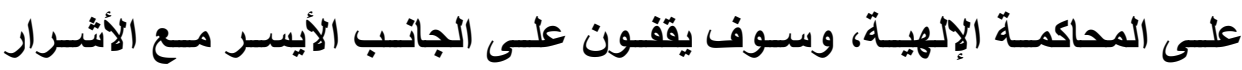

${ }^{160}$ Edwards, J. (1741) "Sinners in the Hands of an Angry God".

${ }^{161}$ Edwards, J. (1773) "The End of the Wicked Contemplated by the Righteous, or the Torments of the Wicked in Hell, No Occasion of Grief to the Saints in Heaven" ,pp. 13-14

${ }^{162}$ Edwards, J. "Eternal Torment for the Wicked: Unavoidable and Intolerable", pp. 9-10 
مجلة كلية الآداب، جامعة سوهاج، العدد التاسع والأربعون، الجزء الأول، أكتوبر 1 ـ ب م

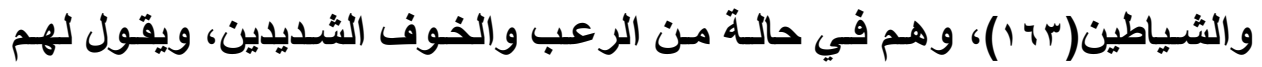

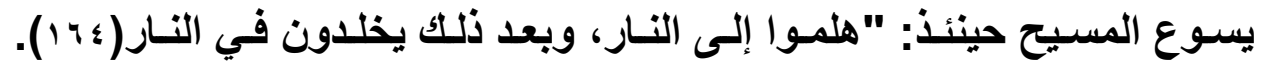

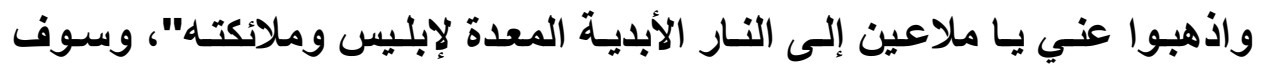

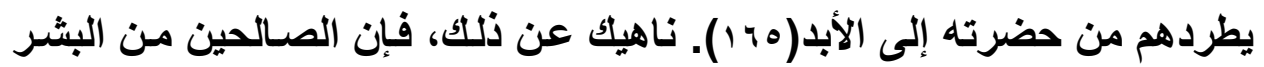

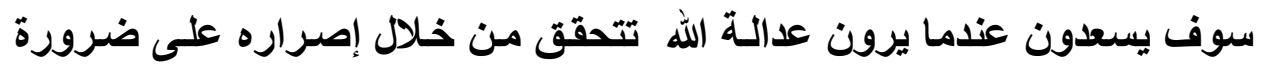

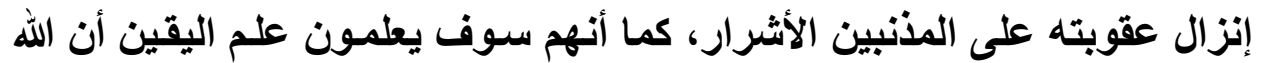

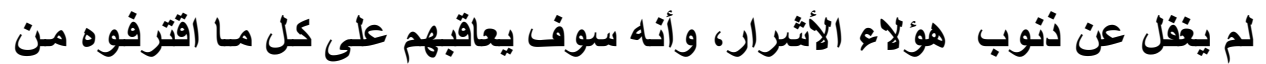

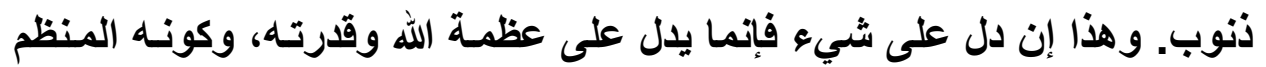
الرئيس للكون ولكل ما فيه(

سادساًا: "جونـانان إدواردز": رؤية نقدية.

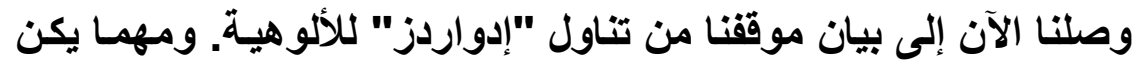

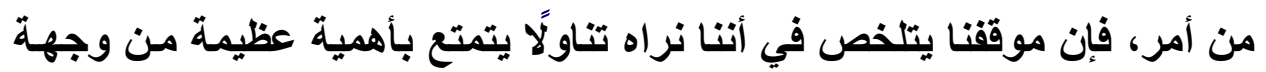

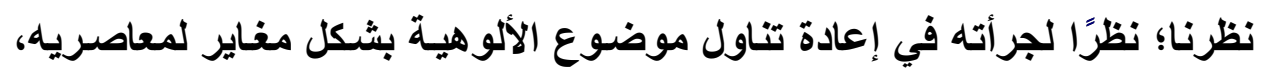

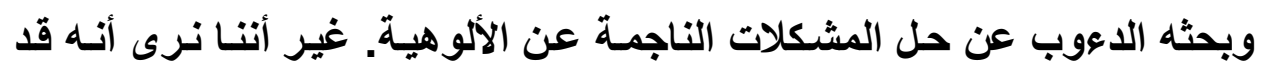
أخفق في بعض الجوانب شأنه شأن الكثيرين من الفلاسفة واللاهوتيين. وبـالطبع

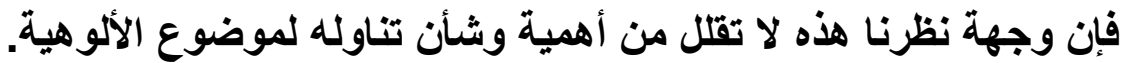

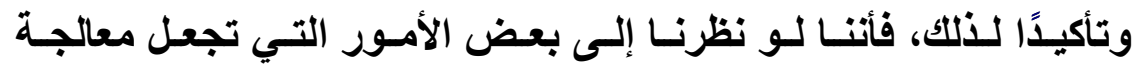

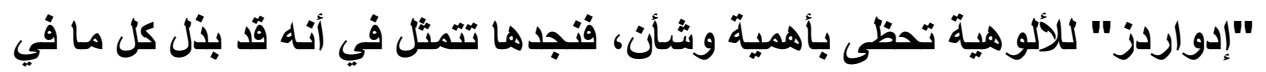

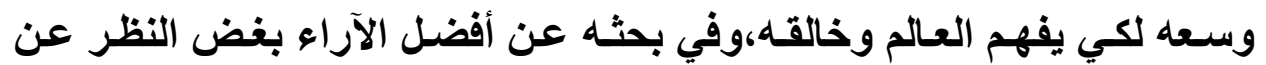

${ }^{163}$ Edwards, J. "The books Opened, the Sentence Pronounced and Executed", From" The Final Judgment", pp. 13-14

${ }^{164}$ Edwards, J. (1773) "The End of the Wicked Contemplated by the Righteous, or the Torments of the Wicked in Hell, No Occasion of Grief to the Saints in Heaven", p. 4

${ }^{165}$ Edwards, J. The books Opened, the Sentence Pronounced and Executed", p-p. 15-17

${ }^{166}$ Edwards, J. (1773) "The End of the Wicked Contemplated by the Righteous, or the Torments of the Wicked in Hell, No Occasion of Grief to the Saints in Heaven", p.6 
قائلها، وإدراكه أن العقل منحة من الله، واهتمامـه بجميع الكتابـات التي تثوافق

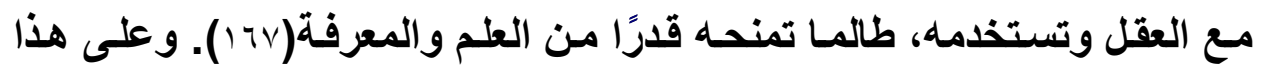

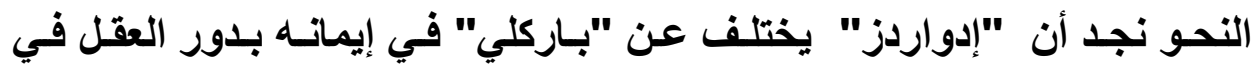
الإلهيات، في حين أن "باركلي" يرى إنـا لو سلمنا بالتفسير والتعقل والتأويل

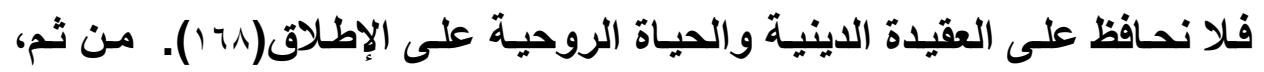

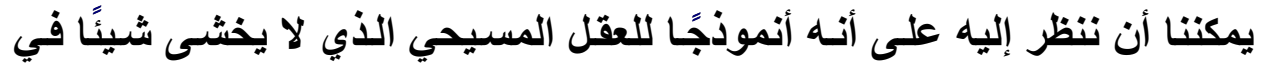
العالم، وفيلسوف عقلاني تنويري( 199 (1). هذا يعني أن "إدواردز" قـ اعتمد على التفكير القلسفي بطريقة منظمـة

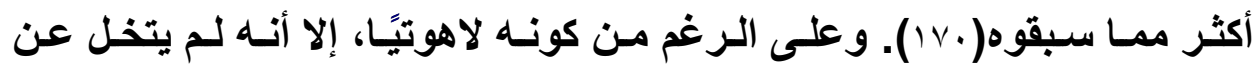
القلسفة حتى ولو جزعًا قليلاً من الوقت(

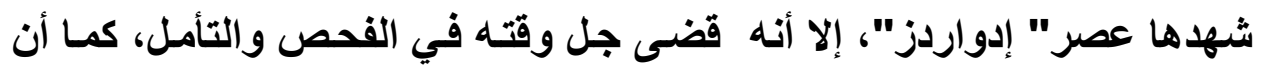

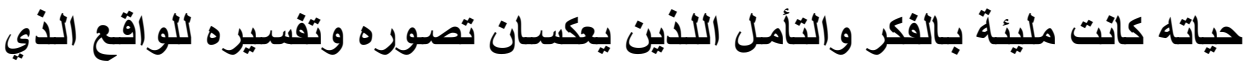

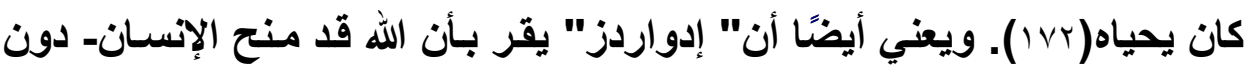

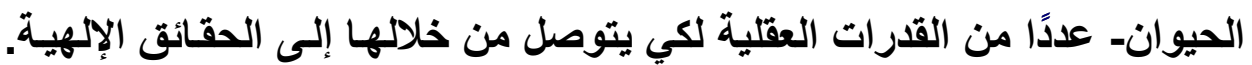

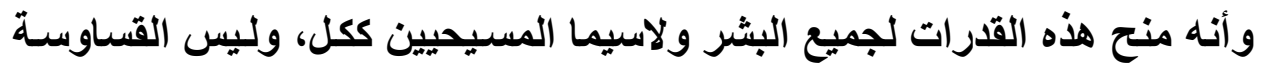

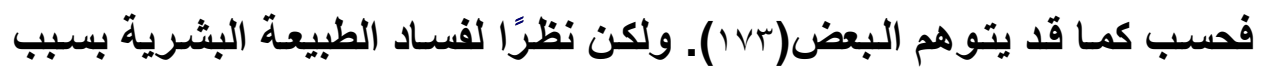

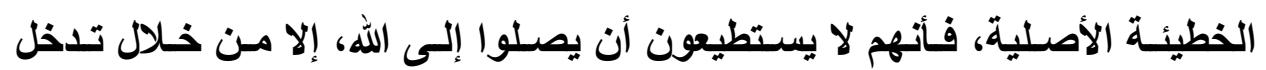
النعمة الإلهية Grace التي تقودهم حتمًا إلى الخلاص، وبالتالي تجعلهم قادئه لادرين على الوصول إلى الله(ء ال).

${ }^{167}$ McDermott, G. R. (2009) "Conclusion: Edwards's Relevance Today", p.204

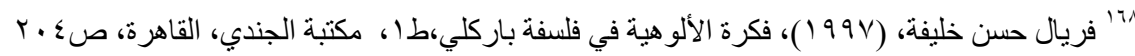

${ }^{169}$ McDermott, G. R. (2009) "Conclusion: Edwards's Relevance Today", p.204

${ }^{170}$ Veto. M. (2009) "Edwards and Philosophy", p.152

${ }^{171}$ Sevickova. M. (2009) "Alternative Viewpoint: Edwards and Philosophy", p.171

${ }^{172}$ Jenson, R. W.(1988)" Americas Theologian: A Recommendation of Jonathan Edwards", p.15

${ }^{173}$ Edwards, J . "Christian Knowledge".

${ }^{174}$ Haykin, M. A.(1995) "Jonathan Edwards and His Legacy", p.81 
مجلة كلية الآداب، جامعة سوهاج، العدد التاسع والأربعون، الجزء الأول، أكتوبر 1 + بام

من ثم تراعى لـــــ" إدواردز" ضرورة اعتبـار الألوهيـة أنهـا العيش لله

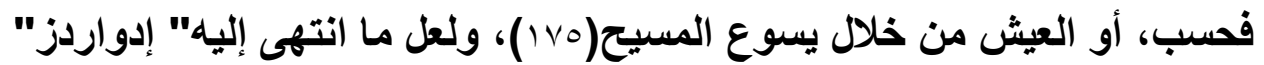

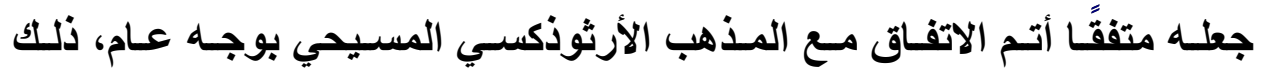

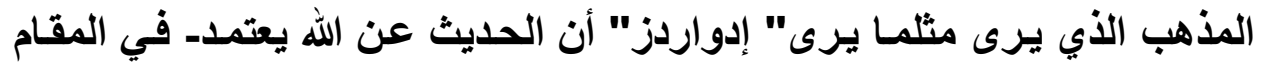

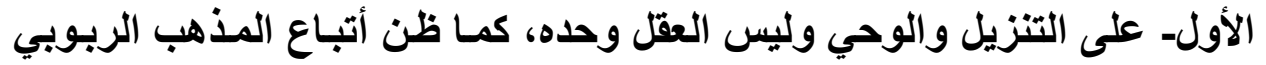

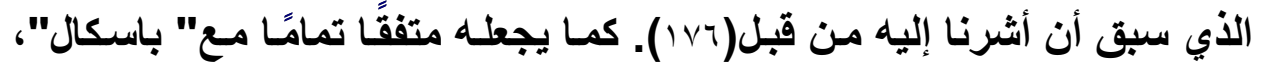

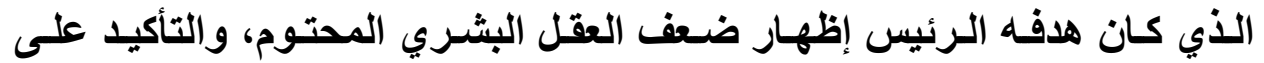

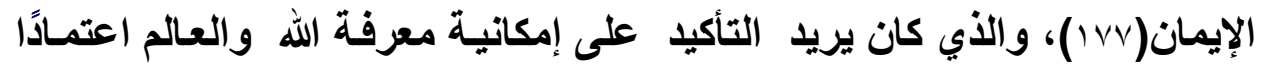

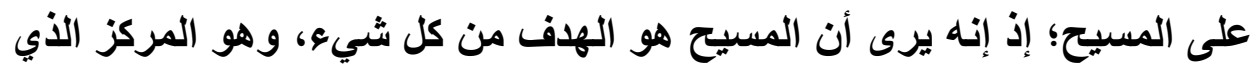

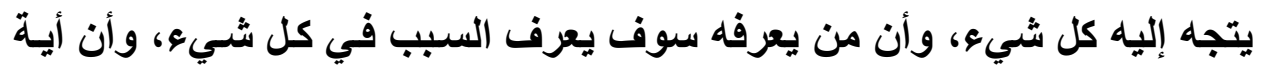
محاولة لإثبات أي شيء باستخدام العقل وحده- مثل إثبات وجود اللهـ تعد محاولة

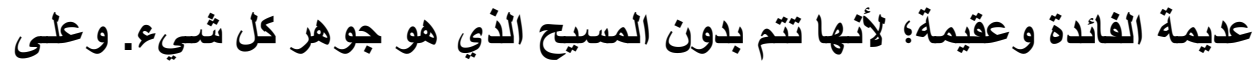

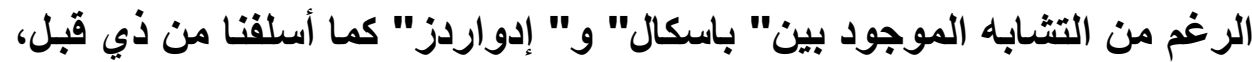
إلا أن إله " باسكال" لم يكن ممـاثلًا تمامًا لإلهـ "إدواردز"؛ ذلتك لأن " باسكال"

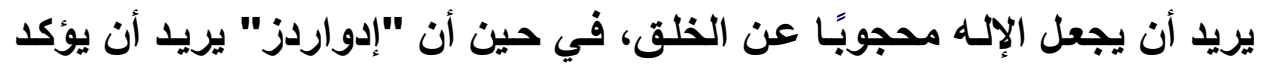
على ظهور الله بشكل مستمر لخلائقه (ivi).

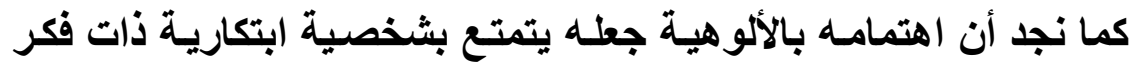

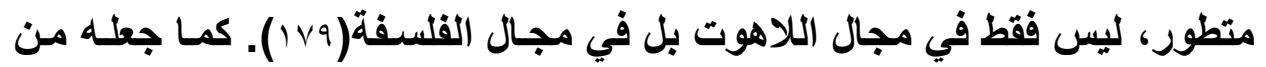

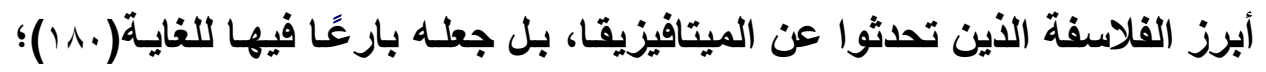

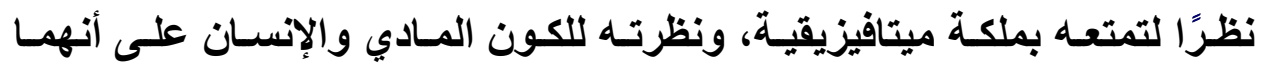

${ }^{175}$ Edwards, J . "Christian Knowledge".

${ }^{176}$ McClymond, M .J. (1998) "Encounters With God :An Approach to the Theology of Jonathan Edwards ", p.58

"ستيو ارت هامبشر ، (1911) ، عصر العقل: فلاسفة القرن السابع عشر، ترجمة ناظم طحان، ط؟، دار الحوار

${ }^{178}$ Zakai, A. (2010) "Jonathan Edwards's Philosophy of Nature: the Reenchantment of the World in the Age of Scientific Reasoning" pp. 261262

${ }^{179}$ Reid, J, W. (2003) "Jonathan Edwards on Space and God",p.385

${ }^{180}$ Fisher, G. P. (1879)"The Philosophy of Jonathan Edwards", p. 284 
مظاهر للأات الإلهية، وكذا تمتعه بآرائه الجادة والمهمة عن المثالية( (1)). ولعل

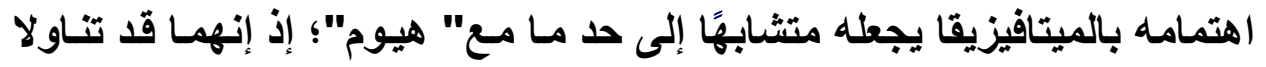

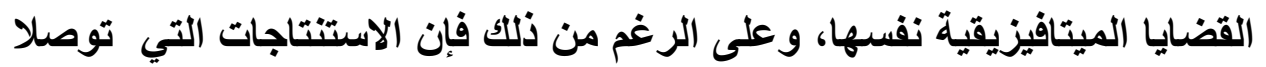

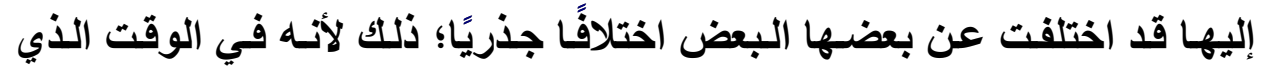

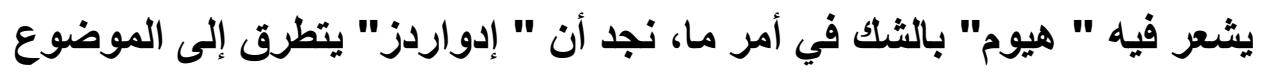

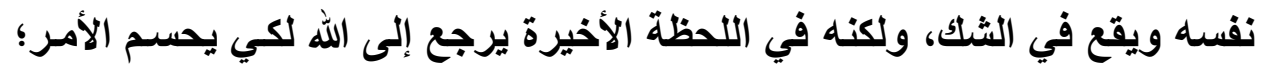
الأمر الأي أدى بدوره إلى جعل فلسفة "إدواردز" تتخذ طابعًا مسيحيًا محضًا.

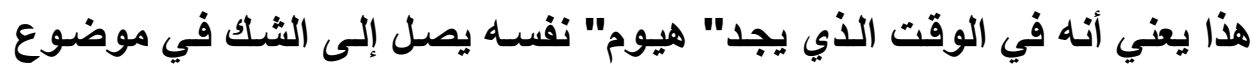

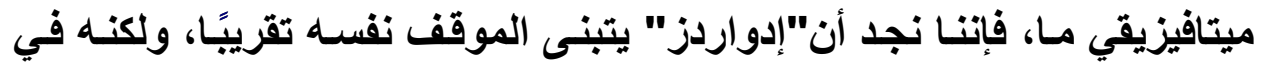

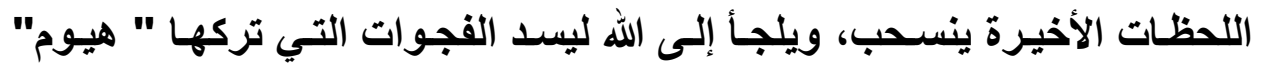

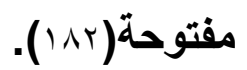

ونجد أن اعتمـاد " إدواردز" على الجمـال في الوصـول إلى الله يجعلنـا

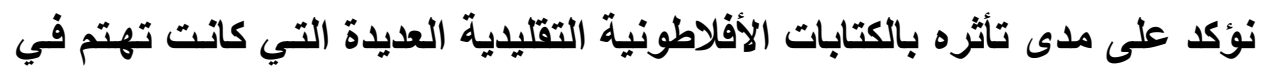

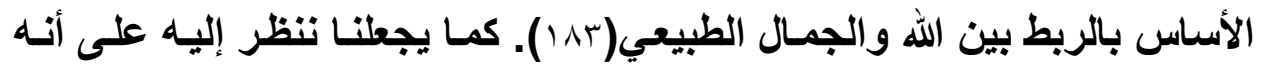

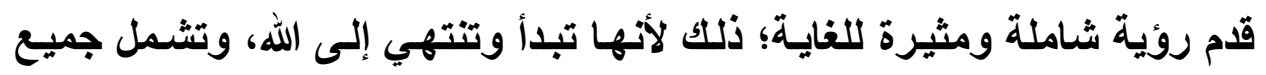

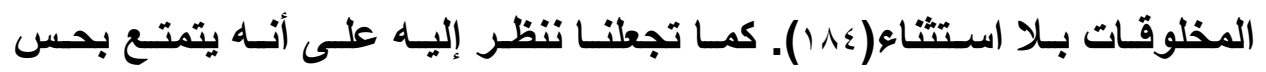
قوي(100). وبدوره أسهم كل ذلك في كونه متفوقًا على جميع معاصرياه، وكونـها.

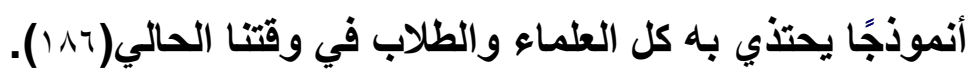

${ }^{181}$ Veto. M. (2009) ) "Edwards and Philosophy",p.155

${ }^{182}$ Reid, J.(2006) "The Metaphysics of Jonathan Edwards and David Hume",pp. 53-54

${ }^{183}$ Jenson, R,W. (1988)" Americas Theologian: A Recommendation of Jonathan Edwards", p.18

${ }^{184}$ Mitchell, L, J. (2007) "The Theological Aesthetics of Jonathan Edwards", p.36

${ }^{185}$ Delattre, R, A. (2003) "Aesthetics and Ethics: Jonathan Edwards and the Recovery of Aesthetics for Religious Ethics", p.277

${ }^{186}$ Kallay, K, G. (2009) "Alternative Viewpoint: Edwards and Beauty" in, " Understandings Jonathan Edwards: An Introduction to America's Theologian, (ed) McDermott. G..R. Oxford University Press. Pp.127128 
مجلة كلية الآداب، جامعة سوهاج، العدد التاسع والأربعون، الجزء الأول، أكتوبر 1 + بام

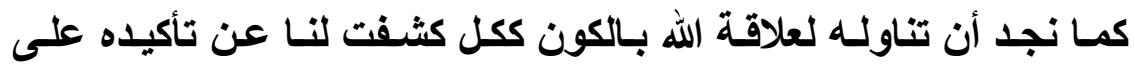

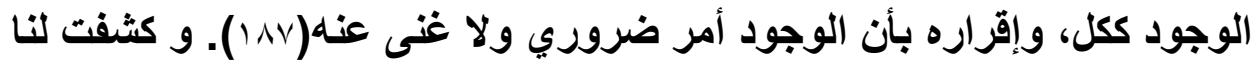

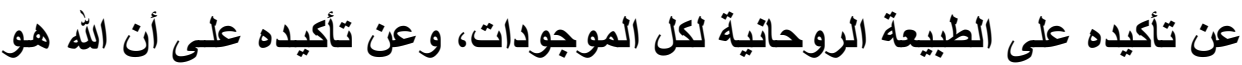
الموجود الأي يتمتع بجميع صفات الكمال. وترتب على ذلتك مسـاهمته في تقديم

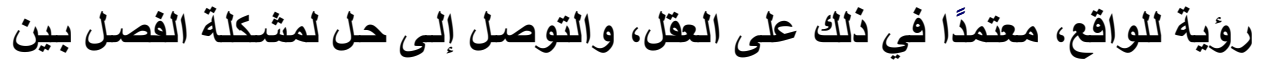

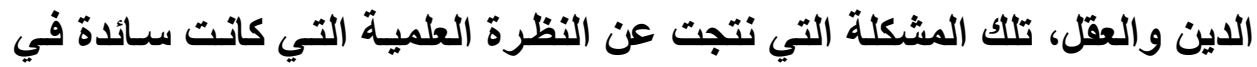

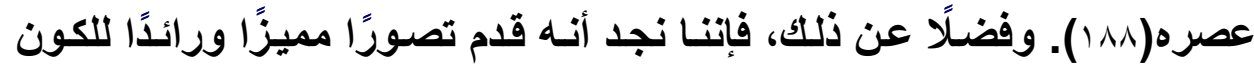

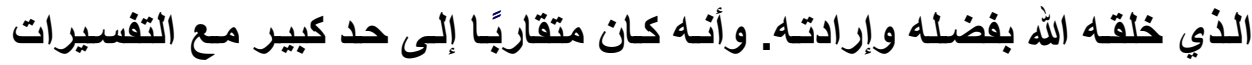
الحديثة والمعاصرة التي قدمها المتخصصون في الكون؛ ذلك لأنه يتفق معهم في أن الكون يتطور بشكل مستمر ومنظم، وتحكمه بعض العلاقات المعقدة(1) (1)).

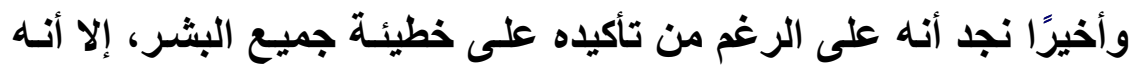

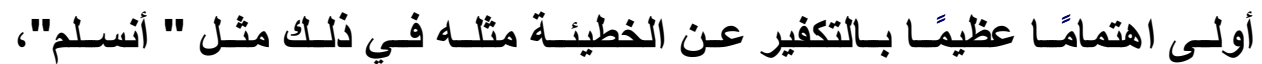

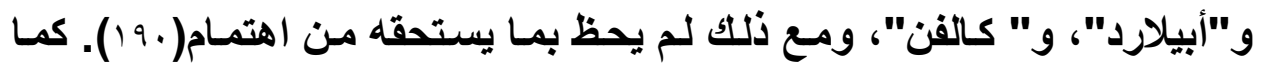

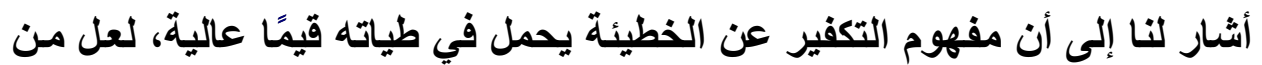

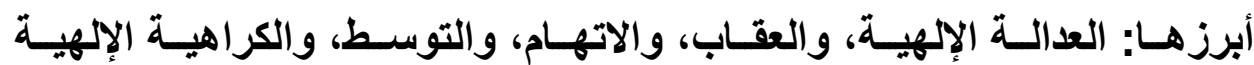

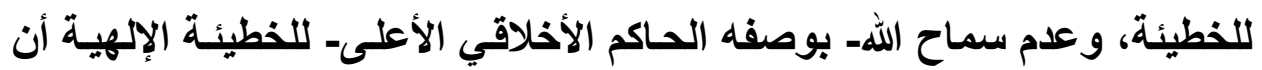
تمر دون عقاب(191). (19).

${ }^{187}$ Veto. M. (2009) "Edwards and Philosophy", in " Understandings Jonathan Edwards: An Introduction to America's Theologian",p.155 ${ }^{188}$ Sevickova. M. (2009) "Alternative Viewpoint: Edwards and Philosophy",p.172

${ }^{189}$ Delattre, R, A. (2003) "Aesthetics and Ethics: Jonathan Edwards and the Recovery of Aesthetics for Religious Ethics", pp. 277-278

${ }^{190}$ Hamilton , S, M. (2013) "Jonathan Edwards on the Atonement", International Journal of Systematic Theology, Vol.15, No.4 ,p.394. ${ }^{191}$ Cooley, D, W. (2014)" The New England Theology and The Atonement: Jonathan Edwards to Edwards Amasa park", pp. 66-67 
وعلى الرغم من المعالجـة الجيدة التي قدمها" إدواردز" للألو هيـة، إلا

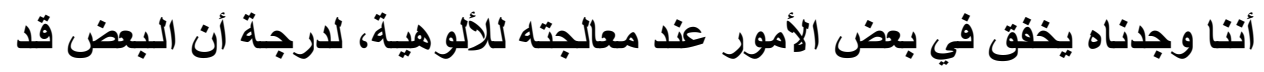

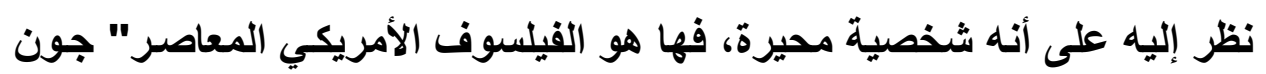

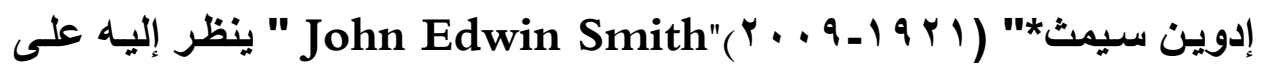

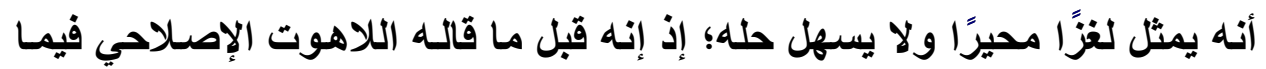

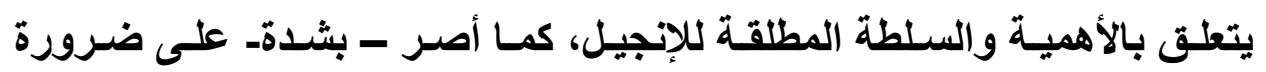

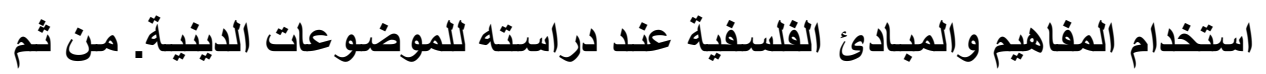

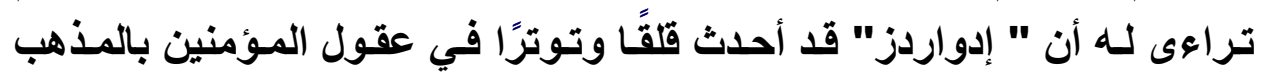

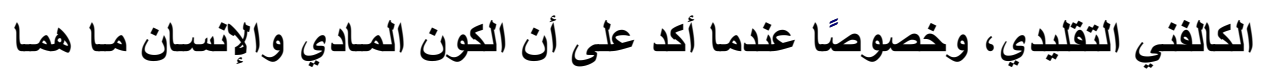

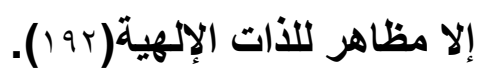

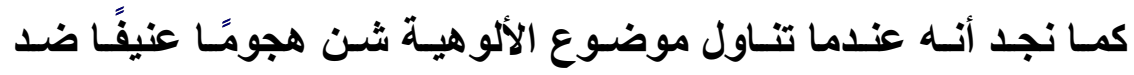

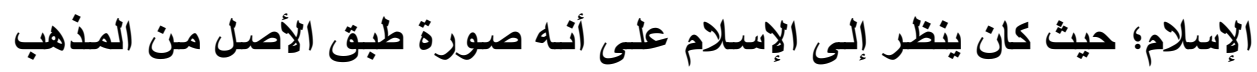

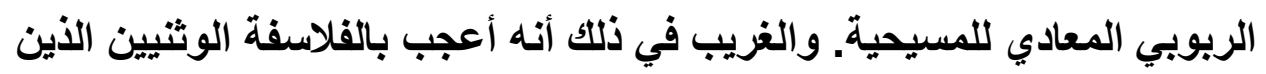

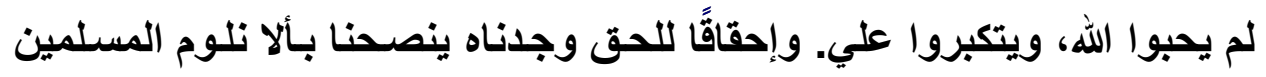

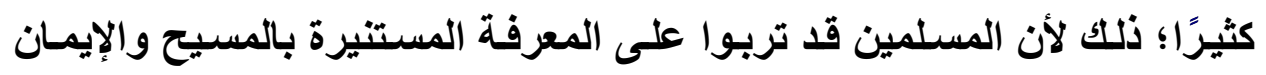

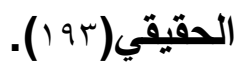

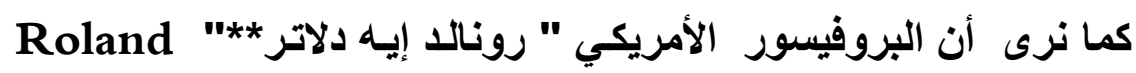
"A. Delattre"

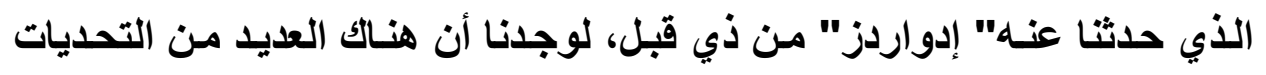

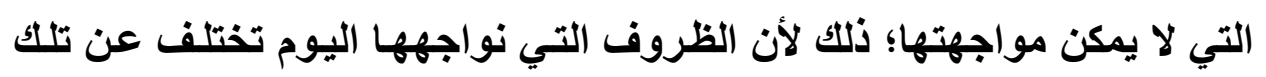

* جون إدوين سيمث: فيلسوف برجماتي أمريكي اهتم بالكتابة عن "إدو اردز" https://www.nytimes.com/2009/12/23/arts/23smith.html

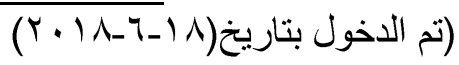
${ }^{192}$ Smith, J, E. (1976) "Jonathan Edwards as Philosophical Theologian" ${ }_{193}$ Mc.306 and Islam" Part .3, pp. 39-40

* * رونالد إيه دلاتر: بعمل أستاذا للار اسات الدينية بجامعة مينيسونا الأمريكية http://jonathanedwardscenter.blogspot.com/2007/04/roland-andre-

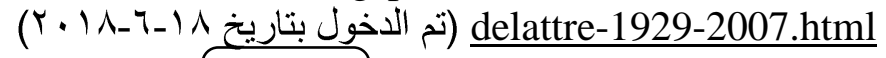


مجلة كلية الآداب، جامعة سوهاج، العدد التاسع والأربعون، الجزء الأول، أكتوبر 1 + بم

الظروف التي كاتت سائدة منذ ثلاثمائة عام(ء9 1). علاوة على ذلك، فقد تراءى

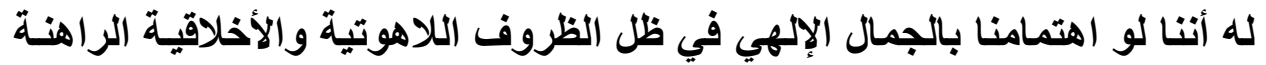
لم ولن نتوصل إلى حلول مرضية لجميع القضايا الأخلاقية والروحية التي نحتـاج

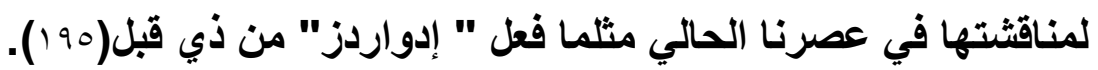

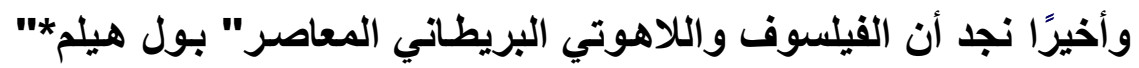

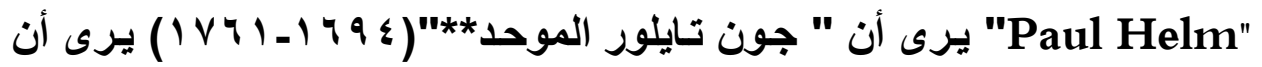

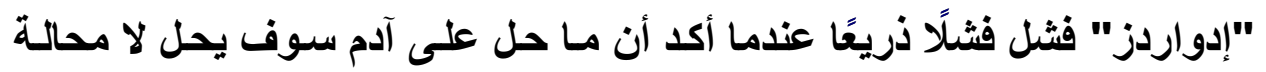

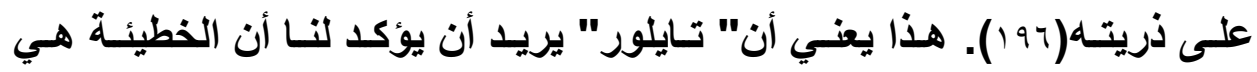

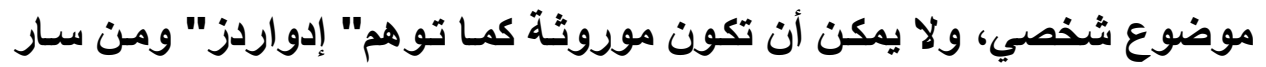

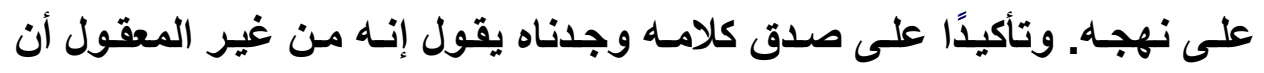

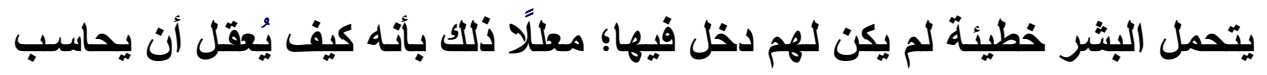

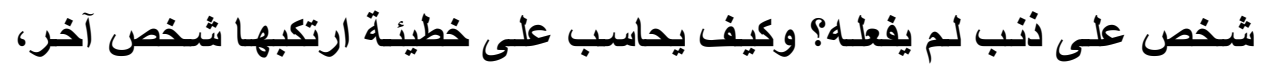

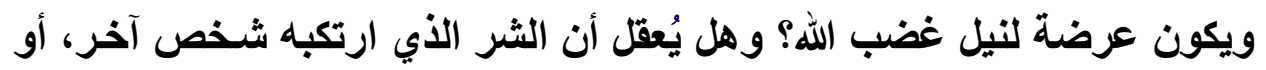

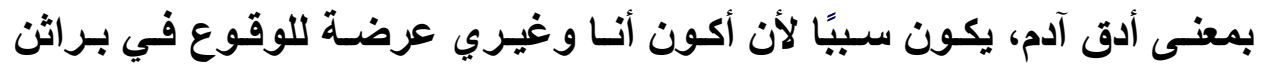

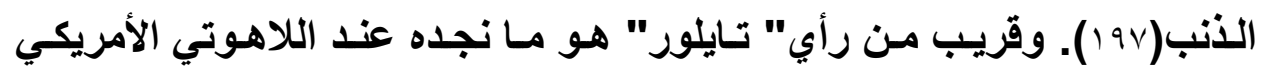

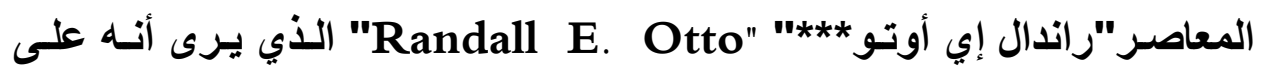

${ }^{194}$ Delattre, R, A. (2003) "Aesthetics and Ethics: Jonathan Edwards and the Recovery of Aesthetics for Religious Ethics", p.278

${ }^{195}$ Ibid, p. 280

* بول هيلم فيلسوف و لاهوتي متخصص في اللاهوت الفلسفي و لاهوت الإصلاح، ولا سيما

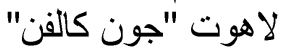



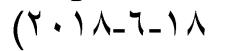
* * * * تايلور الموحد: واعظ إنجليزي اهتم بالحديث عن الخطيئة الأصلية تمttps://babel.hathitrust.org/cgi/pt?id=hvd.hwt785; view=1up;seq=7

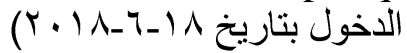
${ }^{196}$ Helm, P. (2004) "The Great Christian Doctrine (Original Sin)",pp.184185

${ }^{197}$ Otto, R, E. (1990) "The Solidarity of Mankind in Jonathan Edward's Doctrine of Original Sin", the Evangelical Quarterly. Pp.205-206

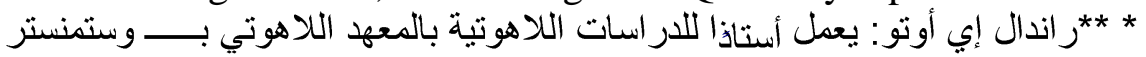

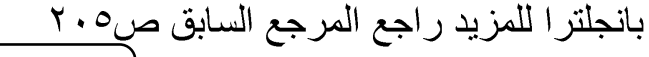

YV $\varepsilon$ 
الرغم من أن اللاهوت المسيحي قد أكد منذ البدايـة أن الخطيــة الأصلية لآدم قد

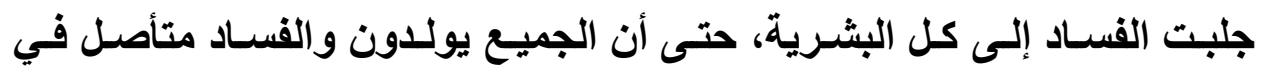

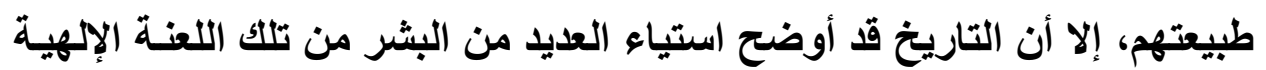

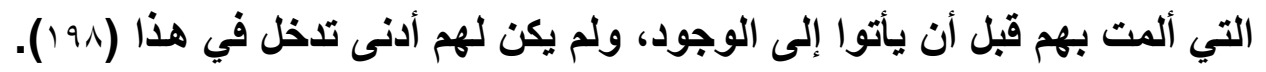

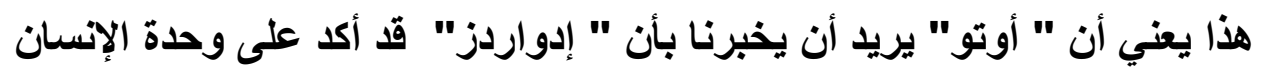

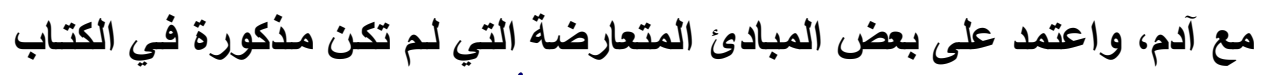

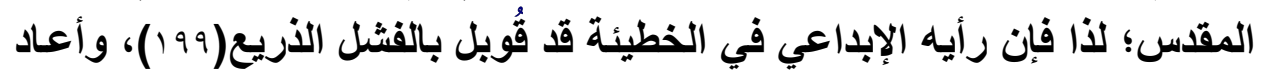
من جديد الجدل العنيف الذي حدث بين " بيلاجيوس" والابه و القديس" أوغسطين"

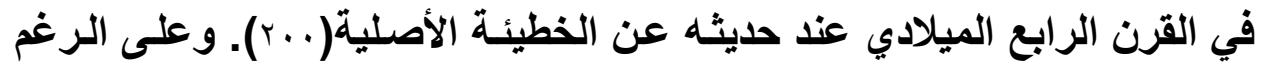

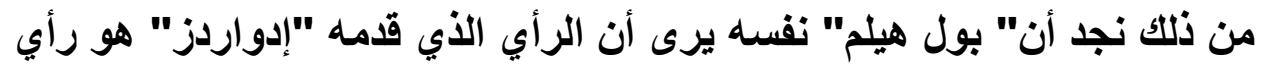

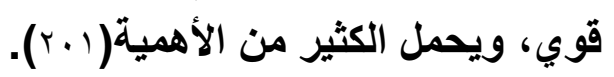

الفاتمة.

توصلت هذه الاراسة إلى مجموعة من التتائج المهمـة، لعل من أبرزهـا ما يأني: - يعد " إدواردز" من أبرز الفلاسفة واللاهوتيين الذين انشـلوا بإصلاح

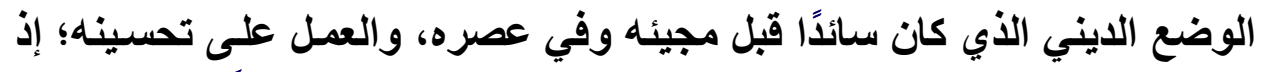

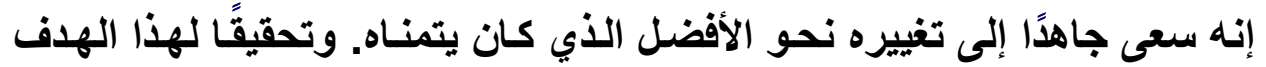

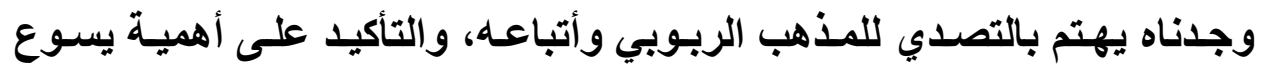

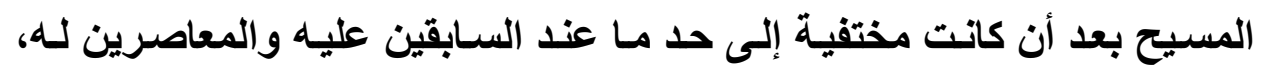
مثلما أوضح لنا عبر كتاباته العديدة.

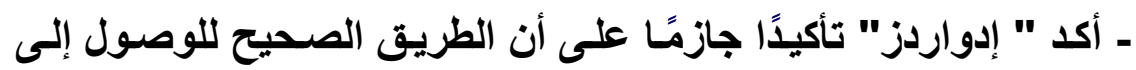

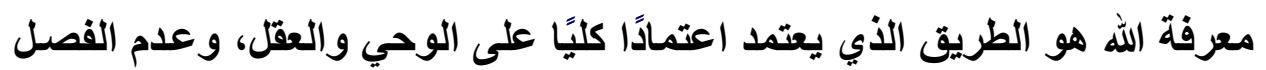

${ }^{198}$ Otto, R, E. (1990) "The Solidarity of Mankind..., p.205

${ }^{199}$ Ibid ,p. 220

${ }^{200}$ Ibid, p. 205

${ }^{201}$ Helm, P. (2004) "The Great Christian Doctrine (Original Sin)", pp. 184-185 


\section{مجلة كلية الآداب، جامعة سوهاج، العدد التاسع والأربعون، الجزء الأول، أكتوبر 1 ـ ب م}

بينهما بأية حال من الأحوال، لارجة أنتا رأيناه يؤكد لنا على أنه لو حدث اتفصال بينهما فسوف لا نصل إلى معرفة الله الحقة.

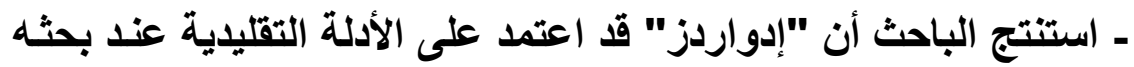

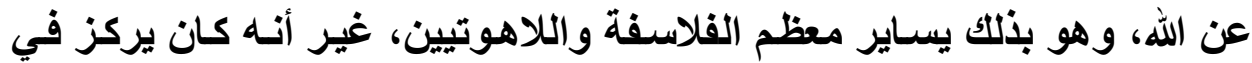
الأساس على دليلي الوحي والجمال؛ لكونهما دليلين رئيسين، ولا غنى عنهمـا عند البحث عن الله ومعرفته. - من الممكن أن ننظر إلى" إدواردز" على أنه فيلسوف جمال بكل ما تحويه الكلمة من معنى؛ إذ إنه كان يحثنا على ضرورة إدراك الجمال الجمال الإلهي الأي يمكنتا أن نكتثفه في العالم الطبيعي الموجود من حولنا.

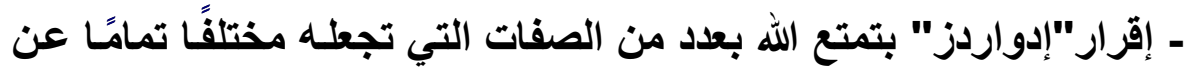
مخلوقاته، وهو بذلك يساير معظم الفلاسفة واللاهوتيين الذين تحدثوا عن صفات

ـ إقرار" إدواردز" بوجود علاقة وثيقة بين الله والكون؛ إذ إن الله هو المتحكم والمتصرف الوحيد في الكون. ولعل اهتمامه بييان هذه العلاقة جعله يقر بوجود وحدة بين الله والوجود ككل، غير أن حديثه عن الوحدة يختلف اختلافًا

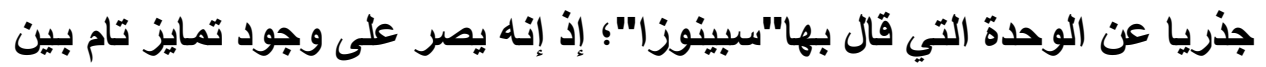

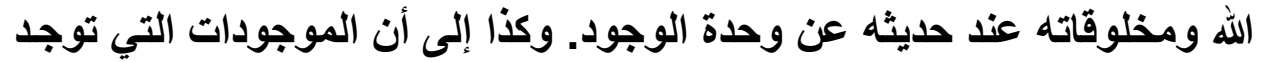

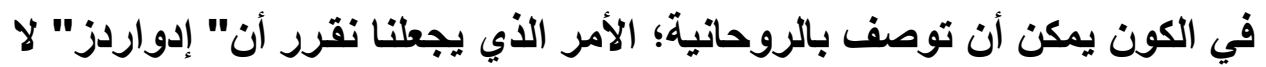

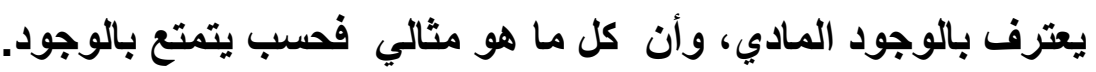

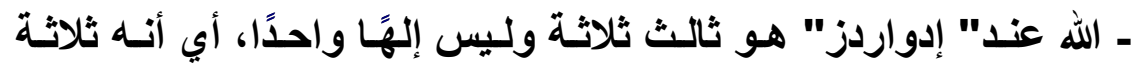

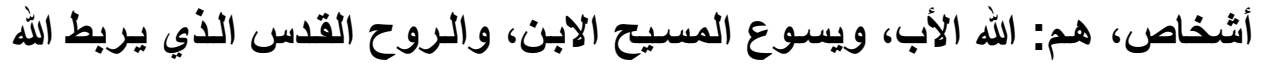

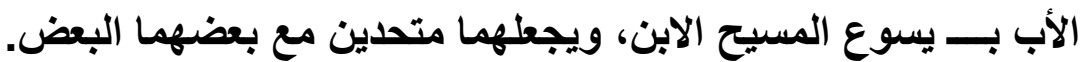

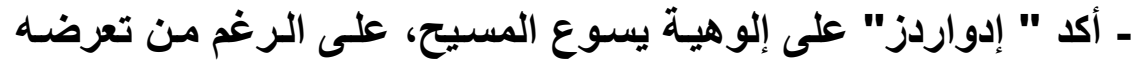

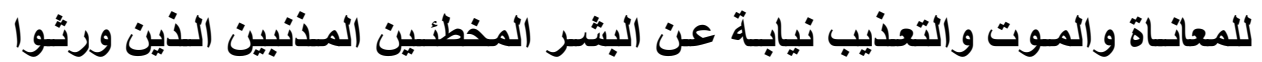
الخطيئة عن آدم. ـ وأخيرًا يعتمد الله وفقًا لــ" إدواردز" اعتمادًا كليًا على يسوع المسيح

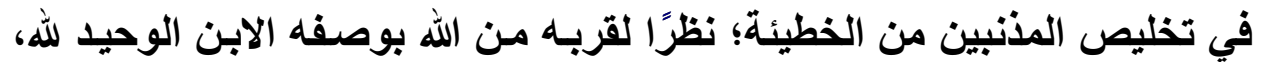
ولما يتمتع به من أهمية عند الله. 
قائمة المصادر والمراجه:

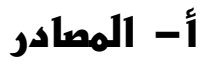

1 -Edwards, J. (1735) "The Sole Consideration, that God is God Sufficient to Still All Objections to his Sovereignty", Sermon II.

(https://www.monergism.com/thethreshold/sdg/pdf/edward s_divinesovereignty.pdf)

2- Edwards, J. (1738) "Who is this King of Glory?" (https://www.scribd.com/document/56163459/Who-is-ThisKing-of-Glory)

3 -Edwards, J. (1740) "The Portion of the Righteous", (http://www.prayermeetings.org/files/The_Portion_of_the_ Righteous.pdf)

4 -Edwards, J. (1741) "Sinners in the Hands of an Angry God", Enfield Connecticut .

(https://www.blueletterbible.org/comm/edwards_jonathan/s ermons/sinners.cfm)

5 -Edwards, J. (1773) "The End of the Wicked

Contemplated by the Righteous, or the Torments of the Wicked in Hell, No Occasion of Grief to the Saints in

Heaven"',

(http://www.prayermeetings.org/files/The_End_of_the_Wic ked_Contemplated_by_The_Righteous_or.pdf )

6 -Edwards, J. "Evidence of the Truth of the Gospel", New hope, Presbyterian church, (http://www.newhopefairfax.org/files/Edwards_Evidence_T ruth_Gospel.pdf) 
مجلة كلية الآداب، جامعة سوهاج، العدد التاسع والأربعون، الجزء الأول، أكتوبر 1 ـ ب م

7 -Edwards, J. "The Justice of God in The Damnation of Sinners" (www.jonathan-edwards.org/Justice.pdf)

8 -Edwards, J. "The Warning of Scripture are in the Best

Manner Adapted to the Awakening and Conversion of Sinners"

(http://www.prayermeetings.org/files/The_Warnings_of_Sc ripture.pdf )

9 -Edwards, J. "Justified In Christ", Chapel Library, (http://www.chapellibrary.org/files/7313/7643/3397/uwchfg.pdf) 10-Edwards, J. "An Unpublished Essay on the Trinity" http://www.monergism.com/thethreshold/sdg/Edwards, \% 20Jon athan\% 20-

20An \% 20Unpublished \%20Essay \% 20on \% 20the\% 20Tr.pdf 11 -Edwards, J. "Eternal Torment for the Wicked:

Unavoidable and Intolerable", Chapel Library, (http://www.chapellibrary.org/files/2713/7643/3243/hellfg.p df)

12-Edwards, J. "Exhortation to Escape Hell", Chapel Library,

(http://www.chapellibrary.org/files/2713/7643/3243/hellfg.p df)

13 -Edwards J. "Jesus Christ the Same Yesterday, Today, and Forever",

(http://www.prayermeetings.org/files/Jesus_Christ_The_Sa me_Yesterday_Today_And_Forever.pdf )

14 -Edwards, J. "Gods Wisdom in Christ's Substitution", From " The Wisdom Of God Displayed in The Way Of 
Salvation", in "The Works Of Jonathan Edwards", Vol.2, (www.chapellibrary.org/files/7513/7643/3386/subsfg.pdf ). 15 -Edwards, J. "Jesus Christ the Judge", From" The Final Judgment", in "The Works Of Jonathan Edwards", Vol.2

(https://www.chapellibrary.org/files/7613/7643/3187/dojufg.pdf). 16 -Edwards, J. "Christian Knowledge", (https://biblesnet.com/Jonathan\% 20Edwards\% 20Christian \%20Knowledge.pdf)

17 -Edwards, J. "The Unreasonableness of

Indetermination in Religion, (http://www.prayermeetings.org/files/The_Unreasonablenes s_Of_Indetermination_In_Religion.pdf) . 18 -Edwards, J. "The Pure in Heart blessed", (http://www.prayermeetings.org/files/The_Pure_in_Heart_ Blessed.pdf )

19 -Edwards, J. "The Believers Delight in the Beauty of Divine Things", Form Religious Affection. (ed), by John E. S, Vol, 2 Works, Yale 1959.

(http://www.newhopefairfax.org/files/edwardsbelieversdelig ht.pdf )

20- Edwards, J. "The books Opened, the Sentence Pronounced and Executed", From" The Final Judgment", in "The Works of Jonathan Edwards", Vol.2 (https://www.chapellibrary.org/files/7613/7643/3187/dojufg.pdf). 


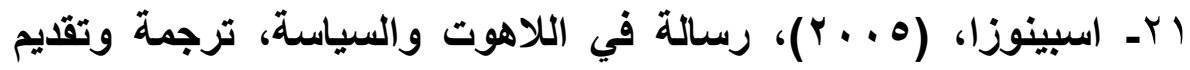

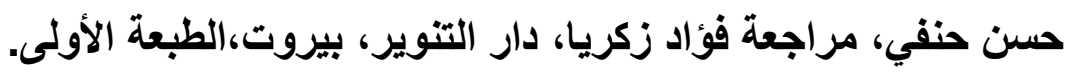

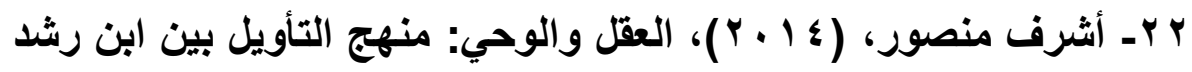
وموسى بن ميمون وسبينوزا، دار روئة، القاهرة، الطبعة الأولى.

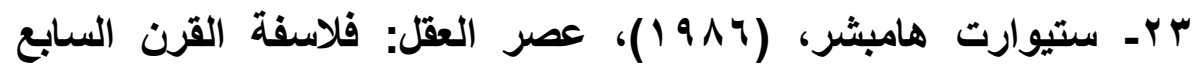
عشر، ترجمة ناظم طحان، دار الحوار، سوريا، الطبعة الثانية.

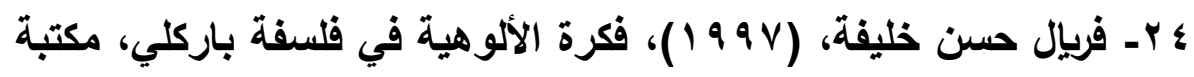
الجندي، القاهرة، الطبعة الأولى.

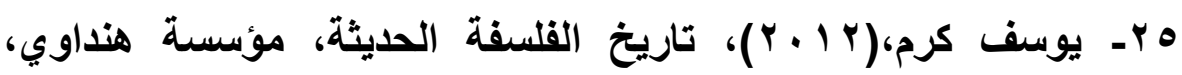
القاهرة

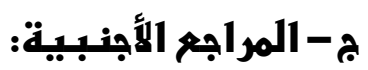

26 -Anderson, O. (2010) "A Short Life of Jonathan Edwards" ,Journal of History and Sociology of Religion, Blackwell Publishing Ltd.

27 -Chamberlain, A. (1996)" Brides of Christ and Signs of Grace: Edwards's Sermon Series on the Parable of the Wise

and Foolish Virgins" Part .1, In :" Jonathan Edwards's Writings: Text, Context, Interpretation", (ed)Stein.

Stephen J, Indiana University Press.

28 -Cooley, D, W. (2014)" The New England Theology and The Atonement: Jonathan Edwards to Edwards Amasa park", Deerfield Illinois.

29 -Creegan, N, H. (2007) "Jonathan Edward's Ecological and Ethical Vision of Nature", Stimulus, Vol.15, No.4. 
30 -Crisp, O, D. (2003)"Jonathan Edwards on Divine Simplicity", Religious Studies, Vol.39, No.1, Cambridge University Press.

31-Crisp, O. D. (2009) "Jonathan Edwards on the Divine Nature", Journal Reformed Theology .

32 -Delattre, R, A. (2003) "Aesthetics and Ethics:

Jonathan Edwards and the Recovery of Aesthetics for Religious Ethics", Journal of Religious Ethics, Inc. 33 -Edwards, R, B. ( 1998) "Edwards, Jonathan. The Works of Jonathan Edwards: Sermons and Discourses, 1723-1729, The Review of metaphysics, vol.52, no. 1, philosophy Education society Inc.

34 -Fisher, G, P. (1879)" The Philosophy of Jonathan Edwards", the North American Review, Vol.128, No.268, University of Northern Iowa.

35 -Hamilton, S, M. (2013) "Jonathan Edwards on the Atonement", International Journal of Systematic Theology, Vol.15, No.4

36 -Hamilton, S, M. (2014)" Jonathan Edwards, Anselmic Satisfaction and God's Moral Government", International Journal of Systematic Theology, Vol.17, No.1, John Wiley \&Sons Ltd.

37 -Hamilton, S, M . (2016) "Jonathan Edwards on the Election of Christ", DE GRUYTER. 38 -Haykin, M, A. (1995) "Jonathan Edwards and His Legacy", Reformation \& Revival, A Quarterly Journal for Church Leadership, Vol.4, No.3. 
مجلة كلية الآداب، جامعة سوهاج، العدد التاسع والأربعون، الجزء الأول، أكتوبر 1 ـ ب م

39 -Helm, P. (2004) "The Great Christian Doctrine

(Original Sin)", in A God Entranced Vision of All Things:

The Legacy of Jonathan Edwards, (Ed), John piper and

Justin Taylor, Crossway Books.

40 -Jenson, R,W. (1988)" Americas Theologian: A

Recommendation of Jonathan Edwards", New York,

Oxford University Press.

41 -Kallay, K, G. (2009) "Alternative Viewpoint: Edwards and Beauty" in, " Understandings Jonathan Edwards: An Introduction to America's Theologian, (ed) McDermott.

Gerald .R. Oxford University Press.

42 -Lee, S, H. (2009) "Edwards and Beauty" in,"

Understandings Jonathan Edwards: An Introduction to America's Theologian, (ed) McDermott, Gerald.R.. Oxford University Press.

43 -Lee ,S, H. (2014) "Jonathan Edwards" in, "Early

Modern Philosophy of Religion" (ed) Graham Oppy\& N. N .Trakakis, Vol. 3, The History Of Western Philosophy Of Religion, Rout ledge, London \&New York. 44 -Louie, K, Y. (2007), "The Theological Aesthetics of Jonathan Edwards", University Of Edinburgh. 45 -McClymond, M , J. (1998) "Encounters With God :An Approach to the Theology of Jonathan Edwards "New York, Oxford University Press. 46 -McDermott .G, R. (1996) "The Deist Connection Jonathan Edwards and Islam" Part .3, In :" Jonathan Edwards's Writings: Text , Context, Interpretation", (ed)Stein. Stephen J, Indiana University Press. 
47 -McDermott, G, R. (2000) " Jonathan Edwards

Confronts the Gods : Christian Theology, Enlightenment Religion, and Non - Christian Faiths", Oxford University Press.

48 -McDermott, G, R. (2009) "Conclusion: Edwards's

Relevance Today", in" Understandings Jonathan Edwards:

An Introduction to America's Theologian, (Ed)

McDermott, Gerald. R.. Oxford University Press.

49 -Mitchell, L, J. (2007) "The Theological Aesthetics of Jonathan Edwards", Theology Today, Vol.64.

50 -Otto, R, E. (1990) "The Solidarity of Mankind in

Jonathan Edward, s Doctrine of Original Sin", the

Evangelical Quarterly.

51 -Reid, J. (2002) "The Trinitarian Metaphysics of

Jonathan Edwards and Nicolas Malebranche" Hey j Xliii,

Ltd, Oxford, UK \&Boston, USA.

52 -Reid, J. (2006) "The Metaphysics of Jonathan Edwards and David Hume", Hume Studies, Vol.32, No.1.

53-Reid, J, W. (2003) "Jonathan Edwards on Space and

God", Journal of The History of Philosophy, Vol.41, No.3,

Johns Hopkins University Press

54 -Salladin, J. (2016) "Nature and Grace: Two

Participations in the Thought of Jonathan Edwards",

International Journal of Systematic Theology, Vol.18, No.3.

55 -Sevcikova, M. (2009) " Alternative Viewpoint: Edwards and Philosophy"," in " Understandings Jonathan

Edwards: An Introduction to America's Theologian, (ed)

McDermott, Gerald.R.. Oxford University Press. 
56 -Smith, J, E. (1976) "Jonathan Edwards as

Philosophical Theologian", The Review of Metaphysics,

Vol.30, No.2, Philosophical Education Society Inc.

57-Strobel , K. (2016) "Jonathan Edwards's Reformed

Doctrine of Theosis", Harvard Theological Review.

58-Veto, M. (2009) )"Edwards and Philosophy", in "

Understandings Jonathan Edwards: An Introduction to America's Theologian", (ed) McDermott, Gerald.R..

Oxford University Press.

59-Wainwright, W, J. (1980) "Jonathan Edwards and the Language of God" Journal of the American Academy of Religion, Vol.48, No.4, Oxford University press. 60-Woodbridge, F, J. (1904) "Jonathan Edwards", the philosophical Review, Vol.13, No.4, Duke University Press on behalf of philosophical Review. 61- Zakai, A. (2010) "Jonathan Edwards's Philosophy of Nature: the Re- enchantment of the World in the Age of Scientific Reasoning" ,T\&T Clark International. 